University of Louisville

ThinkIR: The University of Louisville's Institutional Repository

Electronic Theses and Dissertations

$12-2007$

\title{
The learner in the learning environment : a multiple-case study of nursing students in the hospital clinical setting.
}

Rhonda Stuart Helm 1951-

University of Louisville

Follow this and additional works at: https://ir.library.louisville.edu/etd

\section{Recommended Citation}

Helm, Rhonda Stuart 1951-, "The learner in the learning environment : a multiple-case study of nursing students in the hospital clinical setting." (2007). Electronic Theses and Dissertations. Paper 604. https://doi.org/10.18297/etd/604

This Doctoral Dissertation is brought to you for free and open access by ThinkIR: The University of Louisville's Institutional Repository. It has been accepted for inclusion in Electronic Theses and Dissertations by an authorized administrator of ThinkIR: The University of Louisville's Institutional Repository. This title appears here courtesy of the author, who has retained all other copyrights. For more information, please contact thinkir@louisville.edu. 
THE LEARNER IN THE LEARNING ENVIROMNENT: A MULTIPLE-CASE STUDY OF NURSING STUDENTS IN THE HOSPITAL CLINICAL SETTING

\title{
By
}

Rhondal Stuart Helm

B.S.N. Western Kentucky University, 1989

M.S.N. Murray State University, 1994

\author{
A Dissertation \\ Submitted to the Graduate Faculty of the \\ University of Louisville \\ and \\ Western Kentucky University \\ For the degree of
}

Doctor of Philosophy

College of Education and Human Development

University of Louisville

Louisville, Kentucky

Deccmber 2007 
Copyright 2007 by Rhonda Stuart Helm

All rights reserved 
THE LEARNER IN THE LEARNING ENVIRONMENT: A MULTIPLE-CASE STUDY OF NURSING STUDENTS IN THE HOSPITAL CLINICAL SETTING

By

Rhonda Stuart Helm

B.S.N., Western Kentucky University, 1989

M.S.N., Murray State University, 1994

A Dissertation Approved on

November 6, 2007

by the following Dissertation Committee:

Dissertation Co-Director

Dissertation Co-Director 


\section{DEDICATION}

This dissertation is dedicated to my husband Jerry, and sons, David and Darin. Their love, encouragement, and assistance have enabled me to devote my

time and energy to this endeavor. Without my family's constant and abiding support, completing this monumental task would not have been possible. 


\section{ACKNOWLEDGEMENTS}

This arduous journey would have never been possible withou my co-chairs, Dr. Sharon Spall and Dr. Stephen Miller. Dr. Spall inspired me to embark on this joumey by assisting me in developing my rescarch interest and affirming my ability to complete this project. Throughout this entire endeavor, Dr. Spall and Dr. Miller have shared their knowledge and expertise with me, teaching, guiding, and supporting me through all stages of this dissertation. Dr. Spall and Dr. Miller worked diligently to cdit my work and to help me improve each rough draft by demanding nothing less than my best. Dr. Miller was a constant source of support and encouragement while challenging me to achieve more than I thought possible. Dr. Spall spent countless hours by my side, mentoring, encouraging, and befriending me when the work felt insurmountable. I realize now that it was the long journey itself, with Dr. Spall and Dr. Miller as my guides, which was as enriching and transforming as reaching the final destination.

I am very appreciative of my dissertation committee: Dr. Mary O’Phelan, Dr. Thomas Reio, and Dr. Deborah Williams. Thank you for always providing me with positive, helpful suggestions to improve and expand on my work.

I am very grateful to the hospital for their appreciation of research and so graciously allowing me to conduct my study in their facility. Thank you to the three nursing students, the faculty teacher, and the five clinical staff nurses who allowed me to enter their world to observe and interview them. Your willingness to share your innermost thoughts and feclings with me will never be lorgotten. 


\begin{abstract}
THE LEARNER IN THE LEARNING ENVIRONMENT: A MLLTIPLE-CASE STUDY OF NURSING STUDENTS IN THE HOSPITAL CLINICAL SETTING

\author{
Rhonda Stuart Helm
}

November 6, 2007

The clinical experience represents a critical component in nursing education. During the clinical, students apply classroom theory to nursing praclice and become socialized into the nursing profession. Because of the current nursing shortage, understanding clinical education is vital and may help in retaining and graduating increased numbers from nursing programs (Vollman, 1989). This multiple-case study is grounded in the literature on the history of clinical education and the perspectives of students, faculty teachers, and clinical staff nurses of nursing clinical cducation.

Narratives of the three students' clinical experiences were constructed from data from intervicws, observations, and document analysis. Data from interviews with the faculty teacher and the clinical staff nurses further informed the cases. From these stories, the within-case and the across-case themes cmerged. The Hinshaw Socialization Model (1976, 1986) provided a lens through which the central research question and the subquestions were analyzed.

The findings reveal that the students experience similar challenges as cited in the previous literature. However, the students all demonstrate perseverance, determination, 
and coping, which sustain them during the clinical experience. These concepts were not previously explored in the literature. The nursing students in each case recognize that they are in the transitioning process of becoming a nurse as described by Hinshaw (1977, 1986). These narratives will serve to inform future and prospective nursing students abeut what to expect from clinical experience and how the three students faced challenges. Additionally, clinical staff nurses and nursing program administrators can benefit from reading the stories of the students' perspectives of the clinical. 


\section{TABLE OF CONTENTS}

PAGE

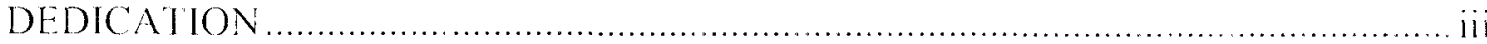

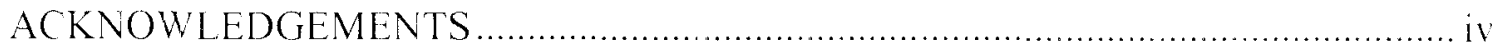

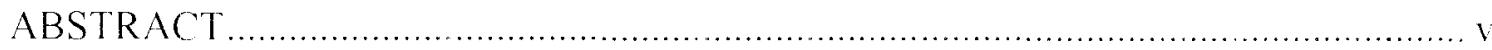

CHAPTER

1. STATEMENT OF THE PROBLEM

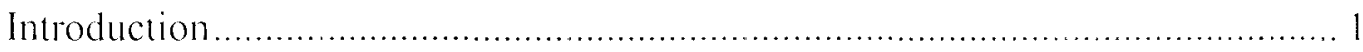

Purpose of the Study ................................................................. 10

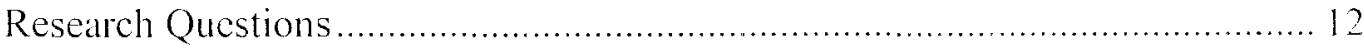

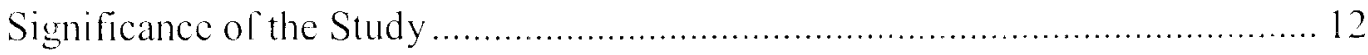

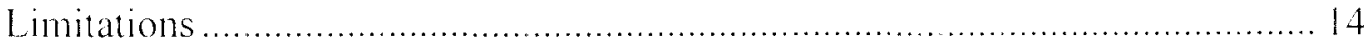

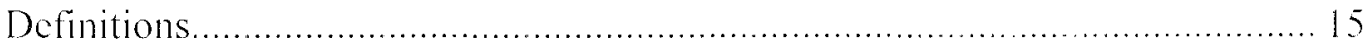

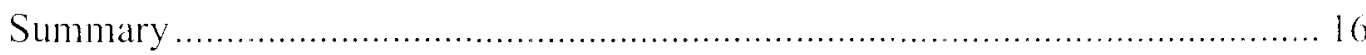

II. REVIEW OF LITERATURE

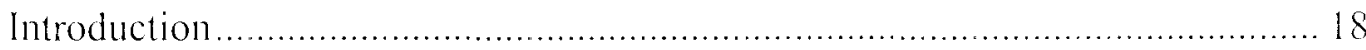

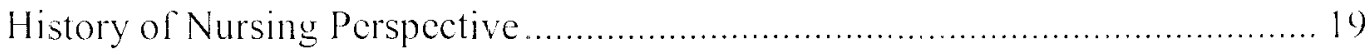

The Learner--Student ............................................................... 24

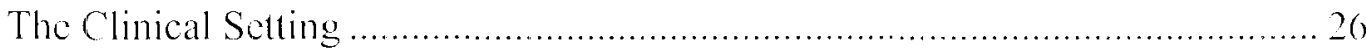

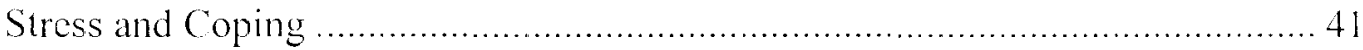

Relationships That Impact the Clinical Learning Environment ..................... 45 
Summary

III. METHODOLOGY

Introduction 69

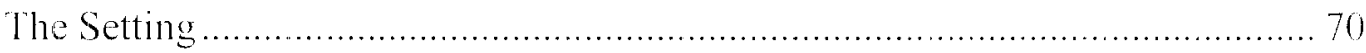

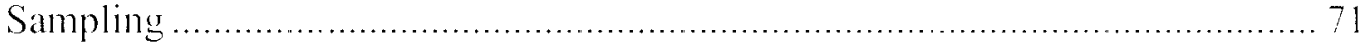

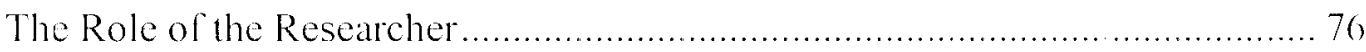

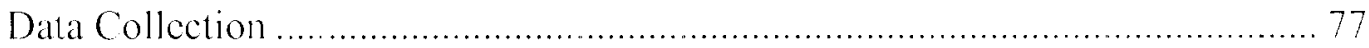

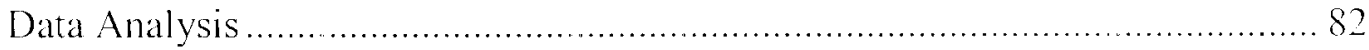

Provision for Trustworthiness ............................................................ 8 (

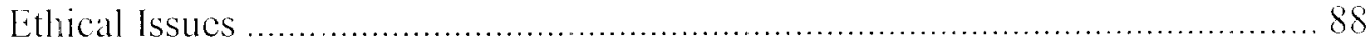

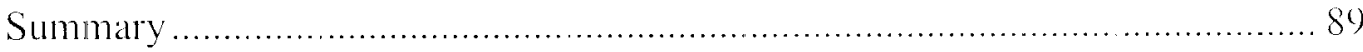

IV. RESLLTS

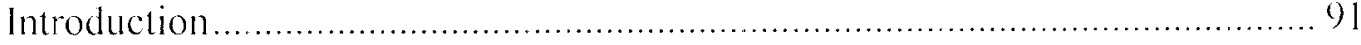

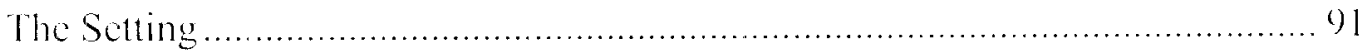

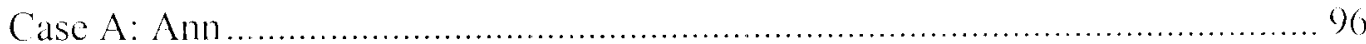

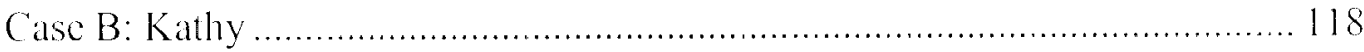

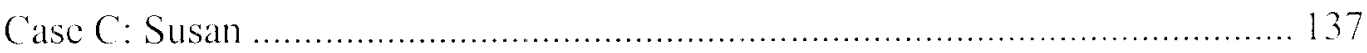

The Rescarch Question Considered ............................................... 150

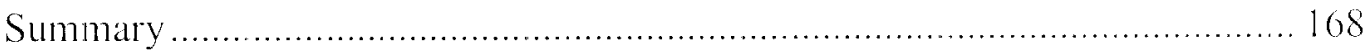

V. DISCUSSION AND CONCLUSIONS 
The Study in Brief.................................................................... 179

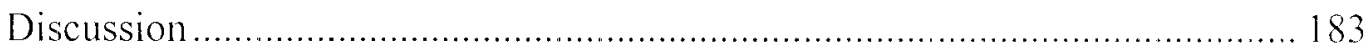

Recommendations ..................................................................... 209

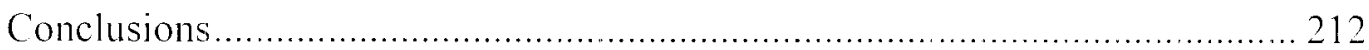

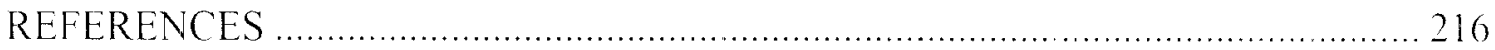

APPENDICES

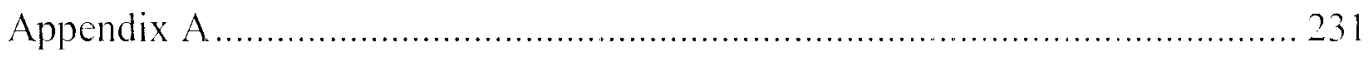

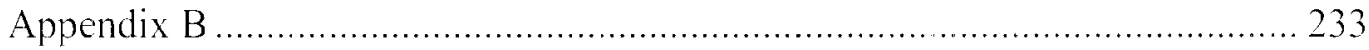

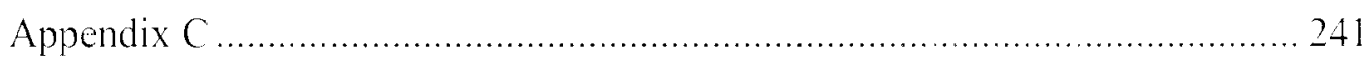

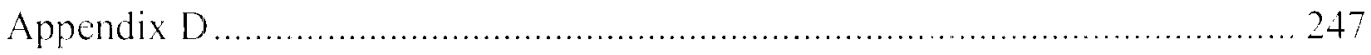

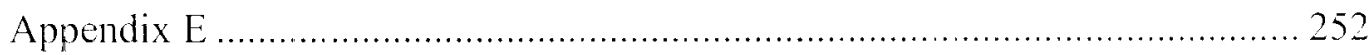

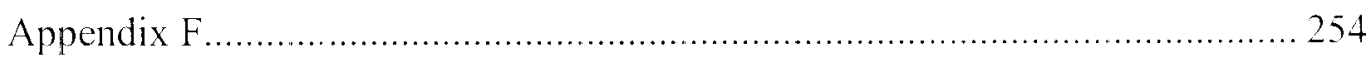

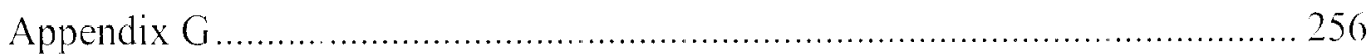

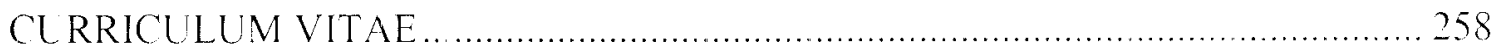




\section{CHAPTER I \\ STATEMENT OF THE PROBLEM}

Introduction

Nursing education involves academic study and the application of theory, as well as skills in the clinical setting. In the classroom, the faculty teacher controls the environment and adjusts situations to meet the learning needs of each student. The student practices skills needed for patient care in the school laboratory. Howerer, in the clinical setting, the environment demands that each student assume responsibility for patient care and apply leaming from the classroom to real-life situations (Knox \& Mogan, 1985). The student must integrate all prior classroom theory, skills, and knowledge to address the demands of the unforeseen and unpredictable nature of patient care (Jacobson, 1966).

During the clinical experience, nursing students must develop competence in the performance of psychomotor skills introduced in the classroom ab (Fox. Diamond, Knopl, \& Hogden. 1963; Gunter, 1969; MacMaster, 1979; Pagana. 1988; Sellek, 1982). For example, students attend to the basic skills for patient care, such as bathing. bedmaking, as well as more specialized procedures such as administration of injections and urinary catheterization. The ability to perform psychomotor skills successfully becomes critical in the development of the competent nurse. These more complex skills have an inherent patient safety risk (Bell, 1991). Nursing students must develop not only theoretical knowledge on which to base nursing care but the practical application skills 
required to implement that knowledge. These skills, acquired only through clinical experience, prepare students to practice safe, beginning level nuring care (Dum \& Hansford, 1997).

Infante (1975), in her classic work, The Clinical Laboranory in Nursing

Estucation, asserted that the clinical laboratory should contain the following: (a) opportunity for patient contact, (b) competent guidance, (c) practice for skill learning, both motor and intellectual, (d) encouragement for critical thinking, (c) opportunity for problem solving, (f) opportunity for observation, (g) developmen of professional judgment or decision making, and (h) utilization of the team concept. Some of the problems cited in the literature associated with clinical education are stress and anxiety. the initial clinical experience, and the theory-practice gap ( $\triangle$ silnworth \& Morrison, 1989; Beck, 1993; Campbell, 1985; Lindop, 1989: Parkes, 1985: Selleck. 1982). Part of this learning situation includes working with the faculty teacher and the clinical staff nurse who support student learning and have expectations for student competence (Wine, 1980). Students must develop competency in new and previously practiced skills within the atmosphere of the combined intricacies of the unpredictability of patient needs and patient care, the responsibility for the patient's well-being, and the scrutiny of experienced professionals.

Another issue in e inical education is prolessional socialization. While still learners, nursing students begin to experience socialization into the nursing profession. Through socialization, students are invited into the culture of nursing and are mentored by members of the profession toward an understanding and assimilation of the values. beliefs, and practices of the nursing profession (Jeffreys, 2004). Jeffrevs assorted that indeed the efforts of members of the nursing profession and not nurse educators alone are 
crucial in building supportive networks for students which are fundamental in the development of professional socialization. The clinical is the setting where socialization occurs as students interact with the clinical staff nurses as well as the facully teacher. According to Clouder (2003), current research on the dynamics of becoming a professional in a health or social care profession is meager. However, severat authors address aspects of the nursing socialization process (Boyle, Popless-Yawter, \& Taunion. 1996; Cohen, 1981; Simpson, 1967, 1976; White \& Ewan, 1991).

White and Ewan (1991) spoke of the dilemma that students experienee in the clinical setting. Because in the busy environment of patient care the clinical nursing stafl tends to focus on what the students can do to get the work done and accomplish the administrative tasks, such as paperwork, while students and faculty teachers strictly focus on education with student as learner and not the student as worker. Infante (1975) added that students have long expressed firstration because the elinical nursing staff often perceives them as workers rather than learners. Students who are still learners are piunged into the clinical area as temporary members of the clinical nursing stafi. Therefore the status of students is unique since students goals are usually different from the clinical nursing staff (Ashworth \& Morrison, 1989). Ashworth and Morrison also stated that many clinical units pay little attention to the idea that the nursing student's clinical assignment is an cducational experience, and students are often perceived as an extra pair of hands to assist in helping the nurses complete their work. Infante believes that this ideology may be the result of the former long-held tradition of nursing education as apprenticeship training Infante emphasizes the idea that a student is still a learner and not yet a nurse is often forgotten. Carpenito and Duespohl (1985) stressed that students are in the clinical setting to learn professional nursing, and all leaming activities should 
reflect that goal to prevent students from becoming involved in extrancous,

nonprofessional activities. Ilowever, this philosophy creates a conflict because students feel that they should accommodate and please the clinical nursing staff in order to be accepted, while some directives may not be related to learning objectives. Students, desiring relationships with prolessional nurses, which are conducive to socialization, feel pressured to respond to the immediate needs and requests of stalinurses, but at the same time, students must complete the requirements of the faculty teacher. Wentworth (1980) argued that when one desires to become a professional, the person is willing to yield to expectations.

Melia (1987) described the "umbritten rules" in the clinical seltmg that when followed, would allow students to behave in a way that the clinical nursing staff would lind acceptable. Some of these unwritten rules involved "pulling your own weight." "looking busy." and "working quickly." Melia stated that these rules are called "unwritken" because students express difficulty understanding where they are found, which leads to difliculty differentiating their roles of learner and worker.

Another ability that nursing students must acquire is critical thinking. Students must gain the ability to think through each patient situation to provide individualized, holistic nursing care, since patients respond uniquely to health problems, wather than simply follow routine procedures (Billings \& Halstead, 1998, 2005). The term critical lhinking means the ability to analyze, interpret, and evaluate data reflectively in order to develop a nursing diagnosis and plan lor patient care (Berger \& Williams. 1999). Students must develop the ability to become critical thinkers in order to practice nursing Benner (1984), in her classic work on clinical nursing practice. From Novice to Expert. describes critical thinking. For example, the nurse must determine the type and size of 
intravenous catheter or needle to use when initiating an intravenous line. In this situation. the nurse must think. "Why is the intravenous line needed?" Then the nurse must consider several conditions and ask. "What substance will infuse through the intravenous line? Is the intravenous line for continuous or intermittent access? Are the patient's veins firm or fragile?" The nurse draws on previous knowledge and experience to think critically through this situation. In short, nurses consider variables in given situations to formulate appropriate solutions. Students or novices must develop critical thinking ability with limited knowledge and experience. Infante (1975) stated that the ability to think critically demands that students be given the opportunity to try different alternatives in the clinical setting, detect lapses in knowledge and skill, adjust and correct skills, and increase competency through experience. Infante emphasizes that students must be accountable for learning in the clinical laboratory rather than simply for patient care. Because the clinical environment cannot be controlled specilically for the learning needs of each student (Jacobson, 1966), such an environment presents a challenge to nursing preparation institutions. The idea of a "theory practice gap" has been evident in discussion about the clinical experience of students for several years (F/kan \& Robinson, 1993; Itlio1, 1993; Wong, 1979), with students pereciving discrepancies between what is taught in the classroom and what is practiced in the clinical area.

\section{Background: Nursing Shortage and Preparation}

The number of full-time nursing professionals will fall short of national demand by 2010) (American $\Lambda$ ssociation of (colleges of Nursing $[\Lambda \Lambda(N] .2001,2002,2005$; Wiens, 2002). Presently, n some geographic areas and in some specialized care units, shortages exist which force hospital administrators to divert patients to other hospitals for specialized care or surgery due to an inadequate nursing staff. 
While statistics in the 1990 s reported a rise in the number of practicing nurses (AACN, 2001, 2002, 2005), recent reports point to shortages since 2000). The United States Department of I Iealth and Human Services $(2004,2005)$ predicted shortages of six percent in 2000 and increased shortages as high as $12 \%$ by 2010 . Factors that contribute to the overall shortage include changes in the health care environment, nurses retiring, and declining numbers of nursing graduates (United States Department of Health and Human Services, 2004, 2005). Also, as the increased numbers of Americans join the age group of over 55 , health care needs will increase. This, coupled with the increase in numbers of patients with chronic conditions, will increase the gap between demand and supply of competent nursing professionals. $\Lambda$ t the same time, the experienced nursing professionals grow older and reach retirement. This retirement will contribute to the overall shortage in 2010 .

Registered nurses in the workforce are in high demand and a rapidly decreasing resource. According to the United States Bureau of I abor Statistics (2005), more than one million new and replacement nurses will be needed by 2012 . Therefore, it is imperative for nursing program administrators to maximize graduation rates to increase the number of nurses entering the work force (Norman, Bucrhaus, Donelan, Mecloskey, \& Dittus, 2005). The effort to address the nursing shortage must begin with retaining and graduating students enrolled in nursing preparation programs.

Additionally, across all degree programs, graduation rates show a marked decrease over a 5 year period (1995-2000). The National I eagut for Nursing (2004) reported that the total number of admissions in all registered nurse programs in the United States increased from 127,184 in 1995 to 133,011 in 2003. However, the number of graduates in all programs decreased from 97,052 in 1995 to 76,659 in 2003 . The area 
of concern appears to lie in students remaining in and graduating from a program of study. Findings in research show that the clinical component of nursing education presents the most challenges to students (Chapman \& Orb, 2001; Windsor, 1987). National attrition rates for total programs are not available. The 24 . Associale Degree Nursing Programs in Kentucky reported in 2004 an average retention rate of $73 \%$, an average graduation rate of $62 \%$, and an average employment rate of $93 \%$ (Kentucky Board of Nursing, 2005). The statistics demonstrate an adequate number of admissions to Associate Degree Nursing Programs in Kentucky with excellent prospects for employment for those who complete the program.

These challenges in clinical education are important because of the vital part the clinical component plays in overall nursing preparation. According to the latest available statistics from the National League for Nursing (2004), associate degree nursing programs, the program focus for this study, have the highest enrollment $(52 \%)$ of 78.912 , while baccalaureate nursing programs have an enrollment $(43 \% ;$ of 47,903 and diploma programs have an enrolment (5\%) of 6,196. The number of admissions to Associate Degree Nursing Programs in Kentucky increased by 538 from 1.437 in 1996 to $1.975 \mathrm{in}$ 2004. However, the number of graduates decreased by 462 from 1,013 in 1996 to 1,151 in 2004. Clinical experience in nursing education is related to students decisions to drop out of their program of study and is discussed in the following section.

\section{The Problem Defined}

Nursing students must complete a significant number of elinical hours in preparation programs, and students cite the clinical experience as complex, demanding, and a reason for dropping out of the nursing program (Boyle et al., 1996: Pringle \& Green, 2004). While nursing students, faculty teachers, and clinical stafi nurses perecive 
this practice setting as the most influential context in which to acquire nursing skills. knowledge, and socialization, at the same time students describe the clinical setting as a barrier to completing the nursing program (Boyle et al.). Pringle and (ireen cited clinical experience as one of the reasons students leave nursing programs, while other studies (Deary, Watson, \& Hogston, 20(03), point to the clinical as a reason 10 drop out, but do not give specific details. Ilowever, several studies pointed to problems in the clinical component of nursing education that can be viewed as contributing factors to the nursing student drop out problem ( $A$ shworth \& Morrison, 1989; ( ampbell, I arivee, Field, \& Day, 1994; Mclia, 1987).

Additionally, the clinical experience comprises the largest portion of nursing education. The student nurse spends more hours in the elinical setting than the classroom (Vollman, 1989). Students who are unable to practice, master skills, and gain knowledge in nursing preparation, of which the clinical is the major portion, experience difliculty in socializing into the nursing profession and may not complete the program of study (Boyle ct al., 1996). The failure of students to complete the program of study adds to the nursing shortage.

For every credit hour assigned to the clinical component of a nursing course, three hours are spent in the elinical setting in direct patient contact. Contact hours assigned 10 the elinical typically range from 6 to 12 hours per week. The clinical practice area includes many more variables than the academic setting (Wilson, 1994). Students must gain proficiency in the simultaneous performance of psychomotor and critical thinking skills in an atmosphere of constant surveillance by faculty teachers and clinical staff nurses where mistakes can result in harm or death to patients. Sudents have the added stressor of experiencing socialization into nursing among the very gatekeepers to the 
proficssion.

The clinical component of nursing preparation focuses on the studemi s ability to perform psychomotor skills as well as develop critical thinking ability and experience socialization into the profession of nursing (Boyle et al., 1996; Cohen, 1981: Fox et al.. 1963; Gunter, 1969; MacMaster, 1979; Pagana, 1988; Sellek, 1982: , Simpson, 1967. 1976; White \& Ewan, 1991). Many problems and difficulties associated with the clinical aspect of nursing education that are cited in the literature relate to psychomotor and critical thinking skills as well as issues of socialization (C amphell el al. 1 1994; Parkes. 1985). Problems with psychomotor skills identified by students include awkwardness, developing manual dexterity, assembling equipment, making errors and identilying how to correct them, performing skills in a timely manner, all while being monitored by the laculty teacher or the clinical staff nurses (White \& liwan, 1991).

The student also struggles with patient care challenges that require critical thinking skills. Students identilied these challenges in clinical as perplexity in applying constructs to practical situations, the ability to discern what nurses do besides psychomotor skills, and learning to prioritize quickly patient care (Infante. lorbes. Thoudin, \& Naylor, 1989; Windsor, 1987). Another concern cited by students regarding critical thinking involved organizing and completing clinical work in a timely manner (1)unn \& Burnett, 1995).

Students become socialized into the nursing profession during clinical education. Research lindings have shown that students who do not experience adequate socialization are not prepared to deal with the realities of nursing practice as graduates (Dalme, 1983). Working closely with faculty teachers and clinical staff nurses plays a major part in the socialization process. Problems in socialization arise in the clinical environment when 
students fail to reconcile their role expectations with those of the faculty teacher and clinical staff nurses, from failure to attach to these nurse role models, and from failure to internalize the role values and behaviors of the profession (Hinshaw, 1977, 1986).

Students who experience such socialization problems may not complete the program of study (Boyle et al., 1996).

\section{Purpose of the Study}

Because of the great impact on student learning, the nursing clinical environment is vitally important to understand. Previous studies (Atack, Comacu, Kenny, LaBelle. \& Miller, 2000; Dunn \& IJansford, 1997; Glover, 2000; Jackson \& Mannix, 2001: Knox \& Mogan, 1985: Pagana, 1988; Speck, 1990) have focused on aspects of nursing student learning in the clinical environment, such as student relationships with faculty teachers and clinical stafl nurses and initial clinical experience and initial skills performance, but have fallen short of a holistic description of learning in the hospital clinical laboratory. Socialization, entwined with the performance of psychomotor and critical thinking skills, occurs in the clinical setting and helps nurture growth, development, and integration into the nursing culture (Jeffreys, 2004). When socialization is inadequate, graduates are illprepared to function within the nursing profession (Dalme, 1983). The nursing culture refers to "the learned and transmitted life ways, values, symbols, patterns, and normative practices of members of the nursing profession of a particular society (Leininger. 1995. p. 208). According to Spradleys (1979) definition of culture. the shared knowledge people use to interpret experience and generate behavior, the clinical setting in nursing education constitutes a culture.

Researchers often utilize ethnography to examine culture. However. Merriam (1998) explains that qualitative case studies about the culture of a school, a profession or 
a classroom would be appropriately called an ethnographic case study (Merriam, p. 34). This type of educational case study would describe and seek to understand students within an educational culture. Because the educational case produces a comprehensive, rich description of an entity, the educational case study research method provides a means to investigate holistically the substance of the clinical experience (Creswell. 1997). The present study focused on what occurs in the clinical setting, how this impacts student learning, and ultimately the entry into professional nursing practice. Additionally, the study examined the context of the elinical experience through the multiple lenses of the student, student's faculty teacher, and elinical staff nurse (1)i(jiacomo, 1993).

In each of the proposed case studies in this research, the laculty leacher and clinical staff nurses, who provide guidance and support, contributed information about the learner and the learning process in the elinical setting. Providing data from students, the faculty teacher, and clinical stalf nurses, this multiple-case study examined the learning experiences of three associate degree nursing students in the complex, real-life clinical setting (Chapman \& Orb, 2000; Windsor, 1987). Using a purposive sample, each case described the interactions of a student, the faculty teacher, and the elinical stafl nurse. The clinical setting was a hospital medical-surgical unit located in the same city as the university where participants attend. The study included observations and interviews of three students in the Medical-Surgical Nursing I course, the faculty teacher of the course, and a clinical staff nurse during the third semester of the associate degree nursing program. The investigation included the examination of relevant documents. Fach participant shared learning experiences in the clinical environment regarding the performance of skills introdueed in the academic classroom and new skills inherent within the patient/hospital setting (Chapman \& Orb, 2000; Jacobson, 1966$).$ 


\section{Research Qucstions}

Bccause numbers of graduates from nursing programs are declining ( AACN. $2001,2005)$, it is important that a deeper insight be gained regarding a large part of nursing education--clinical experience. Nursing program administrators, laculty teachers, and elinical stall nurses may obtain a clearer understanding of what happens to nursing students in the clinical setting. This new knowledge may aid in the development of nursing programs that are sensitive to the needs of students. Therefore, this study addressed the following central, overarching research question and subquestions (Creswell, 1997):

1. What is the nature of the socialization experience during the clinical laboratory that prepares the associate degree nursing student to enter professional practice?

a. How does the student experience the social, psychomotor, and critical thinking skills in the clinical laboratory?

b. What support systems sustain the student during the clinical laboratory experience?

c. How do the faculty teacher and the clinical staff nurse influence student learning, the clinical setting, and interaction in the clinical setting?

\section{Significance of the Study}

This study has significance for four groups--nursing students, faculty teachers, clinical stafl nurses, and nursing program administrators--in understanding the clinical experience. Ultimately, the improved understanding will contribute to the development and improvement of nursing programs in facilitating students to complete their program 
of study. For all of these groups, findings from this case study provide more concrete knowledge from vivid descriptions in the narrative report. The three cases detail the intricacies of clinical experience and the factors contributing to learning (Merriam, 1998). This study provides nursing students with a picture of what to expect from clinical experiences and factors that help or hinder learning. $\Lambda$ s students read the expressive, rich descriptions in the case study, they can estimate what clinical experience will be like and have a better understanding of expectations and demands placed on them. The detailed descriptions may guide students that prepare for the clinical experience, as well as provide cncouragement through other students" accounts of achievement in similar situations. In addition, the data from the faculty teacher and clinical staff nurses provide valuable information to the student who begins clinical experience.

Faculty teachers will benefit from this study through an understanding of students pereeptions of elinical experience through these three stories. Through the detailed, concrete accounts, the faculty teacher may respond to unknown needs of students and variables of which they were previously unaware (Memiam, 1998). Faculty teachers could also benefit from the study through insights gained from the vicwpoint of clinical stafl nurses, because the staff nurse remains in the clinical learning facility and has a unicue perspective.

Clinical stafl nurses could benelit from the study through an understanding of elinical experience from the stories of students, the faculty teacher, and other clinical staff nurses. The everyday language used in the case study naratuve report allows the story to be told more easily rather than with the use of scientific language (Merriam, 1998). (linical stafl nurses could gain an appreciation of the restraints placed on students and faculty teachers and recognize ways in which students can be supported. Clinical 
staff nurses could also gain insight into classroom curriculum and linkages to students" ciinical experience.

Finally, from this multiple-case study, nursing program administrators have information that could support students receiving passing grades in the clinical component and completing their program of study. This study uncovers knowledge about student learning that can be applied to clinical nursing education to create the very best possible programs (Merriam, 1998). This information, in turn. can contribute to increasing the retention and graduation numbers of nursing students.

\section{Limitations}

Limitations to this study related to the nature of the case study and the examination of three students. Therefore, this case study does not include or compare general demographics such as those found in quantitative studies with large sample sizes. The cases did not compare such attributes as age, situation (traditional versus nontraditional), ability, race, marital status, or sociocenomic status across individuals or groups. Time and place constituted the boundaries for the case studies: one segment of time and one setting. Therefore, study findings are not generalized to other groups of students. However, the intent of case study research was not to generalize, but to provide a holistic view through the concentrated attention of a problem-centered situation (Merriam 1998). The case studies of three particular nursing students describe the clinical lcarning situation in depth.

The purposive sample limited the case study to three individual students. To identify the student with the richest information for the case study, a set of criteria established attributes of a typical associate degree nursing student. Iistablishing age, background, previous experience, and personal information desired for each case restricts 
the selection only to the sample of students who meet the criteria.

Sampling of associate degree nursing students only limits the study to one preparation program. Inherent differences in clinical experience exist across the different nursing preparation programs, because students in associate dogrec, baccalaureate, and hospital-based programs would experience the clinical setting differently. Additionally, the study focuses only on the clinical component of associate degree nursing preparation rather than purely academic courses or the entire preparation program.

Sampling of associate degree nursing students in only one state presents another limitation. While national guidelines exist for all types of nursing programs, each state can prescribe specilic practices. For example, different states may place restrictions on faculty-student ratios in clinical laboratories. Such restriction creates variation in clinical experience across different states.

While retention remains an interest to the researcher and the nursing profession, this study did not include students who do not complete or drop-out. Although the perspectives of former students offer additional viewpoints, their point in time requires a retrospective reflection and is different from the current study.

\section{Definition of "Tcrms}

1. Clinical Experience--a laboratory class in which a nursing student performs care for patients in a hospital under the supervision of the faculty teacher (White \& Ewan, 1991).

2. Nursing Student--a person who is enrolled in a nursing preparation program (Infante, 1975).

3. Faculty Teacher--a person who is a registered nurse, possesses at least a master's degree in nursing, and teaches in the university classroom as well as 
hospital clinical nursing laboratories in an associate degree nursing program (Infante, 1975).

4. Clinical Stafr Nurse--a registered or licensed practical nurse employed by the hospital in the study, whose assigned patients are being cared for by a nursing student during a clinical learning experience (Infante, 1975).

\section{Summary}

The improvement of nursing preparation programs relates to the graduation and retention of nursing students. Because the clinical experience is a major component of nursing education (Vollman, 1989), a careful examination of this complex learning environment may reduce attrition from nursing programs. An in-depth exploration of the clinical laboratory can result in improvement of the overall nursing program and thereby decrease drop outs and increase the number of nurses entering the profession.

Faculty teachers, elinical stalf nurses, and students all have an investment in program improvement and the ultimate suecess of the clinical laboratory experience. Faculty teachers maintain the integrity of the nursing profession and support the graduation of competent professionals. The primary interest of the clincal staff nurse remains with the patient, while facilitating student development as a prolessional service. The student begins the clinical experience with time and effort invested in nursing education. The interrelatedness of these interests demonstrates the social and prolessional complexity of the clinical setting. Such investments underscore the complexity and importance for understanding and improvement of the clinical learning setting.

The purpose of this study was to describe the experiences of associate degree nursing students in the clinical setting--learners in the hospital environment. The multiple-case study design presented the lives of three nursing students in the clinical 
setting. Each case glimpsed into the real-life experiences of a nursing student.

Collectively, the three cases are designed to answer the central research question for the study: What is the nature of the socialization experienee during the clinical laboratory that prepares the associate degree nursing student to enter professional practice? 


\title{
CIIAPTLR II
}

\section{REVIEW OF TIIE LITERATURF}

\author{
Introduction
}

The purpose of this study is to describe the experiences of three associate degree nursing students in the hospital clinical setting. The literalure review includes a brief history of nursing preparation, a description of the nursing student, a description of the clinical setting, stress and coping in nursing students, relationships that impact the clinical learning environment, and professional socialization. Classic studies that remain relevant to clinical nursing education and recent research are included in each section.

The review includes literature derived from a comprehensive searel via IBSSCO HOST. Electronic searches were performed on Academic Search Premier, Pre-CINAHI, CINAHI, Health Source: Nursing/Academic Edition, Psych INFO, FRIC, and ProQuestDigital Dissertations databases from 1969 to 2005. Although the search strategy varied depending on the database, search terms included nursing students and stress, anxiety, burnout, clinical experience, nursing education, stress, coping, nursing teachers, nursing students" perceptions of nursing preparation. nursing teachers" perceptions of nursing preparation, clinical staff nurses, relationships in the clinical setting, and history of nursing. Through branching from primary and review articles, other citations were included.

To understand better the origins of clinical nursing experience, the literature review begins with a brief presentation of the history of nursing preparation. The review 
continues with a description of the nursing student. This is followed by studies that describe the clinical component of nursing education, including stress, anxicty, state-trait measures of emotion, and burnout. The review proceeds with a section on stress and coping, and then includes a section focusing on relationships that impact the clinical larning enviromment. The final section of the review discusses theories of professional socialization.

\section{History of Nursing Preparation}

The beginnings of what is considered modern nursing have their roots in the work of Florence Nightingale. Prior to the Nightingale influence on nursing cducation, there was no formal preparation for a nurse. Hospital care of the sick was left to women prisoners, prostitutes, and alcoholics (Lilis \& Hartley, 1988).

From her experiences gained in the Crimean War. Nightingale developed a model for nursing education. In 1859 , she wrote the first nursing text, Notes on Nursing, which described her ideas for nursing education. In 1860, she founded the first education training program for rurses at St. Thomas Hospital in London (Robinson, 1946). By the early 1870 s, three schools of nursing based on the Nightingale model opened in the Lnited States in New York, Connecticut, and Boston (Berger \& Williams, 1999).

In the beginning, nursing education consisted of mainly on-the-job training or apprenticeship programs. Farly nursing students primarily worked in the hospital and attended a few classes. Often the work days were 12 hours or longer. Curricula in these early programs consisted of some anatomy and physiology, selected diseases, nutrition, and hygiene. I ectures on all subjects, including nursing, were given by physicians (Kalisch \& Kalisch, 2004). Instruction was also received in areas such as housekecping, bandaging, and patient comfort (Viahealth, 2004). These early programs lacked the 
scientific knowledge base which is now the foundation ol nursing education.

Early nursing students carned a certificate or diploma in nursing rather than an academic degree. During training, the nursing student adhered to a rigid code of conduct that if not adhered to, would lead to dismissal from the program. The code of conduct required that students remain unmarried and live in a dormitory or nurses residence connected to a hospital and students became a source of cheap or frec labor (/erwekh \& Clacorn, 2000). The head nurses, who were often a senion student or ward sisters comnected to a religious order, usually provided early nursing clinical education. This training emphasized the performance of psychomotor skills, such as bathing. bedmaking, and medication administration, rather than the science of nursing theory. This lack of emphasis on scientific theory was cause for concern for many progressive nurses.

Kalisch and Kalisch $(1986,2004)$ stated that in response to concerns about nursing education, the Rockefeller Foundation appointed a committee to study the condition of hospital training schools in 1923. This study, the Goldmark Report, rcommended higher nursing education standards, nursing service separate from nursing education, and support for preparation at the university level (Berger \& Williams, 1909). Preparation at the university level marked the beginning of the concept of a thorough liberal education in nursing rather than the concept of training in the hospital (Kalisch \& Kalisch, 1986). This report elearly established the need for basic preparation for all nurses (Kalisch \& Kalisch, 1986, 2004).

However, some difficulties were experieneed in implementing this new concept of nursing education. The hospital-based nursing schools faced problems with the imperative that nursing service operate separately from nursing education. Many nursing schools had been opened solely to provide free patient care for the hospital. Hospitals 
were almost entirely staffed by students in order to spare the expense of hiring graduate nurses. The new guidelines set forth by the Goldmark Report mandated the correlation of classroom instruction and clinical experience. Students no longer were placed within a hospital and exploited for free labor according to its staffing needs. These changes brought about the closure of many hospital-based nursing schools and secured a place for nursing education in colleges and universities (Berger \& Williams, 1999).

As nursing preparation moved from the hospital to the college and university, formal educational programs developed. Now, diploma, associate, and baccalaureate degree programs lead to licensure as a registered nurse (RN). Diploma programs, though patterned after the Nightingale concept, have changed dramatically from the original but st ll retain some educational elements of that early, apprenticeship model (Berger \& Williams, 1999). The hospital-based diploma programs emphasize clinical skills and require 2 to 3 years for completion. The diploma programs, although usually connected to colleges or universities, primarily emphasize technical skills associated with the hospital. Hospital-based diploma programs have declined in number with the trend towards placement of nursing programs in a system of higher education within colleges and universities (Kozier, Erb, Berman, \& Snyder, 2004).

Associate degree nursing programs (ADN) developed in the 1950 as a response to the nursing shortage. ADN programs, located mainly at community colleges and usually 2 years in length, include selected social and physical sciences that provide a base for nursing at the technical level (Kozier et al., 2004). ADN programs focus on both clinical and classroom learning in a variety of settings. The majority of nurses in the United States hold the associate degree (Berger \& Williams, 1999).

Baccalaureate or generic nursing degree (BSN) programs, located in colleges and 
universities, take 4 years for completion. Kozicr et al. (2004) note that graduates must complete the degree requirements of the university and the nursing program before being awarded the Bachelor of Science degree in nursing (BSN). The lirst 2 years of the program usually focus on the liberal arts, humanities, and physical and social sciences. Typically, the last 2 years consist of nursing courses focusing on critical thinking, decision making, leadership and management, as well as clinical knowledge and skills (Berger \& Williams, 1999). In 1965, the American Nurses Association (ANA) recommended baccalaureate education for entry into professional nursing practice. Although not yet mandated, nursing leaders strongly support this position (American Association of Colleges of Nurses, 2005; Ellis \& Ilartley, 1988).

Advanced or specialty nursing practice requires master"s or doctoral education. Nursing education programs at the master`s level (MSN) prepare nurses lor advanced clinical practice, as nurse educators, or nursing administrators. The curriculum, based on theory and research from nursing and related disciplines, places particular emphasis on advanced scientific concepts and guided clinical practice (Berger \& Williams, 1999). Doctoral programs in nursing award degrees of doctor of philosophy (Ph1)). doctor of nursing science (DNS), or nursing doctorate (NI)). (jraduates of nursing doctoral programs produce nurse philosophers and researchers who contribute to the development of new knowledge in nursing and the advancement of the profession. Many eolleges and universities require that nursing faculty obtain doctorates. Ilospitals often seek doctoral prepared nurses for positions as executives and directors of education and rescarch (Berger \& Williams). Many nurses who hold faculty positions obtain doctoral degrees in education rather than in nursing.

As of 2005 , only three masters entry-level nursing programs and three doctoral 
entry-level programs in nursing in the United States were identified. These programs prepare college graduates with degrees other than nursing as entry level nurse gencralists, with advaneed knowledge, skills, and specialization (Berger \& Williams, 1999).

Another historical event that has affected nursing preparation and practiec is the development of the role of the advaneed nurse practitioner. This role evolved in response 10 a physician shorlage in Colorado in 1965. Registered nurses were given six weeks of continuing education to prepare them for the role of physician extenders. That education was increased until today, preparation for advanced practice is at the maste's level (Blais, Ilayes, Kozier, \& Erb, 2002). There are four gencral categories of advanced practice nurses. They include (a) clinical nurse specialists (CNS), (b) nurse practitioners (NP), (c) nurse midwives, and (d) nurse anesthetists.

The number of nurse practitioners has particularly grown as the demand for primary care has increased. Primary care is the provision of a basic level of health care. usually in an outpatient setting (Office of Technology Assessment). Primary care emphasizes prevention through physical assessments as well as diagnosing and managing acute and chronic conditions (Safriet, 1992). Nurse practitioners, according to guidelines in each state, may provide primary care to patients under the supervision of a physician. According to the latest statistics, there are an estimated 102,829 nurse practitioners in the United States (American College of Nurse Practitioners [ACNP], 2005). More alfordable care can be provided from nurse practitioners due to lower preparation costs in a shorter period of time as compared to physician education. The costs for educating nurse practitioners are one-fifth of the cost related to educating physicians. In addition, the employment costs of nurse practitioners are four times less than that of physicians (Safriet, 1992). Even though these statistics are dated, the ACNP reports that these 
percentages are still correct. This cost-effectiveness, combined with the proven ability of nurse practitioners to provide quality care to a large number of people, suggest that they play an important role in response to the health care crisis.

In summary, nursing education today, though far advanced from its beginnings as an apprenticeship, retains many similarities to the early years. In clinical, students continue their struggle with applying classroom teaching to the real-life clinical setting (Chapman \& Orb, 2000). They work with patients, experience conflict with nursing instructors and stalf nurses, experience work overload, and have fears regarding rendering patient care and performing psychomotor skills (Speck, 1990). Therefore, the clinical experience remains a timely topic for rescarch within the nursing profession. The nursing student, as learner, represents another topic of interest to the nursing profession.

The Learner-Nursing Student

Norman, Buerhaus, Donclan, Mc( loskey, and Dittus (2005) conducted a study that assessed the characteristics of nursing students. A profile of today ${ }^{\circ}$ nursing student was obtained from a national survey. The mailed, self-administered survey was completed by 496 nursing students who were either enrolled in a basic entry registered nurse program or who declared nursing as their intended major. Students" names were randomly chosen from the American Student Lists of College Nursing Students. The data were weighted using nursing students available from the American Association of Colleges of Vursing to ensure balance by geography and program. Most of the nursing students responding to the survey were white, single, and female. Their average age was 26, with most $(76 \%)$ aged between 18 and 30 years. I ess than one-fith $(15 \%)$ of the students were older than 36 years. Students emrolled in associate degree programs were, on average, 6 years older (30 years old) than those enrolled in baccalaureate degree 
programs (24 years old). Approximately one-third had children younger than 18 years living in the household and one quarter $(27 \%)$ were married or living with a partner. $A$ few students aged 25 years and younger were married $(12 \%)$ and only a small percentage had children (10\%), where most of those older than 25 years were married $(55 \%)$ and three-fourths had children.

A greater proportion of minority students $(42 \%)$ versus nonminority students $(\$ 2 \%)$ had children, were slightly older, and were enrolled in an associate degree program (31\% versus $25 \%$ for nonminority students). Most were enrolled in a nursing education program and two-thirds (64\%) were taking clinical courses. A few were attending school but were not yet accepted into a nursing program. The sample contained a fairly balanced distribution of freshmen, sophomores, and juniors but included few scniors. This may be explained by the fact that associate degree programs are 2 years in length and baccalaureate programs (diploma students were not included in the study) are 4 years in length. For example, there are greater numbers of associate degree students who have either freshmen or sophomore status. Baccalaureate students progress from freshman, sophomore, junior, to senior status (Norman et al., 2005). Nationally, the number of male registered nurses rose from $5.4 \%$ in 2000 to $5.7 \%$ in 2004 (D)epartment of Health and Human Services, 2004). According to the Kentucky Board of Nursing (2005), only 3,530 of the 53,424 total number of registered nurses licensed in the state were male.

This section provided a profile of students who enter nursing programs and study in the academic classroom, then move into the clinical setting as part of the nursing curriculum. The clinical environment, addressed next, multiplies the complexity of the experience for the learner (Jacobson, 1966). 


\section{The Clinical Setting}

More early research focused on student learning in the nursing classroom rather than the clinical leaming experience (Brown, 1981). Early studies did not always make a distinction between these two areas, assuming that clinical experience always accompanied classroom instruction in the basic nursing curriculum. While older studies added to the body of knowledge in both classroom and clinical education in nursing, later studies contributed knowledge solely on the clinical experience. However, these classic studies laid the groundwork for most of the current research and remain timely. The revicw of the literature includes research on the nursing clinical experience as well as some studies that combine nursing clinical and classroom education.

The clinical setting is defined as any environment in which a nurse interacts with a patient, such as hospitals, nursing homes, and clinics (Vollman, 1989). I) unn and Burnett (1995) defined the clinical enviromment as "an inteactive network of forces within the clinical setting which influence the students" clinical laaming outcomes" (p. 1,299). The teaching of nursing requires learning in the clinical setting. The clinical experience involves working with human beings, unlike the simulated clinical setting, the school practice laboratory (Jacobson, 1960). Clinical learning is very different from classroom learning; learning takes place in a complex cnviromment where both the students and patients needs must be considered (Windsor, 1987). Massarweh (1999) described the clinical setting as the clinical classroom.

Theory and practice, although interrelated in nursing education, are treated and taught as two separate entities, didactic and clinical (Vollman, 1989). (Opportunities to work with real patients and real problems make the clinical practice setting significant and essential to nursing preparation (Chapman \& Orb, 2000). The 14 nursing students 
interviewed by Chapman and Orb expressed this significance.

The importance of clinical experience in nursing education is apparent when one considers that twice as many hours are spent in the clinical environment than in the didactic portion of the nursing curriculum (Vollman, 1989). Clinical placement provides students the opportunity to apply theory and knowledge from the classroom as well as to observe role modeling of nurses in practice (Thorell-Ekstrand \& Bjorvell, 1995). In fact, the socialization of students into nursing practice occurs in the clinical setting (Windsor. 1987).

Clinical experience is an expensive form of teaching/learning (Crealish \& Carroll, 1998) because of the low faculty/student ratios imposed by Boards of Nursing. In the state of Kentucky, for example, the Board of Nursing (2005) mandates that a nursing instructor may supervise no more than 10 students in the clinical setting at one time. In order to adhere to this mandate, nursing programs are stretched to the limit of their budgets in hiring the additional faculty necessary to maintain the 10 10 1 ratio in the clnical setting.

Even though clinical practice remains fundamental to nursing preparation, students experience many problems ard constraints during the clinical experience. Some problems are cited as the theory-practice gap, stress, and anxicty (Chapman \& Orb, 2001). Quint (1965) noted that students are concerned about doing something in the clinical setting that might cause them personal discomfort and cmbarrassment. Often students have very little knowledge about their patient's health problem. the problemsolving process, and the equipment in the clinical area (Infante, 1985).

Although few studies were identified that focused solcly on the provision of clinical experience, DiGiacomo (1993) conducted a case study to examine one clinical 
lacility to observe how nursing programs provided student clinical experience. Data were collected from interviews and observations from students and faculty teachers. The narrative was organized around three themes: use of time, activities requiring exchange of information, and the clinical assignment. Use of time examined waiting time when students had nothing to do. Exchange of information activities were related to giving and receiving the change of shift report and student-staff and student-faculty teacher interactions. The clinical assignment focused on patient care, medication administration, observation experiences, and nursing care plans. The themes developed from faculty teachers were control, flexibility, and being alone, while student themes were the real world and being competent.

In the simulated setting, students practice on equipment and their pretend patients are manikins. At some point, in order to learn to practice nursing, real patients must be used in an actual clinical environment. Inherent stress is involved because with human patients, mistakes cannot be undone and real harm may result. Students perceive clinical experience as a larger threat than learning in the classroom. Nursing students describe the clinical experience as anxiety-provoking in many studies (Kushnir, 1986). Stress and anxiety in the clinical setting are addressed in the next subsection.

\section{Stress and Anxiety in the Clinical Setting}

Level and source of stress and anxiety for the nursing student appear to be well documented in the literature. Kushnir (1986) addressed the stressor and effects of the presence of a nursing instructor on student nurses behavior. Female nursing students ( $n$ $=20)$ were asked to report stressful encounters with their instructors. The results showed that most of the stressful encounters occurred during unique situations, such as the first clinical experience, the first injection, or placement on a new clinical ward. The 
remaining stressful encounters involved evaluation of the students performance by the instructor. Students described instructors as highly critical, incisive, interfering, and inconsiderate in two respects: first, the fact that the student was not yet prolicient and second, the fact that the patient was a witness to the student's stress and embarassment. About one-third of the reports in Kushnir's study (1986) described physiological svmptoms of the stressful encounter as muscle tension, increased heart rate, blushing, and tremors of the hands. Some of the respondents reported that the mere presence of instructors affected their performance negatively. The psychological effects included cognitive, emotional, and behavioral responses. The effects on cognitive process included impairment of memory and loss of cognitive control. Effects on behavior included crying, clumsiness, and inability to respond. Effects on emotional reactions included anxiety and fear of failure, stress and tension, loss of confidence, anger, and embarrassment.

The implications of this study (Kushnir, 1986) demonstrate that clinical nursing education involves paradoxical requirements. Nursing students must be supervised in the clinical area to protect patients' safety: yet the presence of the instructor can negatively alfect students' performance. Kushnir states that instructors should emphasize their evaluative role less, and help create a more supportive learning environment in which crrors are treated as opportunitics for learning rather than occasions for criticism.

Kleehammer et al. (1990) sought to identify potentially anxiety-provoking clinical experiences for junior $(n=39)$ and senior $(n=53)$ baccalaureate nursing students using a comparative descriptive, longitudinal design over 4 years. The tool used for data collection was the Clinical Experience $\Lambda$ ssessment Form. The 16 items on the questionnaire included communication and procedural aspects of patient care. interpersonal relationships with healthcare providers, and interactions with faculty. 
Subjects were asked to respond to a Likert-type scale for each item from "strongly agrec" with a score of five to "strongly disagree" with a score of one. $\Lambda$ n open-ended question was included in which students were asked to identify the most anxiety-producing aspect of their clinical experience.

Results $(t=2.20, p<.03)$ indicaled that juniors were significantly higher in their expression of anxiety than seniors. The highest levels of anxiety expressed by students concerned the initial clinical experience $(83 \%)$ and fear of making mistakes $(88 \%)$. Clinical procedures $(77 \%)$, hospital equipment $(65 \%)$, talking to physicians, $(71 \%)$ and being late $(61 \%)$ were identified by the students as producing anxicty. Observation $(67 \%)$ and evaluation $(62 \%)$ by faculty were also indicated as situations that prompted student anxiety. Ninety-seven percent of subjects answered the open-ended question. "What has been the most anxiety-producing aspect of your clinical experience?"* From the content analysis, four major themes emerged: (a) negative interaction with the instructor was mentioned most often, with (b) student anxiety concerning nursing procedures, (c) fear of making mistakes, and (d) the initial clinical experience as sccond, third. and fourth (no percentages were included in the study). Kleehammer et al. (1990) state that nursing educators need to examine anxiety-producing situations for the clinical student and interventions that can decrease that anxiety.

Beck and Srivastava (1991) investigated the perception of level and source of stress in nursing students in classroom as well as clinical courses in a descriptive correlational study. The subjects $(n=94)$ included all levels of generic baccalaureate nursing students and registered nurse (RV) students who were completing their baccalaureate degree. The instruments used to gather data were the (icneral Ilealth Questionnaire (GHQ) and the Stress Inventory Questionnaire (SIQ). The GHQ provided a 
measure of general distress and minor psychiatric disorders. The SIQ provided descriptions of stressful incidents. Data were analyzed using frequency distributions, content analysis, measures of correlation, and analysis of variance.

The findings (Beck \& Srivastava, 1991) revealed consistently high scores on the GllQ across academic years, with lower scores in the RN students (mean for all groups -24.21, means for each type of student not provided). The mean scores for all groups were considerably higher than the accepted cut-ofl score of three. Overall, the prevalence of psychiatric symptoms was higher than that found in the general population. Beck and Srivastava stated that the RN students may have had lower scores because of their maturity and previous experience and stress management skills. Results on the SIQ showed that although more students identified stressors related to academic work (28), stressors related to clinical experience were identified as second and third highest. These stressors were identificd as (a) lacking clinical knowledge/experience to accomplish a lask (16 students), (b) clinical work in an unfamiliar area (nine students), and (c) working with dillicult patients (live students).

Correlations of demographics variables with GHQ seores revealed a signilicant difference at the .002 level between stuclent status and GHQ scores. The RN group had lower GHQ scores than the generic students. Correlations of demographic variables with the stress scores revealed a significant difference at the .02 level between student status and stress; again, the RN students scored lower overall than the generic students. $A$ significant difference at the .04 level was also found between work status and stress with those working reporting more stress. The two instruments (SIQ and GIIQ) were correlated at the .0001 level, meaning that the higher the scores on the stress scale (SIQ), the greater the distress as measured by the GHQ (Beck \& Srivastava, 1991). 
Beck and Srivastava (1991) identified a limitation of the study as the relatively small sample size which precluded goneralization to other groups and settings. This study aiso only looked at selected characteristics of the students, while many other variables could account for differences in the stress experienced by students.

Pagana (1992) assessed nursing students stress in an initial clinical experience as either threatening or challenging. The Clinical Stress Questionnaire (CSQ) was used to collect data. Threat was defined as the potential for harm; challenge was defined as the potential for mastery and growth. Subjects were baccalaureate nursing students $(n=246)$ from seven colleges and universities in their first medical-surgical clinical experience. Results revealed that many students expressed feelings of inadequacy related to their lack of knowledge and experience with simultaneous increased responsibility and expectations. Students also expressed fear of making an error or mistake that could result in harming a patient. $\Lambda$ frequently mentioned threat by the students was the clinical instructor, seen often as intimidating, demanding, and impatient. Students directly stated that the instructor watched and evaluated every move. Students also mentioned the challenge of organizing their work and getting finished with clinical assignments on time.

Williams (1993) conducted a study to ascertain the concerns of beginning baccalaureate nursing students $(n=245)$. Data were collected with the Nursing Students Concern Survey. Students were asked to rate each of the 38 items using a Likert-type format according to degree of concern. One open-ended item for additional concerns was included. Findings showed that the three items on the survey identified as causing the greatest concern were, in rank order, (a) kecping up grades $(44 \%)$, (b) learning clinical procedures $(42.4 \%)$, and (c) fear of doing something wrong to a patient $(41 \%)$. $\Lambda$ though Williams" study included students" concerns that related to all aspects of their 
nursing educational experience, clinical concerns, in rank order were (a) fear of doing something wrong to a patient, (b) learning clinical procedures, and (c) difliculty of clinical work. Factor analysis yielded the following factors related to clinical concerns: (a) fear of catching something in the hospital and (b) not enough guidance from professors in the clinical setting. Williams suggests that interventions such as developing orientation and support programs can facilitate the alleviation of students concerns and provide the best chance for their suceess. The findings of this study are similar to findings in other studies (Beck \& Srivastava, 1991; Klechammer et al., 1990).

Similar concerns were reported by Admi (1997) who studied nursing student perceptions of stress in their initial clinical experience in a nursing school in Isract. The six subscales that resulted from a factor analysis of 25 stress items were (a) inadecuate knowledge and training. (b) averse and embarrassing sights. (c) instructor ${ }^{\circ}$ s close slipervision, (d) insufficient hospital resources, (e) causing pain and suffering, and ( $f$ ) education-reality conflict.

A study conducted in Ireland (Timmins \& Kaliszer, 2002) examined nursing students ( $n=10$ ) reported stress. A 12 -item questionnaire, based on themes from the literature on stress in student nurses, was used to collect data. The respondents were asked to rate, on a 4 point Likert-type scale, items that might cause stress and to select levels from one (not at all stressful) to four (extremely stressful). Results revealed that academic-related concerns and financial constraints emerged as the most stressful areas for students. However, one-third of the students reported that clinical placements, relationships with teachers and clinical nursing staff, and being involved with the death of a patient caused some degree of stress. Timmins and Kaliszer stated that their study supported the view that factors concerning both the academic and clinical component of 
nursing education are sourees of stress. Other studies completed by Hamill (1995) and Jones and Johnson (1997) further document the academic stress experienced by nursing students. However, financial concerns are documented n few studies (Williams, 1993).

Several studies focused on state-trait measures of emotion. This will be explored in the next subsection.

\section{Siate-trait Measures of Emotion}

Biggers, Zimmerman, and $\Lambda$ pert (1988) compared students $(n=171)$ from three different nursing programs on various state and trait measures of emotions, including general anxicty, apprehension about communication, and anxicty about their future nursing career. Socio-demographic data and responses to items from live psychometric scales based on the Mehrabian Emotion Theory (1980) were collected fiom graduating students from associate $(n-2)$, diploma $(n=2)$, and baccalaureate $(n-57)$ nursing programs.

Mehabrian's (1980) theory is based on research of trait and state emotions and their relationships, describing them in terms of the emotional responses of pleasure, arousal, and dominance. These three state emotions have been found, in various combinations, as capable of describing a variety of emotional states. For instance. Mehabrian's theory suggests that those who have greater state anxicty related to their profession will also pereeive their work as less pleasurable, more arousing, and less dominance-eliciting than those experiencing lower anxiety about their profession.

Results were discussed in terms of the Mehrabian's Emotion Theory which was the also the framework for the study (Biggers et al., 1988). 'The term dominance was used in the study to mean the opposite of submissiveness, and refers to internal control. Findings indicated that baccalaureate students were least apprehensive about 
communicating and felt most dominant in the nursing setting. Associate degree students were most anxious about nursing if they did not feel dominant. Diploma students were most anxious if they did not feel dominant or were apprehensive about communication. Baccalaureate students were most anxious if they were generally unhappy, which was a measure of a state emotion on one of the psychometric scales.

Biggers et al. (1988) suggested that nursing education practices should consider change in light of the results of this study. Screening of applicants to nursing programs based on trait emotion variables should be considered. The implementation of various interventions in the three types of educational programs to counterbalance predispositions toward experiencing stress on the job should also be considered. The authors (Biggers et al.) stated further that future research should be done to investigate how differences in nurses" educational background may affect their on-1he-job stress.

Bell (1991) conducted an experimental study to identify the anxiety profile of nursing students when learning a complex psychomotor skill. The purpose of the study was to determine the effect of preclinical skill evaluation on student anxicty and performance when applying the skill in a patient situation. The sample $(n=30)$ consisted of first-semester nursing students in a baccalaureate nursing program. Volunters were administered the State-Trait Anxiety Inventory (SIAI) before receiving instruction on the skill of female urinary catheterization during a laboratory class. The STAI consisted of two subscales, state or situation anxiety and trait or anxiety proneness.

Immediately after the laboratory class, all subjects again completed the Sl $\mathrm{AI}$, along with questionnaire I, which asked students for the amount of prelaboratory preparation, self-rating of performance and confidence, and concems about performing the skill in a patient situation. Subjects were then randomly assigned to either 
experimental or control groups. During the next week, the experimental group participated in preclinical skill evaluation by the investigator. During the evaluation, students demonstrated the skill on a manikin, had an opportunity to ask any questions, and were given immediate feedback on skill performance. Subjects then completed the State-Anxiety section of the STAI and questionnaire II, providing a second self-rating of performance and confidence in performing the skill (Bell, 1991).

The control group was instructed briefly by the investigator to view a videotape of the skill and to complete the data collection instruments. There was no opportunity for subjects to ask any questions about the skill and the investigator was not present during the viewing. After viewing the videotape, each subject completed the State-Anxicty scetion of the STAI and questionnaire II (Bell, 1991).

During the remainder of the semester, the clinical instructor evaluated subjects" first time performance in an actual patient situation. Immediately after this performanec and at the end of the clinical day, all subjects completed the State-Anxiety section of the STAI. Questionnaire II was also completed at the end of the day, which provided the amount of preparation after completing the laboratory class, a self-assessment of perceived stress when performing the skill in a patient situation, and a self-rating of confidence about future performance of the skill (Bell, 1991).

The findings (Bell, 1991) showed that the experimental group reported signilicantly less anxiety during clinical application and less anxiety about performing the skill in the future than the control group $(t=2.514, d f=28, p<.05)$. Immediately following treatment, the two groups did not differ significantly in self-confidence and performance in the future. However, after clinical application, the experimental group reported significantly more self-confidence about performing the skill in the future $\left(\chi^{2}=\right.$ 
$9.592, d f-2, p<.01)$.

Bell (1991) suggested that although the anxicty-reducing benclit of preclinical skill evaluation did not result in significantly better first-lime performance in a patient situation, the experimental group did report less anxiety and more self-confidence about performing the skill in the future. Minimizing anxiety, according to the author (Bell), should enable students to become more involved in other important aspects of the clinical experience. Bell also states that preclinical evaluation/videotape viewing may have some merit in increasing students' comfort level in the clinical area.

Swafford (1992) also investigated the effectiveness of a stress management program on the anxiety reduction of nursing students $(n=122)$ in the lirst semester of a nursing program. The State-Trait Anxiety Inventory (SIAI) was used in this study as well as in the Bell (1991) study. The STAI, however, was administered in the Swafford study at the beginning and at the end of the first semester of a nursing program to profile the anxiety level of a class of associate degree nursing students. The treatment group $(n=$ 8i attended weekly 1 -hour stress management/anxiety reduction sessions. 'The control group $(n=64)$ received no intervention. The effects of a stress inoculation program in the treatment group were evaluated. The results of this study did not demonstrate a relationship between anxiety, anxicty reduction, and success in al nursing program. Regarding attrition, there was no attrition in the experimental group, while eight out of 64 students $(12.5 \%)$ in the control group either withdrew or failed. The z score for this difference was signilicant at the .05 level. Swafford concluded that an intervention strategy could make a difference in the success of students in the first nursing course. The resulting difference in attrition could not be attributed to a significant reduction in anxicty. 
Kim (1997) described the most anxiety-producing clinical experiences of senior baccalaureate nursing students $(n=61)$ in a descriptive study. $\Lambda$ s in the Bell (1991) and Swafford (1992) studies, the Slate Trait Inventory (STAI) was used as the instrument. In the Kim study, however, data were collected using only the Trait Anxicty scale of the STAI. In addition, the Clinical Lxperience Assessment Lorm (Kleehammer et al., 1990) was used.

Analysis demonstrated that $36 \%(n=22)$ of the students experienced a moderate level of anxiety. The results demonstrated that senior nursing students reported the most anxiety-producing experiences in the clinical setting such as (a) arriving late (72\%), (b) being observed by instructors $(64 \%)$, (c) responding to initial clinical experiences $(64 \%)$, (d) having a fear of making mistakes (51\%), and (c) talking to physicians $(51 \%) . \wedge$ main theme from the content analysis revealed that students anxiety was increased in the clinical setting by their perceptions of uncertainty about their own skills. Moderately signilicant and positive relationships $(p \leq .05)$ were found between the trait anxiety and the clinical experiences that were anxiety-producing. A higher level of perceived anxiety accompanied the following clinical experiences: (a) being observed by instructors, (b) doing before clinical preparation in the hospital, (c) asking questions of instructors, (d) being evaluated by faculty, (c) reporting to the team leader. There was no significant relationship between demographic variables and trait anxicty and clinical experiences that produced anxiety in senior nursing students (Kim, 1997).

Kim (1997) states that by identifying the most anxiety-producing clinical experiences for students, clinical teaching will be more effective. The findings in this study (Kim) were similar to those of Bell (1991). Continued and unrelieved stress and anxiety can lead to serious consequences and will be explored briefly in the nexi 
subsection of the literature review.

\section{Burnout}

Mild anxiety is to be expected during the clinical experience and may even enhance learning by providing positive motivation. Moderate or severe anxicty, however, interferes with learning and the ability to focus on the learning experience (Blainey, 1980). Many students with signilicant anxiety become increasingly disillusioned with learning (Phillips, 1988) and experience physical symptoms sucll as muscular tension, headaches, and nausea (Russo, 1984; Wine, 1980). Continued stress can lead to burnout, a syndrome composed of emotional exhaustion, depersonalization, and reduced personal accomplishment (Maslach, 1982).

Beck (1995) found that bumout could even result in nursing students" experiencing a state of exhaustion caused by all of their demands. In a study, Beck explored the meaning of burnout as experienced by nursing students. The population $(n=$ 28) consisted of a convenience sample of sophomore nursing students. This study included both classroom and clinical aspects of the students" nursing education experience. The subjects were enrolled in their first two clinical courses. All students who said that they had experienced burnout were included in the study. Subjects responded in writing to a statement in which they described their burnout cxperience.

Analysis of the 28 written descriptions of students lived experiences of burnout yielded 129 significant statements. Meanings were categorized into the following nine theme clusters: (a) engulfing demands, (b) time pressure, (c) no outlet, (d) physically debilitating, (c) emotionally overwhelming, (f) lack of concentration, (g) decreased motivation, (h) impeding relationships, and (i) coping attempts. These nine theme clusters and their formulated meanings were integrated into an exhaustive description of 
undergraduate nursing students' lived experience of burnout (Beck, 1995).

Highlights of the exhaustive description revealed that at midterm, toward the end of the semester, and during final examinations, students are more prone to experience burnout. They state that they feel as if they are drowning and cannot keep their heads above water. Students report that as a result of the stress they experience, fatigue leaves them feeling washed out and lacking energy. Their eating habits change; they may gain or lose weight. During burnout, students describe riding an emotional roller coaster, experiencing feelings of inadequacy, frustration, anger, hopelessness, and being overwhelmed. During burnout, students state that interpersonal relationships with family, friends, and even their pets, are affected. They also report increasing irritability and moodiness and that they may take their frustration out on family and liriends. Students state that attempts to cope with burnout may include reading only the bare minimum to pass courses or completing assignments without caring about quality. Students said that they periodically call in sick to work so that they can have some time just for themselves (Beck, 1995$)$.

This study (Beck, 1995) has important implications for nursing educators. The author suggested that before the start of the semester, nursing faculty who teach the same level students can meet and plan strategies for spreading out the students work load more evenly over the semester to prevent the "crunch periods." "The author also states that educators need to examine how they may contribute to burnout and that faculty roles, ways of interacting with students, and unrealistic expectations may need to be examined.

In summary, a predominant theme in the literature is student reports of stress and anxiety in nursing clinical experience. Infante (1985) suggests that clinical instructors have expectations of students as if they were already nurses during their clinical 
experience and forget that they are learning to become nurses. This expectation, combined with the unpredictable environment in the clinical setting and fear of making mistakes, contributes to stress and anxiety on the part of the student. Students are olten thrown into foreign surroundings, not knowing the staff, patients, or ward routine. Patients and staff may have high expectations of them, even though they are "just a student" (Elliot, 2002, p. 34). The clinical instructor may also have high expectations of them even though they are still learning. Students may be expected to be familiar with pathophysiological or pharmacological concepts they have not yet been taught in their program of study (Elliot). How nursing students deal with stress and anxiety can have important implications for their ability to complete successfully their program of study. Stress and coping in nursing students will be discussed in the next section.

\section{Stress and Coping}

While some authors (Biggers et al, 1988) declare nursing student experience more stressful than that of students in other fields of study, Carter (1982) disagreed with the commonly held belief. In Carter"s study. stress and coping styles of female senior nursing students $(n=103)$ and senior liberal arts students $(n=103)$ were compared. In addition to collecting demographic information, four instruments measuring emotional distress, social network systems, coping styles, and drug use were administered to the participants. Other differences between the two groups were that the nursing students depended on their children more than the liberal arts students; they also depended more on friends away from school. Liberal arts students depended more on friends at school and also depended more on dormitory counselors than did the nursing students. The two groups were similar in coping style with the exception that the liberal arts students depended on college-oriented resourees such as dormitory counselors and college 
administrators to a greater extent than did nursing students (Carter).

Findings revealed that the two groups were similar in their symptom distress levels except for the psychoticism symptom dimension, which was significantly higher for the liberal arts women $(t=1.98, p<.05)$. This dimension measures psychological symptoms from mild interpersonal alienation to more pronounced psychosis. The measure of availability and use of significant others during stressful periods was similar between the two groups; $21 \%$ of each group reported having only wo or less friends to whom they felt close. Forty-three percent of the liberal arts students reported only two or less relatives to whom they felt close as compared to $37 \%$ of the nursing students (Carter, 1982).

In general, reported drug use for both groups was low. The only difference noted (data not provided in study) was a greater consumption of over-the-counter analgesics by the liberal arts students. However, more liberal arts students $(47 \%)$ reported using alcohol once a week or more than did nursing students $(39 \%)$. The author concluded from the research that nursing students are no more subject to distress and dysfunctional coping than students in other majors (Carter, 1982).

Studies in other countries have also been conducted on nursing students" perceptions of stress and coping in their nursing program. Hamill (1995) conducted a case study at a nursing college in Ireland to investigate student nurses perceived stress and coping mechanisms in relation to their Diploma in Nursing Studies course. The participants were the first cohorts in a nursing program implementing national higher education standards. $\Lambda$ questionnaire was sent to each participant $(n \quad 35)$. Unstructured formal interviews were conducted with 10 of the participants. Although analysis of the data revealed that categories of codes clustered around both classroom-based and 
clinical-based stress, only results from the clinical area are reported here.

Students reported these items from the clinical category as stressful: (a) lack of practical skills, (b) negative attitudes of ward staff, (c) not being expected on the wards, (d) misunderstanding course aims and student status, and (c) short clinical placements. Results showed that stress was perceived in relation to non-integration with the classroom environment and the clinical environment and nursing stafl (Hamill, 1995).

Coping with clinical stressors was varied. Students reported that they became more assertive in interacting with nursing staff by introducing themselves and stating their purpose in being on the ward. Informants reported that coping strategies used for clinical stressors included developing very supportive networks with their peers, more so than with their families. They often discussed their stress and derived comfort from mutual support. Other emotion-focused coping mechanisms were also reported: (a) binge eating, (b) sitting in the bath, (c) having a good cry, (d) exercising, (c) being irritable, and (1) use of alcohol (Hamill, 1995).

Jones and Johnston (1997) examined distress, stress, and coping before and after an initial clinical placement of two cohorts of nursing students $(n=220)$ in Scotland. Data were collected with the General Health Questionnaire, the Beck and Srivastava Stress Inventory, and a modified Ways of Coping Questionnaire. Results revealed that the group of students screened before the initial clinical placement as well as the group screened after the initial clinical experience both suffered significant emotional stress $(50.5 \%$ in cohort I, $67.9 \%$ in cohort II). In both cohorts, the use of direct coping was associated with lower levels of distress and with lower total stress scores on the instruments used. The authors (Jones \& Johnston) suggest that there is a problem with student distress associated with initial clinical placements and a multidemensional stress 
management approach is needed.

The sources and level of stress experienced by student nurses in associate and baccalaureate degree programs was investigated by Kane (1998). Stressful situations and/or experiences of these two groups $(n-16)$ of students were measured with the Student Stress and Coping Inventory (SSCI). lindings showed that there were no significant differences in perceived level of stress between the two groups at the .05 level of significance. Students in both groups identificd academic experiences as most stressful, such as long hours of study, taking examinations, grades, and lack of free time. Students in this study also identified performing psychomotor skills, potentially caring for a patient in an emergency situation and presentation of content in examinations (not sure what is being asked) as stress producing. lindings in this study (Kane) are similar to those of only a lew other studies (Beck \& Srivastava, 1991; Nikou, 1999).

An exploratory study by Nikou (1999) investigated the relationships among hardiness, stress, and health-promoting behaviors in baccalaureate nursing students ( $n$ 250) from 39 colleges. Hardiness was defined as the ability to use all available resources to cope effectively with stressful events. Results showed that hardiness was inversely related to stress, hardiness was positively related to health-promoting behaviors, and stress was negatively related to health-promoting behaviors. An interesting linding of the study was that participants identified the nursing classroom as more stressful than the clinical. This was a finding in direct opposition to that of earlier studies (Kushnir, 1986; Windsor, 1987) and consistent with findings of later studics (Beck \& Srivastava, 1991; Kane, 1998).

Many variables have been shown to affect the student in the clinical learning environment. The following section explores specific relationships in the clinical setting 
and how they impact the nursing clinical experience.

Relationships That Impact the Clinical l carning Lnvironment

Nursing research contains abundant studies in the area of nursing student and teacher perceptions of nursing instruction. Beginning in the 1960 s, many rescarchers examined this topic. Early studies did not always make a distinction between these two arcas, assuming that clinical experience always accompanied classroom instruction in the basic nursing curriculum. Older studies added to the body of knowledge regarding nursing student and teacher perceptions of both classroom and clinical cducation, whereas, more recent studics were more likely to contribute knowledge solely on the clinical experience. Ilowever, these classic studies laid the groundwork lor most of the current research and for this reason they remain timely and are included in the following two subsections.

\section{Nursing Faculty as Perceived by Sudents}

Jacobson (1966) identified the behaviors and characteristics of nursing teachers in both clinical and classroom that students perecived as effective and ineffective. They were identilied as (a) availability to students, (b) personal characteristics, (c) apparent general knowledge and professional competence, (d) interpersonal relations with students and others, (c) teaching practices in classroom and clinical areas, and (1) evaluation practices.

Elements of these categorics were also found in subsequent studics (Kiker, 1973; Lowery, Keane, \& Hyman, 1971). The findings of all of these studies revealed that students view the elements in teaching practices such as open teacher-student communication, personal warmth, and thorough knowledge of subject matter as the most important teacher characteristics. 
Kiker (1973) conducted a study to compare the characteristics of teaching effectiveness considered most essential by junior nursing students $(n=37)$, junior education students $(n=30)$, and graduate nursing students $(n=36)$. The students were administered a questionnaire and asked to rank the characteristics desirable in teachers in order of most to least essential.

The 12 characteristics on the questionnaire were loosely grouped into three categories: (a) professional competence, (b) relationships with students, and (c) individual personal attributes. All three groups of students ranked characteristics in the professional competence category as most essential. The education students ranked, "displays confidence in his/her ability as a professional person," as the most essential characteristic. Of almost equal importance was "encourages independent thinking and learning." The undergraduate nursing students placed "organizes classroom content/and/or laboratory experience in a manner which is meaningful to the student." in first place. They ranked, "demonstrates skills, attitudes, and values that are to be developed by the student." as second. The nursing graduate students rated "is creative and stimulative." as the most essential characteristic. This group of students also highly rated, "encourages independent thinking and learning." In addition, all groups of students ranked characteristics in the relationships with students category in the top half of the rankings (Kiker, 1973).

The category regarding individual personal attributes was ranked as least essential by all groups of students. Items from this category ranked lowest by all groups of students were "presents a neat, personal appearance," and "has a speaking voice conducive to learning." The author (Kiker, 1973) suggests that nursing instructors should seck to develop a greater interest in students and their problems in order to prevent 
problems from occurring in the classroom and clinical area.

$\Lambda$ study by Wong (1978) examined students perceptions of helpful or hindering behaviors of nursing clinical instructors. The behaviors identified as helplul were similar to those categorized in previous studies (Dixon \& Kocrner, 1976; Gunter, 1969; Kiker, 1973; Lowery et al., 1971) as interpersonal interactions with students: (a) relating to students as mature individuals, (b) creating an atmosphere where the student felt comfortable approaching the instructor when help was needed, (c) providing support, and (d) encouraging independent thinking. Teacher behaviors reported by students as hindering their learning were (a) posing a threat, (b) being sarcastic, (c) acting in a superior manner, (d) belittling students, (e) correcting students in the presence of others, (f) supervising students too closely, and (g) a tendency to emphasize the students" mistakes or weaknesses.

A descriptive study was conducted by Cooper (1982) to determine the characteristics of nursing faculty that students viewed as most important. The convenience sample consisted of 75 senior baccalaureate nursing students. The students were asked to complete the Clinical Instructor Ranking Scale. The instrument consisted of 18 behaviors which were divided into three groups and each behavior was categorized as person role, nurse role, or teacher role. The findings suggested that nurse role behaviors were more frequently rated highest. Teacher role behaviors were more frequently rated second, and behaviors associated with person role were more frequently rated third. The author (Cooper) stated that the implications of these findings suggest that students perceive faculty serving as role models as the most important teacher characteristic.

In addition to this work on students' perceptions, many studies examine the 
pereeptions of nursing faculty from the viewpoint of faculty as well as students. The next subsection will provide a review of these studies.

\section{Nursing Faculty as Perceived by Students and Faculty}

A qualitative study was carricd out by 0 'Shea and Parsons (1979) to discover the perceptions of baccalaureate nursing students $(n=205)$ and faculty $(n=24)$ of what teacher behaviors facilitated or hindered students" learning in the clinical setting. Respondents were asked to list three to five behaviors each that facilitated or hindered students clinical experience. The responses were sorted into three categories of teacher behaviors: (a) evaluative behaviors, (b) instructive/assistive behaviors, and (c) personal characteristics. 'The lindings of O' Shea and Parsons revealed that the most agreement between student and faculty was in the areas that facilitated learning such as "positive and honest feedback," in the evaluative category; "available in the clinical setting" in the instructive/assistive category; and "supportive" and "concerned/understanding" in the personal characteristics category. The most marked difference of opinion in the study between faculty and students was in respect to role modeling. Faculty indicated "role modeling" as a facilitative behavior in the instructive/assistive category live times as often as students did, including demonstration and explanation in their definition of role modeling, whilc students definition was more restricted to setting an example. While not all of the respondents listed interference behaviors for each category, they were generally listed as the absence of the facilitative behaviors.

Brown (1981) conducted a study of nursing faculty and student pereptions of effective clinical teachers. The subjects collectively ranked the three categories of characteristics of effective teachers in order of importance: (a) professional competence, (b) relationship with students, and (c) personal attributes. Students ranked these 
categories in order of importance: (a) relationships with students, (b) professional competence, and (c) personal attributes. The faculty group indicated an inverse relationship, ranking these categories in order of importance: (a) professional competence, (b) relationships with students, and (c) personal attributes. The subjects also ranked individual characteristics in each category in order of importance. The items that both groups ranked among the top five characteristics of an effective clinical teacher were (a) provided useful feedback on student progress and (b) objective and fair in the evaluation of the student. In this study, nursing students regarded the instructor"s relationships with students as more important than professional competence. Kiker (1972) reported this same finding. Brown stated that these findings had strong implications for nursing educators to keep the lines of communication open with their students.

A study based on Brown's (1981) descriptive research was conducted by Bergman and Gaitskill (1990). This study investigated the perceptions of nursing students and faculty of effective clinical teacher characteristics. Results of the study suggested that both faculty and students perceive effective clinical teachers as articulate, knowledgeable, objective, and fair in student evaluation. Although there was a high degree of agreement between the responses of faculty and students, there were differences. Both valued skills related to the student-faculty relationship as more important than professional attributes of the teacher. Faculty appeared to place a higher value on demonstration of genuine interest in patients, while students were more concemed with communication related attributes, such as the ability to relate knowledge to students. The results of this study were similar to that of Brown`s with some significant dillerences. Faculty in the Bergman and Gaitskill study ranked characteristics dealing with the clinical instructor's 
relationship with students to be more important than those dealing with professional competence. This linding is the opposite of Brown's results.

Knox and Mogan (1985) also revealed similar lindings. A survey instrument was developed by the investigators to describe clinical teacher characteristics. A questionnaire was distributed to 500 students, 60 laculty members, and 100 practicing graduates. Evaluation defined as the "type and amount of feedback the student receives from the teacher regarding clinical performance and written clinical assignments." was the highest rated category by all groups except lirst-year students, who at the time had not experienced summative clinical evaluation. Findings also revealed that students ascribed the highest scores to the category. "interpersonal relationships between student and clinical instructor:" Faculty and practicing graduates gave higher scores for the category. "teacher"s nursing competence," which included teacher attitudes. emotional tendencies. and character traits.

Mogan and Knox (1987) conducted a descriptive study in which the Nursing Clinical Teacher Eflectiveness Inventory (NCETI) was used to determine characteristics of 'best' and 'worst' clinical teachers as perceived by nursing faculty and students. The sample of 173 baccalaureate nursing students and 28 clinical teachers were administered the NCTEI, a 48-item checklist which described teacher characteristics. Faculty and students were asked to rate on a 7-point Likert-type scalc, how descriptive a specilic characteristic was of a particular teacher. The findings of the study revealed that faculty and students collectively perceived 'best' clinical teachers as (a) good role models, (b) well prepared for teaching, (c) self-conlident, (d) skilled clinicians, (c) approachable, and (f) respectful of students. Faculty as a group perceived characteristics of 'hest' clinical teachers as (a) having a broad knowledge base in nursing, (b) giving clear explanations, 
and (c) stimulating students' interest. Students as a group perceived 'best' clinical teachers as (a) demonstrating enthusiasm, (b) promoting student independence, and (c) correcting students without belittling them.

Faculty perceptions of 'worst' clinical teacher characteristics were (a) poor communication skills, (b) lack of enjoyment of nursing, and (c) lack of objectivity in dealing with students. Students perceived 'worst' clinical teachers as (a) being unapproachable, (b) lacking empathy, (c) having poor communication skills, and (d) belittling students when they made mistakes. There was agreement between faculty and students in their collective perceptions of 'worst' clinical teachers as (a) poor role models, (b) judgmental, (c) nonsupportive, and (d) not encouraging to students. Although no previous studies comparing 'best' and 't'orst' clinical teachers were identilied in the literature. some authors (Cooper, 1982: Kiker, 1973; 0Shea \& Parsons. 1979: Stuebbe, $1980)$ cited role modeling as a critical clinical teacher behavior (Knox \& Mogan, 1987). Nehring (1990) replicated the Mogan and Knox (1987) study. In the Nehring study, the 'best' clinical teachers wore seen as (a) being a good role model, (b) enjoying tcaching and nursing, and (c) demonstrating clinical skills and judgment. Both faculty and students saw the 'worst' clinical teachers as (a) poor role models, (b) not using constructive criticism, and (c) not providing support and encouragement to students. These findings are similar to those of Mogan and Knox.

Another replication of the Mogan and Knox (1987) study was undertaken by Lee, Cholowski, and Williams (2002). The Nursing Clinical Effectiveness Inventory (NCTLI) was administered to 104 second year nursing students and 17 clinical educators. Respondents rated the characteristics of effective clinical educators on a Likert-type scale. Findings showed that students perceived the most effective clinical educators to be 
those who were good role models. This finding is consistent with that of Mogan and Knox. Clinical educators perceived the most effective clinical educators to be those who enjoyed nursing. This study found that interpersonal relationships were ranked as the highest subset for both students and clinical educators. This finding is different from Mogan and Knox but the same as Kiker (1973) and Brown (1981). All respondents ranked personality traits as the lowest of all subsets, supporting the findings of $O^{\circ}$ Shea and Parsons (1979) and Brown.

Students and faculty in a study by Pugh (1988) agreed on the importance of only one clinical teaching behavior, correcting and commenting on written assignments. Both groups indicated a degree of agreement regarding the use of feedback in clinical teaching Faculty rated giving positive reinforeement and providing helpful comments and corrections on written assignments as among the most important clinical teacher behaviors. Students rated giving specific suggestions for improvement and commenting on written assignments as among the most important behaviors of clinical teachers.

Staff nurses, employed by the agencies where nursing students gain their clinical education, are yet another element that impacts the student learning experience. The review continues with a subsection of studies related to student-staff nurse relationships.

\section{Clinical Staff Nurses}

Previous studies have identified student relationships with staff nurses as both facilitative and impeding in achieving their personal goals in the clinical setting (I Iamill, 1995; Turkoski 1987; Windsor, 1987). However, the role of staff nurses in teaching undergraduate nursing students is poorly explored in the literature (Jackson \& Mannix, 2001). Staff nurses are crucial to student clinical learning and contribute to the learning experience in addition to the responsibilities of their clinical patient load. 
In a study to identify students $(n==143)$ subjective stress in clinical experiences, Turkoski (1987) found that interpersonal communications and intraprofessional role modeling or socialization were primary concerns. Opportunities for cognitive learning related to technical skills were mentioned as stressors, including the difficulty of accessing an instructor when he or she was involved with another student. However, $80 \%$ of the subjects reported clinical staff and student interactions as stressful. Just over onehalf of the students commented about actual nursing activities and professional behavior, i.e., practical role models. Students also reported "reality shock" from the difference in classroom learning and learning with actual patients.

A study (Jackson \& Neighbors, 1988) was conducted to examine staff nurses' ( $n$ $=57$ ) attitudes toward associate degree nursing students and the related concepts of nursing education, patient, physician, work, and nurse. The hypothesis stated that the attitudes of staff nurses to these six concepts would be equally positive. $\Lambda$ semantic differential test was used to collect data. Results demonstrated that the attitudes of staff nurses toward the six concepts were more positive than negative $(p<.0001)$. However, the mean of one concept, which reflected nurses' attitudes toward associate degree nursing students, was significantly lower $(p<.0001)$. indicating that stalf nurses" attitudes toward associate degree nursing students are not as favorable as they are towards other nurses, nursing education, patients, physicians, or work. Jackson and Neighbors recommend a more definitive study which would more thoroughly address the staff-student relationship.

Streubert (1989), in a descriptive study of the perception of clinical experience by clinical nurse educators and students, found that the facilitative behaviors of stafl nurses were giving students directions, assistance, and encouragement. Behaviors of stalf nurses 
that students reported as impeding learning in the clinical enviromment were the feeling by students that staff nurses did not want them there and did not want to be bothered with them.

Few studies have been conducted with the sole purpose of addressing the effect that clinical staff nurses have on nursing students. In a study (Campbell et al., 1994) that examined student socialization into nursing, students reported often feeling unsupported by nursing staff. Students also stated that because they felt vulnerable or inadequate due to lack of experience, feedback from the staff was critical to their lecling of selfconfidence. However, students expressed uncertainty in what to expect. One student described developing feelings of 'thermal invasion, 'or a negative response from stall' nurses when the student had provided what she believed was good patient care. Some students stated that they had the impression that there was a 'collective agreemen' among the stalf not to value the contributions of nursing students.

Stafl'nurse-student relationships were also investigated in an Australian study (Dunn \& Hansford, 1997) of nursing students' $(n=229)$ perceptions of their clinical learning environment. The Clinical Learning Linvironment Scale (CLLS) was used to collect quantitative data; interviews were used to collect qualitative data. $A \mathrm{n}$ important linding was that student-nursing staff interpersonal relationships play an important role in students perceptions of a positive clinical learning environment.

Items with the highest factor loadings were on the staff-student relationships subscale of the CLLS: (a) our questions are usually answered satisfactorily, (b) all staff on the unit, from the nurse manager to the newest student, feel part of the team, and (c) this was a happy unit for both patients and nurses. These items highlighted the importance the students attached to the willingness of the nursing staff to engage in a 
teaching relationship and to accept the student as a learner with a legitimate role on the team (Dunn \& Hansford, 1997).

Interview comments characterizing the influence of the nursing stalfon student perceptions of the clinical learning enviromment included (a) "they (stafl nurses) wer receptive to students and went out of their way to educate you on certain things, what you were doing, why you were doing it; it was good," (b) "the nurses" attitudes towards student nurses was great; it makes a huge difference." and (c) "there are older nurses who haven't gone through the university, and they just hate students: they really get frustrated with us" (Dunn \& I lansford. 1997, p. 1300). The authors stated that interpersonal relationships play an enormous role in students' perceptions of the clinical learning environment. They suggest that effective collaboration between staff nurses and students is crucial if students are to achieve optimal learning outcomes.

The lived experience of the stafl nurse relating to the student nurse during the clinical learning experience was investigated by Thompson (1998). Six common themes arose from interviews with nine staff nurses. The first theme described the experience of interacting with students as a mixed experience, because they worked with "good" and "bad" students. The personality of the student, motivation and level of skill, as well as the experience of the staff nurse and type of unit all impacted the staff nurse/student relationship. Most staff nurses reported that they enjoyed working with students and found it a fulfilling experience.

The second theme related to the behaviors and attitudes of the student. Staff nurses thought they could tell if a student wanted to learn and felt that they related more to a student who showed an enthusiasm for nursing. The third theme was the willingness of staff nurses to relate to the student and desire to help the student learn. Staff nurses 
expressed that the more experience and confidence the staff nurse had, the casier it was to relate to and help students (Thompson, 1998).

The uncertainty of the staff nurse as to her/his role in working with students related to theme four. Staff nurses reported feelings of resentment in not being informed of their role expectations in dealing with students and how their role interacts with that of the nursing instructor. The fifth theme focused on the element of time. Staff nurses wished that they had more time to spend with students. Most reported that they liked working with students but felt that it was a disadvantage for the nurse because it created more work for them. They stated that nursing students required time and could slow down the staff nurse ('Thompson, 1998).

Theme six related to the need to communicate. All of the stafl nurses in the study felt that communication between the staff nurse, student nurse, and instructor was very important. Staff nurses reported that difliculty sometimes occurs when the nurse offers suggestions for improved care; students need to be open to positive criticism by the staff nurse. A common problem voiced by all the stall nurses was that lack of communication between the staff nurse, student, and instructor leads to assumptions relating to the ability or competence of the student. Staff nurses stated that they had concerns that the student would not report significant patient changes to them in a timely manner. All of the staff nurses in the study voiced the opinion that they should be more involved in communicating with the instructor. Staff nurses reported feelings of anger and hostility from lack of communication between themselves, the student, and the instructor (Thompson, 1998).

Many of the same themes emerged in a phenomenological study by Atack, Comacu, Kenny, La Belle, and Miller (2000). The purpose of this study was to describe 
the perspectives of diploma nursing students $(n=40)$ and staff nurses $(n=20)$ on the student-staff relationship and its impact on student learning. A focus group approach was used for data collection.

The themes that emerged from the student interviews that affected the student/staff relationship were (a) student as colleague, (b) shared knowledge and decision-making, (c) professionalization, and (d) staff workload and student hours. Sudents identified open communication based on respect and courtesy as the most important factor positively affecting their relationship with staff. Other factors mentioned by students as characterizing a positive relationship with staff were (a) willingness of staff to share knowledge with them and involve them in planning patient care, (b) professional socialization or being considered a part of the team, (c) welconing and supportive behaviors, (d) and willingness of staff to teach students and act as role models. Students identified two factors that had a negative impact on the student/staff relationship: (a) staff workload and (b) student hours. Sometimes the staff nurse was too busy to make time for the student and students were not on the clinical area for the nurse's entire shift (Atack et al., 2000).

Themes that emerged from staff nurse intervicws that affected the student-staff relationship were workplace environment, role perception, and staff characteristics. Some staff perceived that having a student on their unit decreased their workload if students were at a level that required little supervision. Others perceived students as adding to their already increased patient workload because they spent a lot of time supervising and helping the student complete work. Staff also noted that they often had to complete unfinished student assignments because students did not stay for the complete shift. Staff nurses found their role as educator for students both positive and negative. If the 
instructor was unavailable, the staff nurse did not want the student to miss a learning opportunity, so they did not mind helping the student with patient care. However, staff nurses found the role of evaluator difficult and stated an overall negative impact on the student-staff relationship when they had to go to the instructor with concerns about the student (Atack et al., 2000).

Atack et al. (2000) emphasized the importance of the relationship between nursing staff and students as found in earlier studies (Campbell et al., 1994; Hamill, 1995; Parkes, 1985; Streubert, 1989; Thompson, 1998; Turkoski, 1987). The authors suggest that the student/staff relationship be explored in other settings.

A case study (Glover, 2000) to identify nursing students” $(n=5)$ perceptions and use of feedback in the clinical area was conducted in Australia. Data on students perceptions of and use of feedback from their previous clinical placement (approximately 6 months previously) were collected with questionnaires, clinical logs, and interviews. Participants were asked to record the following in relation to feedback: time, place, who gave it, elements of it, and how they used it.

Findings (Glover, 2000) from three participants revealed that the stafl registered nurse in the clinical setting was the most significant person who explained and assisted in giving valuable positive and negative feedback. The other participants reported that the clinical teacher as well as the staff nurses provided the most significant feedback which encouraged the student to try new techniques and explained rationales for practice

The most significant examples of feedback that the participants recalled from their previous clinical experience were the daily comments of the stalf nurses that were encouraging and very positive and the final comment/assessment from the clinical teacher. The clinical teacher was described as calm, friendly, and knowledgeable. The 
most recorded time that feedback occurred was in the morning, probably because that is the time of high activity. The place where leedback occurred most often was at the bedside or in the patient's room. The author (Glover. 2000) stated that this study demonstrated that fecdback is an essential component in the cducation of nurses. In the clinical setting, feedback has the ability to enhance students' performance and to make them feel confident and competent in their role, especially when the feedback is positive and immediate (Glover).

Student contributions to clinical agencies were investigated in 2001 by Grindel, Bateman, Patsdaughter, Babington, and Mcdici. These authors assert that nursing students, rather than being a burden on the nursing staff, actually make signilicant contributions to clinical sites. In this exploratory study, adult health/medical-surgical nurses and mental health/psychiatric nurses in acute care units were asked about the effects that nursing students had on staff time, staff development, quality of care, staff"s personal satisfaction, and unit standards and practices during the students clinical rotations. Results indicated that students contribute to the personal and professional satisfaction of the staff by (a) offering opportunities for mentoring and reciprocal learning, (b) allowing nurses to participate in students professional development, and (c) contributing to patient care. The authors (Grindel et al.) recommend that their study be repeated in other units.

Jackson and Mannix (2001) explored nursing students" perspectives of the role of nursing staff in students" clinical learning experiences. Students $(n=49)$ who had almost completed their first semester of nursing, and who had approximately 50 hours of clinical experience, participated in the study. A story-telling, or narrative approach was used to collect data. After receiving a guiding statement, students were asked to write the story of 
their clinical experience.

Findings revealed that students experienced the clinical experience as stressful. They described their feclings as anxious about leaving the safely of the university campus but excited about entering the world of the professional nurse. Respondents perecived stafl nurses as central to the suceess of the clinical experience. Students perceived the actions of staff nurses as either helpful or unhelplul. Ilelpful behaviors of nursing staff such as showing understanding, friendliness, interest, and providing explanations were documented by students. Students reported that the single most helpful behavior of stafl nurses was recognizing them as newcomers to the clinical area and showing understanding for their tentativeness and uncertainty. Friendly behaviors of the staff and the creation of an environment in which students felt safe to ask questions were also identified by students as being particularly benelicial to clinical learning. Students greatly appreciated any interest shown in them by staff that made an effort to explain things to them and include them in planning and delivering patient care (Jackson \& Mannix, 2001).

Staff nurses exhibiting passive rather than active behaviors were viewed as unhelpful by students. Students reported that these behaviors made them feel that they were excluded, ignored, barely tolerated, and even disliked. Several students described fecling intrusive, uncomfortable, and even unwelcome in the clinical area because of murses" behavior (Jackson \& Mannix, 2001).

The authors (Jackson \& Mannix, 2001) stated that the lindings of this study emphasize the importance of the teaching role of staff nurses in student learning. The findings also raised issues about how staff nurses interact with students and the effects that these actions have on clinical learning environments. 
The impact of student-staff interactions are demonstrated in other studies as well. Shipton (2002) investigated the clinical-person-environment relationships that nursing students perceived as stressful. The findings revealed that the actions of the nursing staff were one of the categories identified as stresslul by students. Students described negative comments, actions, and attitudes of the nursing staff as stressful. They described nursing staff as "demeaning," "nasty," and "not wanting to be bothered," as well as laking advantage of them because they were students.

Only one study (Langan, 2003) comprehensively examined the perceptions of staff nurses regarding the staff nurse role in nursing student learning. This study also sought to determine how faculty practice status (continuing to work in patient care as well as teach) affected the perceived roles of nurse faculty and staff nurses in student learning. Clinical faculty, nursing school administrators, staff nurses, and hospital administrators participated in the study. Focus groups and individual interviews were conducted. Content analysis was used to examine the issues. Results revealed that staf $1^{\circ}$ nurses who worked with practicing faculty reported fewer instances of role overload, conflict, and ambiguity than when they worked with nonpracticing faculty.

Lack of clear communication and delineation of expectations among administrators, staff, faculty, and students were cited as major factors in perceived role problems. Administrators, faculty, and staff nurses viewed high student/faculty ratios as a causative factor in the faculty's inability to meet all teaching objectives with students (I angan, 2003).

The author (Langan, 2003) stated that implications of the study are that nursing faculty who maintain practice outside of their roles as educators scem to provide a more meaningful clinical experience and a more positive interaction with stalf nurses. 
Ilowever, staying involved in direct patient care is unrealistic, if not impossible for faculty, due to the already heavy academic workload and requirements necessary to maintain the teaching position.

In summary, setting the stage for a clinical environment that is conducive to learning includes students" interpersonal relationships with the teacher and staff nurse and their interactions within the clinical setting. Reilly and Oermann (1990) stated that student learning in the clinical setting takes place in a climate of trust and caring in which the learner is supported by the teacher. The staff nurse also serves as a teacher, however informally, within the clinical setting and impacts student learning. Most of the literature on teacher characteristics as perceived by students and/or teachers focused on effectiveness or ineffectiveness. While there was some agreement between students and teachers, there were consistent differences. Students, in many studies, viewed the effective teacher as possessing personal characteristics in relating to students (e.g., Gunter, 1969; Jacobson, 1966; Kiker, 1973), while teachers, in many studies, perceived the more important characteristics of effective teachers as professional competence and role modeling (e.g., Brown 1981: Knox \& Mogan, 1985: OShea \& Parsons. 1979).

All of the relationships discussed impact the learner in the learning environment through the process of socialization. It is important to understand how nursing students are socialized into the profession of nursing as this is an important part of the clinical learning experience. $\Lambda$ model of socialization applied to nursing education is discussed in the next section.

\section{Professional Socialization in Nursing}

Various rescarchers have defined professional socialization. Moore (1970) believes that professional socialization oceurs through the attainment of the essential 
knowledge and skills in a discipline as well as the development of occupational identity and assimilation of the norms of the profession. Kramer (1974) stated that socialization is the period of time that individuals spend learning knowledge, skills, and undergoing the internalization process that prepares them for a specific role. Cohen (1981) held that professional socialization is the process through which one gains the knowledge, skills, and the identity of those who are members of a profession. Through this process, Cohen stated that one internalizes the values of the profession into their own behavior.

White and Ewan (1991) defined professional socialization as the process in which one learns the culture of a profession, specifically nursing. The socialization process is beneficial in preparing the student nurse to function well in the professional role. Serious consequences can occur if socialization does not take place. According to Boyle et al. (1996) and Glossop (2002), attrition from the nursing profession, turnover, and decreased productivity can result from lack of socialization. Issues cited by students that impede socialization are the difficulty in building relationships with those in the clinical setting, for example, feelings of distance from faculty and staff, as well as stress associated with feeling unprepared for clinical practice, and feeling incompetent in clinical skills (Beck. 1995; Iammil, 1995; Jones \& Johnston, 1997). Several researchers (Campbell et al., 1994; Kramer, 1986) propose that faculty teachers in the clinical setting have a greater impact in socializing students than classroom teachers. Students value faculty teachers who act as role models, are approachable, demonstrate psychomotor skills, and possess good communication skills.

Windsor (1987) found that students also progressed in their professional socialization by observing clinical staff nurses and participating in nursing activities to "learn how to act like a nurse." Students reported that relating to clinical nursing staff, 
although difficult at lirst, was valuable in clinical learning (Windsor). Some studies revealed that clinical nursing staft that were not supportive to students caused feelings of vulnerability and inadequacy in students which created a less than positive learning environment. Students stated that positive feedback from both faculty teachers and clinical nursing staff was highly valued (Campbell et al., 1994).

Understanding the socialization process in nursing pertains to the present study because the professional socialization of student nurses occurs largely in the clinical setting (Chun-I Ieung \& French, 1997; Windsor, 1987). The models of Kelmanl (1961) and Simpson $(1967,1976)$ proposed explanations of initial socialization into professional roles and served as the basis for the development of later models (Davis, 1966) Hinshaw, 1977, 1986). The Hinshaw Model $(1977,1986)$ expands on the Simpson Model (1967, 1976) and incorporates elements of the Kelman Model. Hinshaw (1977, 1986) proposed an explanation of socialization into the professional nursing role especially relevant to this study. Therefore, the Hinshaw Model provided the theoretical basis to guide the present study. IIinshaw (1977, 1986) defined initial socialization as the way in which lay people become socialized into the nursing profession through the formal education process. Hinshaw $(1977,1986)$ believed that what oceurs during the socialization processes is crucial in developing professional values in the nursing profession.

IInshaw's Model (1977. 1986; Blais. Hayes, Kozier \& Erb. 2002) proposed three phases of socialization into the nursing profession. In Phase One, Transition of anticipatory role expectations to role expectations of societal group, the individual's preconceived notion of the role of the nurse adapts to become congruent with those members of the profession who set the standards or make the rules for them. Hinshaw stated that it must be assumed that in the process of adult socialization, the individuals 
entering the profession have learned other roles through their life experience which gives them a perspective for the evaluation of a new role. In addition, the individuals entering: the new profession chose to actively enter into the socialization process.

The second phase, Atachment to significant others/abel incongruencies, has two components: individuals will attach themselves to significant others in the social system and at the same time they label situations that they perceive as incongruent with their anticipated role and what is presented by significant others. In initial socialization, significant others are faculty, certain colleagues, or immediate supervisors who are influential in the role setting of the new individual. Phase Two is a stage that involves strong emotional reactions to conflicting sets of expectations. Successful resolution of these conflicts depends on role models who demonstrate appropriate behaviors and how conflicting information can be integrated (Blais, Hayes, Kozicr \& Erb, 2002; I linshaw, $1977,1986)$

In phase three of the Hinshaw Model, Internalization of role values/hehaviors, the student internalizes the values and standards of the new role. The degree to which this is accomplished and the extent that incongruencies are resolved varies. Hinshaw (1977, 1986) uses Kelman's Theory of Social Influence (1961) to explicate the idea of value orientation and defined value orientation as compliance, identification, and internalization. For compliance, Kelman explains that the person demonstrates expected behavior in order to get positive reactions from others. For identilication, individuals adopt only specific role behaviors that are acceptable. For internalization, the person accepts the standards and values of the new role and incorporates the standards into his/her own value system (Blais, IJayes, Kozier \& Erb, 2002; Hinshaw, 1977, 1986; Kelman, 1961). 
Hinshaw's Model of Socialization (1977, 1986) provided the theoretical framework in previous studies. Clark (2004) conducted a study comparing the professional socialization of generic and two-plus-two baccalaureate completion programs. Ilinshaw's Socialization Model provided the theoretical basis for Clark's study which revealed that students from both type programs experieneed socialization into a professional role. The Simpson Model $(1967,1976)$ on which the Hinshaw Model expanded, served as the theoretical framework in previous research on the professional socialization of graduate psychology students (Knowlton, 1985) and nurse anesthetist students (Waugaman, 1981 ).

The Hinshaw $(1977,1986)$ Model of Socialization of nurses provides a perspective of the socialization of nursing students in the clinical environment. In the clinical learning environment, the student interacts with other students, nursing faculty, and staff nurses. Through this exposure, students continually attempt to reconcile their anticipated expectations of the nursing role with those who are in the position to set standards for them. I linshaw"s Model describes the "chain of events" or phases of socialization that prepare students in learning and adapting to new roles. This framework adequately guides the present study in the understanding what transpires in the learning environment--the clinical setting--through student experiences.

\section{Summary of the Literature}

The literature reviewed describes nursing preparation from the beginning to the present day. Though dramatically different from the early days, clinical nursing retains many of the same aspects and complexitics for students. Nursing students of today are described and contrasted with those of the past. The literature included rescarch on the teacher working with the student. Some of the studies developed major categories of 
behaviors of teachers and students (e.g., Jacobson, 1966: Kiker. 1973: () Shea \& Parsons, 1979), while others developed specilic behaviors for evaluating the nursing leacher (c.g., Barham, 1965; Brown, 1981; Stuebbe, 1981). Zimmerman and Waltman (1986) stated that Jacobson's behavioral categories appeared broad enough to encompass all of the behaviors described by others (e.g., Brown, 1981; Kiker; O`Shea \& Parsons; Stuebbe). These categories included (a) availability to students, (b) apparent general knowledge and prolessional competence, (c) interpersonal relations with students and others, (d) teaching practices in classroom and clinical arcas, and (e) evaluation practices.

The nursing student and faculty have described the nursing educational experience. One theme found in the research emphasized the stressful nature of the clinical setting for the student in the nursing education process. The characteristics related to the clinical selting included (a) dealing with new clinical situations, (b) interacting with patients, (c) handling emotional problems, (d) taking intimate care of both male and female patients, (c) being critically evaluated by self and others, (1) handling conflicts between information taught in the elassroom and the realities in the clinical area, and (g) dealing with death (Admi, 1997; Gunter, 1969); Klechammer et al.. 1990). Additionally, researchers reported that the staff nurses reported a concem about a lack of time to communicate effectively and support students in the clinical fearning cnvironment (Campbell et al., 1994; Shipton, 2002; 'Thompson, 1998).

Research recommended the need for qualitative studies of nursing education in order to assess qualities of the nursing experience (Brown, 1981; Jacobson, 1966; Kiker, 1973; Mogan \& Knox. 1987; O’Shea \& Parsons, 1979). Quantitative studies utilized instruments that placed students in a variety of predetermined and arbitrarily selected 
categories, which resulted in subjectivity and inability to generalize across studies (Brown; Jacobson; Kiker; Mogan \& Knox; O’Shea \& Parsons).

No case studies in the literature examined the factors impacting leaning in the nursing clinical environment from the perspectives of the student while also including the perspectives of the faculty and staff nurse. In addition, no studies identified the setling as solely the hospital clinical nursing laboratory. This case study research approach describes the multiple aspects of the clinical nursing experience and gives detailed information on the total nursing educational experience. The present study adds to the body of information on nursing clinical education and provides a vivid view of the clinical experience for three students. This study gives detailed information on clinical nursing experience from the words of the students, their assigned faculty teacher, and clinical staff nurses describe the clinical experience.

The linal section of the literature review focused on professional socialization in nursing. Hinshaw's Model $(1977,1986)$ served as a theoretical framework for the present study. During data analysis, the stages in Hinshaw's model provided a lens for understanding the student socialization process.

Chapter III details the methodology for the study. The forgoing literature review provides the background information for the selection of data sources, data collection, and data analysis. 


\section{CHAPTER III}

\section{METHODOLOGY}

Introduction

The purpose of this study was to describe three associate degree nursing students in the clinical setting. A multiple-case study design explored the views of each student nurse in his/her clinical learning experience and includes the views of his/her faculty teacher and staff nurse in the hospital learning environment. Each student represents a unit of analysis for a case (Merriam, 1998). An intensive, holistic description of each student described the student and learning activities within the clinical setting (Burns \& Grove, 1999).

Merriam (1998) states that a variety of disciplines have used the case study method. The descriptive nature of the case study method produces findings that illustrate complexities and offers a comprehensive understanding of the phenomenon. Case study methodology conforms to the philosophy of the nursing profession and the need to understand the whole person. This especially relates to individual student development as well as patient care (Polit \& Hungler, 1989). Polit and Ilungler (1999), authors of Nursing Research: Principles and Methods, also emphasize that the case method can bring to light previously unanticipated relationships. While the case study appears important to the analysis of nursing problems, more case studies appeared in the literature 30 years ago than loday (Burns \& Grove, 1999).

Meicr and Pugh (1986) agree that the holistic case study properly suits the investigation 
of nursing clinical problems, which link research and practice

\section{Setting}

This research examines the lived experience of students who enter nursing programs and study in the academic classroom, and who then move into the clinical setting as part of the nursing curriculum. The clinical enviromment multiplies the complexity of the experience for the learner (Jacobson, 1966). The setting for the study was a clinical nursing laboratory in a hospital in the same cily as the Associate Degree Nursing Program where participants were selected. The hospital is a 211 bed medicalsurgical facility located in a southern state for approximately 32 ycars ( $\Lambda$ merican Ilospital $\Lambda$ ssociation, 2005). $\Lambda$ medical-surgical unit in the hospital, consisting of approximately 25 beds in private rooms and 20 beds in semi-private rooms, was the location for the clinical laboratory in the present study. Clinical laboratories for the nursing clinical course in this study met twice a week for 10 students each day. Over the course of an academic year, approximately 20 associate degree students and 30 baccalaureate degree students from separate nursing programs at the same university have clinical laboratories on the hospital unit on alternating clinical days for 6 hours at a time.

The Associate Degree Nursing Program, part of the community college in a public university, has a typical enrollment of 280 students and has 18 faculty members. The university has an enrollment of 15,415 degree-seeking undergraduates and 2,088 degree-secking graduate students (College Entrance Examination Board, 2008). The university and hospital were located in a city with a population of 50,000 in the southern part of the United States (United States Census Burcau, 2000)

The following profile of the associate degree nursing class provides a picture of 
general characteristics of the enrollment. From the 38 students in the associate degree nursing class, the researcher selected three cases. These 38 students include marital status: (a) 17 single, (b) 16 married, (c) four divorced, and one separated. Six of these students have one dependent, seven have two dependents, four have three dependents, two have four dependents, and 19 have no dependents. Ages of this class range from 20 in the 25 years or less category, live from 26-30 years, eight from 31-40 years, four from 41-50 years, and one from 51-60 years. White females predominate with 33 in this category and four white males. Other ethnic groups include one female black/nonHispanic. Twenty-two students in this class take a full course load of 12 hours or more; 16 take a part-time course load, meaning that they take only the required nursing courses because they previously completed all other required courses. Three students carned a General Education Diploma (GED), while the majority hold a high school diploma. Many in this class hold previous degrees-- 12 associate and three bachelors. Outside employment status for these students ranges from three who work up to 6 hours per week, eight who work 7 to 15 hours per week, 15 who work over 15 hours per week, nine unemployed, and one with employment status unreported (Perkins Grant Data Report, 2006).

\section{Sampling}

Purposive sampling determined each particular ease, the individual as the unit of study. Polit, Beck, and llungler (2006) suggest this strategy to find people who best contribute to the needs of the study. Therefore, three student nurses enrolled in the clinical laboratory at a hospital provided the information-rich cases for the purpose of the research (Patton, 1990). Each of the three nursing students became the focused sample from a population of nursing students in the third semester of their progran enrolled in a 
medical-surgical clinical laboratory.

\section{Student Nurses}

The utilization of the typical case method of sampling described by Patton (1990) necessitated that the researcher develop a qualitative profile of three typical cases. In order to gain consensus regarding the "typical" case or cases for this study, the researcher developed a list of criteria for selection of the students based on professional experience and submitted the list to three faculty members who teach in the associate degree nursing program. After comments and review, the faculty members reached agreement on the appropriateness of the items.

Based on this list, the researcher developed a student screening questionnaire to identify the cases. In addition to demographic data, the questionnaire obtained the following information: (a) no previous clinical or health care experience before the associate degree preparation program, (b) at least 18 years of age, (c) enrolled for the first time in a nursing program, (d) no previous academic degrees, (e) aceepted into the nursing program immediately after completing the prerequisite curriculum, (l) a willingness to discuss clinical experience. and (g) grade of " $\mathrm{B}$ " or higher for each of the previous two nursing courses. The complete Student Screening Questionnaire is attached as $\Lambda$ ppendix A.

The nursing class selected to complete the questionnaire was in the third semester of a four-semester program. This is the lirst clinical experience in a non-specialized arta of general patient care. Students in the Medical-Surgical Nursing I courses held on the university campus responded to the questionnaire. Students in this course attend class on the university campus two times a week for two hours each class meeting and attend the clinical laboratory on the hospital unit twice a week for 6 hours each day. With the 
permission of the course faculty teacher, the researcher attended one class meeting and asked for volunteers to complete the questionnaire and participate in the study.

Completing the questionnaire took approximately 5 minutes. The students who met the criteria were interviewed to determine those showing the most interest in the study, the most likely to disclose information about their clinical experience, and the intent to remain in the study until the conclusion. If more than four participants had met the sampling criteria, names would have been drawn from a hat. Three students were selected, along with a lourth student who served as an alternate in the event that some student did not complete the study. The three students received notification in person of their selection to participate in the study, as well as the fourth student who served as an alternate.

\section{Faculty Teacher}

The faculty of record who teaches the Medical-Surgical Nursing I course also supervised each of the three students identified for the case studies. Therefore, this individual was the only faculty teacher in this study and the purposive sample. This faculty teacher who shapes the learning situation of each student case on campus and in the clinical laboratory was observed and interviewed. The faculty teacher assumes primary responsibility for the instruction of 10 students at a time in the elinical setting and teaches in the didactic portion of the medical-surgical course at the university as well. For each 6-hour time block in the clinical area, the faculty teacher assigns students to patients on the unit the afternoon before the clinical laboratory.

The faculty teacher attempts to integrate classroom subject matter around clinical problems or concepts (White \& Ewan, 1991). Faculty teachers must assume multiple roles in the clinical laboratory, including counselor, problem solver, manager, assessor, 
advocate, guide, and facilitator (White \& Ewan). Faculty teachers guide students through the clinical experience according to the course learning objectives. For example, faculty tcachers reinforce theory from lecture and facilitate student lcarning when applying principles of pain management to patients. Faculty teachers support students tor the implementation of psychomotor skills and observe the student to ensure safety of the patient. The faculty teacher monitors the student during the preparation of the medication: Does the student know the medication action and route of administration? Does the student check the medication against the physician's order for accuracy? Does the student assess for patient allergies? Does the student verify the identity of the patient by checking the patient's identification bracelet before administration?

The faculty teacher may accompany the student to administer patient medication and evaluates the student on the skill to ensure the safety of the patient. In addition, the faculty teacher must assist the student with documenting what was done for the patient on the chart and later verify that the student assessed for the patient's pain relief after the medication administration. The faculty teacher must continually provide the type of assistance, supervision, and evaluation for each of the ten students in a clinical laboratory, which gives students the opportunity to practice already acquired intellectual and psychomotor skills (Infante, 1985).

\section{Clinical Staff Narses}

The individual student case determined the identity of the elinical staff nurse who was interviewed. The clinical staff nurse provides the primary care for the hospital patients. Therefore, the clinical staff nurse was determined by which patients the faculty teacher has assigned to the student nurse, and therefore also represents a purposive sample. Each student case included a different staff nurse. The clinical staff nurse who 
interacted with the student during each observation was interviewed.

The clinical staff nurses, employed by the hospital, serve as a resource and as another model of socialization for students during a particular work shift. However, this involvement with students varies. In the clinical setting, two to four staff nurses are in charge of a group of patients on the unit where students have a clinical assignment. During the clinical laboratory, three to four registered nurses and three to four licensed practical nurses, who work 12 hour shifts, 7:00 a.m. to 7 p.m. may work on the hospital unit. Therefore, the clinical staff nurse that interacts with students on any particular day could be a registered nurse or licensed practical nurse. Hospital nurses rotate to staff the unit on different days. Therefore, over the course of the student's clinical placement, the students will interact with several different clinical staff nurses. Each clinical staff nurse provides guidanee and support for student learners and serves as the expert practitioner. However, clinical staff nurses in the clinical setting are not affiliated with the nursing program. Depending on the clinical staff nurses interest in teaching. she/he may choose a greater student involvement by accompanying students during the performance of certain skills on patients, such as urinary catheterization, giving medication, or discontinuing an intravenous infusion. Because the faculty teacher cannot assist several students at the same time in the laboratory, when an opportunity arises to perform a skill on a patient or when students need guidance regarding patient care, clinical stafl nurses will sometimes volunteer to supervise students in skills performance.

Clinical staff nurses provide continuity of care for a group of patients on the unit by remaining with patients for the entire shift and having the advantage of information learned from reports of nurses from previous shifts. The faculty teacher and students possess knowledge of patient care at only one point in time, during the clinical 
laboratory. As the primary nurse in charge of a group of patients during a shift, clinical staff nurses have more complete knowledge of patients progress and have this information for students. For example, the clinical stafr nurse may provide information to a student on how much assistance a patient requires with ambulation or the lavorite beverages of a patient who needs an increased fluid intake.

The Role of the Researcher

In the multiple-case study design, the researcher as the instrument analyred and gathered data in the natural setting (Merriam, 1998). The sensilivity of the researcher as instrument contributed to the research process from the design of the study through data collection and analysis. The researcher adapted to unforeseen events and integrated pieces of data into the salient patterns during the later stages of analysis (Merriam). Even during early design stages, the researcher, as instrument, decided on sample selection, how to interview, what questions to ask, and details regarding observations. This required that the researcher remain sensitive to all factors in the physical setting, which included all people and events (Merriam).

The researcher remained sensitive to biases present in this type of rescarch. The researcher constantly monitored personal values, perspectives, and world view to ensure that the linal product rellected the views of the students and others in the case rather than the participants" view being filtered through the researcher (Merriam, 1998). Keeping a rellexive journal (Polit, Beck, \& Ilungler 2006) documented a self-analysis on how the researcher and the research affected each other. The researcher wrote in the reflexive journal during data collection and analysis as a means to monitor sell and subjectivity.

The researcher, a registered nurse, had experienced the nursing educational process as a student and as a faculty member. The rescarcher presently teaches in the 
baccalaureate nursing program at the same university, but teaches on another campus. Thus, she did not previously know the associate degree students in the study. With the researcher having graduated from this associate degree program 34 years prior to the study, she remained constantly alert to personal biases and focused on the perspective of the student nurse and guarded against her own opinions that could affect the data collection and analysis. The researcher had not previously taught these students and will not teach them in the future. Some of the staff nurses and the faculty teacher in the study knew the researcher, and the researcher had previously established trust and comfort with these individuals in other professional situations. The researcher belicves that this 1rust provides a foundation for good communication in the research setting (Merriam, 1998). In addition, the researcher remained respectful, nonjudgmental, and nonthreatening during data collection (Merriam).

\section{Data Collection}

Data collection for this study included interviews, observations, and documents. The researcher triangulated information in order to verify findings. Triangulation included collecting from multiple sources as well as including the different perspectives such as those of the faculty teacher, the stafl nurse, and the student in each case. Patton (1990) emphasized the importance of triangulation; multiple subjects and sources provide a comprehensive perspective. Therefore, the addition of the staff nurse and the faculty teacher represented multiple insights within each case and offered a wider range of information about the clinical experience. By using a combination of research tools, the researcher cross-checked findings from observations, interviews, and documents. Mack, Wood, MacQueen, Guest, and Namey (2005) emphasize the use of a wide range of approaches in qualitative methods. The problem and the understanding needed to answer 
the research question and subquestions dictate the degree of flexibility of a particular procedure or method. For example, nonparticipant observation occurred prior to other data collection, as well as during interviews.

\section{Observation}

Nonparticipant observations in a clinical laboratory in the hospital setting yielded thick descriptions of the clinical learning environment. As Gans (1982) described, the nonparticipant observer takes field notes in the social situation but remains uninvolved in the clinical activity. The researcher entered the laboratory to conduct two observations of the learner, one before, and one after the first interview. The first observation included the entire clinical laboratory, approximately 6 hours. During the 6 hours, the student participated in the pre-conference, patient care on the unit, and the post-conference These activities provided opportunities to observe the student interacting with the faculty teacher and clinical staff nurses. The first student interview and the interviews with the faculty teacher and staff nurse followed the typing and preliminary analysis of this observation. The second observation focused on the student for the entire time on the hospital unit, approximately 6 hours. After typing the fieldnotes and preliminary analysis of the first interview, the second student intervicw began.

The researcher did not interact with students or personally participate in the setting. To facilitate becoming a familiar presence in the clinical setting, the researcher made frequent visits. During this process, the researcher facilitated rapport and acceptance in the clinical setting through fitting into familiar routines, being friendly, and showing interest (Merriam, 1998). The observation times established a "normaley" for the researcher's presence within the setting, so that the actual observations created less of a novelty or threatening situation. 
While wearing a white lab coat, the researcher blended into a busy medicalsurgical unit in the hospital. The researcher accompanied the student throughout the day in the unit, observed, and recorded events and behaviors related to both practiced skills and new skills, events, actions, and the total environment. During the observations, the rescarcher also entered memos on ideas and insights into the reflexive journal (see Appendix E).

\section{Interviews}

Interview data collection followed the observations at the hospital clinical site with one additional follow-up intervicw for clarification. Face-to-lace, semi-structured interviews gathered perspectives from participants. The interviews allowed the researcher to gain information for each case from the student, the student's faculty teacher. and the clinical staff nurse who interacted with the student on the day of the lirst observation. With the less formal, open-ended questions, each interviewee selected how to present information as well as the type of information to convey (Merriam, 1998). Probes were used to gain additional information and examples. Merriam and Spradley (1979) suggest beginning an interview with basic, descriptive questions which provide general information about the purpose of the study. The descriptive questions included: "Could you tell me about a typical clinical day at the hospital"." Then. later in the interview. the researcher asked hypothetical, devil's advocate. ideal position, or interpretive questions; (Merriam). $A l l$ intervicws took place as soon after the clinical experience as possible in a quiet, neutral environment. The researcher attempted to obtain thick descriptions of the clinical learning situation from the students" point of view.

The researcher entered any thoughts, ideas, and impressions about emerging data from the interviews into the reflexive journal. $\Lambda$ dditionally, the researeher also entered 
into the reflexive journal omissions and clarification issues identified from the transcriptions (Merriam). During data collection and the remainder of the study, the researcher retained exclusive possession of all transcriptions and tapes. Consult Appendices B, C, and D for the interview questions for the student nurses, laculty tcacher, and staff nurse, respectively.

\section{Student Nurses}

The study focused on learning and becoming a professional nurse in the clinical setting. Therefore, the three students represented the most important participants in each case study. In the interviews, each student shared personal background and information about her nursing preparation. The majority of the interview questions focused on the student's views of the clinical laboratory experience: the purpose. learning activities. challenges, and support systems. In particular, students described clinical experiences, ability to learn and perform psychomotor and critical thinking skills, as well as experiences that begin the socialization process into the nursing profession. The researcher conducted two interviews with each student. 'The first intervicws were conducted during the typical 6-hour clinical day. The student provided general information and verilied the previous observation in the first interview. The second student interview occurred after the second 3-hour observation when the researcher focused on the time spent on the hospital unit. Each interview lasted approximately 1 hour in length. The student interviews took place at a convenicnt time at the end of the day in the hospital or on the college campus (see Appendix B).

\section{The Faculty Teacher}

The faculty teacher fills the role of the academic supervisor in the course in the classroom as well as during the entire clinical laboratory. The faculty teacher determines 
the curriculum objectives that the student will achieve during the clinical and in this way shapes a student's learning experience. The faculty teacher conducts the clinical pre- and post-conferences. The one-hour interview with the faculty teacher took place on the college campus at the instructor's convenience. The interview questions yielded faculty teacher`s views of the purpose, learning activities, challenges, and support systems (sec Appendix ().

Clinical Staff Nurses

As hospital employees, the clinical staff nurses primary responsibility rests with patient care. The clinical staff nurses do not participate in clinical pre- or postconferences but serve as a resource to students who are assigned to the stafl nurses" patients. Students are assigned to one or more patients under the care of a particular staff nurse. The student's patient assignment determines the particular staff nurse to be interviewed alter the 6 -hour observation. The interviews with stall nurses took place at a convenient time. The staff nurse provided information about the purpose of the clinical setting, student experiences, and program expectations.

\section{Documents}

The documents for this study (also defined as artifacts) provided information about program expectations, activities, and processes (I eCompte \& Preissle, 1993). The contents of the documents provided information about the program not directly observable (Patton. 1990). Artifacts used in the study included the students" academic records, clinical assignment sheets, course syllabus, curriculum goals, and other material, which provided information regarding learning in the clinical experience. During document examination (mining), the researcher engaged in memoing these data into field otes, including any new information and connections to observations and interviews. 
Consent to review academic records and clinical assignment sheets was obtained as part of the overall human subjects approval process. The document analysis protocol is attached as Appendix F.

\section{Data Analysis}

The work of data analysis required a continuous process of making sense out of the fieldnotes, transcriptions, and documents (Merriam, 1998). Thoughts about the data began during the first observation and interview. As the researcher listened and watched, ideas, hunches, and insights emerged about the purpose of the study and the overall research question and subquestions. $\Lambda$ t the end of each data gathering session (observation, interview, and document review), the researcher prepared data by typing fieldnotes as well as writing in the reflexive journal. These steps provided a clean record of the data as the study proceeded.

After preparing the fieldnotes into transcripts, coding (organizing) the data began as the researcher divided the prepared text into segments of meaning. Each segment or unit of meaning that could stand alone as an independent piece of information was attached to individual cards. The researcher placed a notation at the top of each card to name that segment and connect to the data source. For example, the notation, $10 / 19 / 06 / \mathrm{SA} / 5 / 23 / 1$, denoted the date, Student A, interview question 5 , card 23 , and the first observation $(\Lambda$ ppendix $(\mathrm{j})$. Using the constant comparative method described by Glaser and Strauss (1967) for processing the data, the researcher began open coding. In this step, the researcher read a segment of meaning and placed the cards in categories that related to the rescarch questions. The researcher worked through the remainder of the cards, compared each segment to the previous segments, and assigned the card to an established category or a new category. Once all of the cards were assigned to a category, 
the researcher examined, arranged, and rearanged the cards within the categories as necessary (Creswell, 1997).

Next, the researcher began axial coding. In this step, the rescarcher determined links between categories which related to the research questions. In this way, catcgories did not stand in isolation but connected and related to the focus of the study (Creswell, 1997).

Iastly, using the ideas generated from the linkages in axial coding, the researeher constructed an explanation or story that identified themes or patterns of meaning, which indicated how the categories addressed the rescarch questions. In this way, the researcher made sense of the data and began to understand the student in the clinical learning environment (Creswell, 1997: Merriam, 1998). For each case, the individual data sets-the (o-hour observation; subsequent interviews with the student, laculty teacher, and staff nurse; the 3-hour observation; final student interview; and document review-- were processed concurrently using the constant comparative method. Alter collection of any particular data set, transcription and the constant comparative method began as soon as possible. For example, after the 6-hour interview, the fieldnotes were analyzed before moving on to the next procedural steps.

The researcher organized the categories or themes into a report that included all of the major information that answered the rescarch questions. Merriam (1998) defined a case study as an intensive, holistic deseription and analysis of a single, bounded unit (p. 193). For this study, the individual student represented the single, bounded unit, which included the faculty teacher and the clinical staff nurse who shape the learning environment. The determination of categories and themes, which included smilaritics and differences, constitutes the within-case analysis, which Merriam described as 
follows:

In a multiple-case study, there are two stages of analysis--the within-case analysis and the across-case analysis. For the within-case analysis, each case is first treated as a comprehensive case in and of itself. Data are gathered so the researcher can learn as much about the contextual variables as possible that might have a bearing on the case. (p. 194)

Within each case the researcher continued to categorize all of the data sets for a comprehensive picture of the nursing students and others in the clinical learning environment. When a rough draft of a case was written, each participant reviewed a copy of the case for accuracy and clarity. The same means of processing data were repeated for each case, so collection and analysis of data were conducted individually for each case. This means that data collection and analysis did not begin for case B until patterns were identified for case A. A discussion of the identificd patterns and themes are provided at the end of each case.

Across-case analysis was then performed in order to draw conclusions from the three cases (Merriam, 1998). Merriam stated: "Once the analysis of each case is completed, across-case analysis begins. A qualitative, inductive, multi-case study secks to build abstractions across cases" (pp. 194-195). Merriam summarized that the researcher attempts to find processes and outcomes present across the cases and seeks to understand how these processes and outcomes (themes and categories) are qualified by individual situations. By doing this, the rescarcher developed more powerful explanations that surpass the single case. The across-case analysis also pointed out similarities and diflerences within the themes from the findings within and between individual cases. The researcher constructed conclusions regarding the purpose of the study and rescarch 
questions based on the thematic patterns from all the cases.

The qualitative analysis developed within the framework of the interview questions, which connected directly to the purpose of the study, the overall rescarch question, as well as the literature review. In addition, the rescarcher cross-referenced all of the questions with the eurriculum objectives for the elinical course. Because the interview obtained specific information (Merriam, 1998), the clinical course objectives provided a guide to elicit information regarding learning in the clinical setting, and to obtain the faculty expectations of the students.

In closing, the case was a student nurse in the clinical setting. Within each individual case, the faculty teacher and the clinical stafl nurse shaped the situation in which the student lived and learned. The degree of congruence or incongruence of perceptions regarding purpose, activities, and challenges illustrated the complexity of the social learning environment (sec Appendix D).

Finally, confidentiality and anonymity protected the participants during the entire study. After selection of the participants the researcher destroyed the sereening questionnaires. The researcher referred to all participants by pseudonyms from the beginning to the end of the study. All data were coded without participants names. During data collection and the remainder of the study, the rescarcher retained exclusive possession of all transcripts, tapes, and fieldnotes and stored all data in a locked cabinel.

\section{Emic and Etic Perspectives}

According to (reswell (1997). the emic perspective provides an insider's view ol members of a group. In the etic perspective, researchers interpret views about human social life in a social science perspective. Imic and etic perspectives have been defined and delineated most frequently by cthnographers. However, emic and etic perspectives 
were employed in this case study to obtain a holistic picture of students in the clinical setting. Emic and etic perspectives provided a means to obtain a portrait of the student in the clinical setting (Creswell). Through the interview, each participant shared individual emic perspectives of the purpose, learning, and support systems in the clinical experience. The emic perspectives of the faculty teacher and clinical staff nurses became etic data about the student nurses when used as outsider perspectives on the student's experience. The documents contributed a unique, additional etic perspective that may be once or twice removed from the student emic view. For example, the academic transcript represented a faculty member's emic evaluation from the institution's emic grading system. Then, when used to describe a student, the transeripts became an etic view. The qualitative researcher attempts to represent the emic perspectives of each person interviewed. The researcher conducted interviews with participants and represented emic insights into the clinical nursing experience als true to the emic views as possible. By organizing fieldnotes, transcriptions, and documents, the researcher analyzed and grouped data into categories and themes. This analysis, and finally, interpretation of data by the researcher constituted an etic social science perspective from an outsider, trained in the methods of science, looking into the clinical setting and described from perspectives of each student (Harris, 1979).

\section{Provisions for Trustworthiness}

Trustworthiness addresses the following question: Ilow can the researeher convinee the reader that the lindings of an inquiry, a case study for example, are worthy of attention, accurate, believable, and display a "fil" with reality (Lincoln \& Guba. 1985)? In this descriptive, qualitative case study, the terms internal validity, reliability, and transferability (external validity) were used to determine trustworthiness for the 
findings (Lincoln \& Guba; Merriam, 1998).

\section{Internal Validity}

Internal validity refers to the extent to which the research findings match reality (Merriam, 1998). In this multiple-case study, three strategies were used to assure the reader that there was a one-10-one relationship between the findings and the reality of the learner in the clinical setting within each case. In triangulation, the researcher provided collaborating evidence on themes or perspectives from multiple types of data; for example, the observations, interviews, and documents represented different types of data that contributed collaborating evidence about a theme (Merriam, 1998, p. 204). An important aspect of this is the clarification of the complex set of emic and etic perspectives that were described in the preceding section. Second, the researcher used member checks and asked participants in the study to read the case for accuracy. Third, the researcher clarified bias by establishing the role of the rescarcher at the onset of the study, commented on past experiences, and maintained an on-going reflexive journal to monitor possible biases (Merriam, 1998).

\section{Reliability}

Reliabilty in the traditional, quantitative sense refers to the extent that lindings can be replicated. However, in qualitative research, the researcher seeks dependability. The issue is not if the findings can be found again, but if the findings are consistent with the data collected and therefore, dependable (Lincoln \& Guba, 1985; Merriam, 1998). Triangulation of sources were also used to establish reliability/dependability of this study. The researcher also gave detailed description of personal perspectives, relationship to the students being studied, the criteria for selecting students, and the social context of the clinical setting. Additionally, the researcher maintained a direct link (audit trail) from the 
raw data to the final version of the case study through the use of codes and a data management system.

\section{External Validity (Transferability)}

In traditional quantitative studies, external validity refers to the extent to which findings of one study can apply to other settings (Merriam, 1998). However, in qualitative research, the term transferability is more appropriate because the rescarcher relies on the reader or the user to determine the extent that the findings of a study can apply to other situations. The thick description of the setting, social contex1, and participants in the study provide the basis for the reader's decision regarding the extent of transferability. The researcher constructed the thick description of the clinical research setting and participants based on the writings of Geertz (1973). According to Geertz, thick description offers a deeper meaning of participants" experiences beyond the obvious and superficial and provides insight into how participants interpret the surroundings.

\section{Ethical Issues}

The researcher applied for permission to conduct the study at the institutional review boards at the two universities in the cooperative doctoral program. The study took place at one of these universities. A letter of permission to conduct the study in the Associate Degree Nursing Program from the program director and the hospital administrator accompanied the human subjects application.

The hospital administrator received a formal letter explaining the purpose of the study and requesting permission to observe and interview students, the faculty teacher, and clinical staff nurses during clinical laboratories at the facility. A follow-up telephone call was made after one week to schedule an appointment to answer any questions, obtain paperwork, and complete the consent forms. After obtaining formal permission from the 
hospital administrator and the respective university review boards, the researcher explained the study to the clinical staff nurses in the hospital.

The researcher also explained the study to the faculty teacher and the students. All participants received a written explanation of the study which included the following elements: the voluntary nature of the study, participation or refusal to participate would not affect standing in the nursing program or in the hospital, and that they could withdraw from the study at any time without consequence. The researcher also advised participants that all information would be kept confidential and anonymous. The researcher destroyed the student screening questionnaires, which contained student names, immediately after selection of the students. Subjects were advised that data would be reported without names and without identifying information. The data report included pseudonyms and no names. Participants were told that the case will benefit other nursing students beginning preparation programs and add to the body of knowledge about clinical nursing education. Nursing students, faculty teacher, and clinical staff nurses provided written consent before the fieldwork begins.

Confidentiality and anonymity protected the participants, and no names appeared with the data. Publication of the findings will not occur until after students complete or end the preparation program.

\section{Summary}

This multiple-case study design focused on three associate degree nursing students as they become nurses. During clinical laboratories, students foeus on three main tasks: psychomotor skills, critical thinking, and socialization. The socialization process becomes entwined with the performanee of psychomotor and critical thinking skills because through social interaction with faculty teachers and clinical stafi nurses in the 
clinical environment, students learn these important skills (Jeffreys, 2004). Therefore, the research questions in the study reflect socialization theory (Hinshaw, 1977) and data analysis was conducted within that framework. A descriptive account of students in the clinical setting was developed from observations, interviews, and documents utilized in the study. The faculty teacher and clinical staff nurses included in the study provided additional insight on how students are socialized into professional practice. In the clinical setting, the combined efforts of the faculty teacher and clinical staff nurses impacted students' socialization process.

From interview questions and observations, a rich, thick, description of clinical cxperience evolved. In the interview, participants gave perceptions of performance of psychomotor skills, recognition of critical thinking incidents, and support systems during clinical education. In addition, observations provided evidence of performance of psychomotor skills, critical thinking ability, and socialization processes with the faculty teacher and clinical staff nurses in the clinical environment. The presentation of findings begins with an in-depth description of the clinical setting, and then proceeds with a detailed account of the three students as they interact with the faculty teacher and clinical staff nurses in the clinical cnvironment. These case studies place the reader in the clinical setting and thereby conveys a comprehensive understanding of the complexity of the student experience during the clinical component of nursing preparation. 


\section{CHAPTER IV \\ RESEARCH FINDINGS}

Introduction

The purpose of the study was to describe three associate degree nursing students in the clinical setting. Data were collected from obscrvations, student, clinical staff nurses, and faculty teacher interviews, which, coupled with related documents, provided information to inform the case fully. Documents included student academic records, the course syllabus, assignment sheets, care plans, and patient assessment forms. Using the constant comparative method, segments of meaning from these data were attached to index cards with a notation indicating the connection to the data source (Glaser \& Strauss, 1967). The quotes found in the following text come from the categorized data. The introduction to the quotes indicates the individual data sources. The following section begins with a description of The Setting--the clinical learning environment. The primary thrust of the findings is a detailed narrative of each of the three cases--Ann, Kathy, Susan--and the patterns of themes within each case. The chapter concludes with a treatment of the Research Question and a Summary.

\section{The Setting}

The clinical lab, the setting for the study, meets in a large, six-story hospital, located in the center of town. The hospital, the county's largest employer. provides many services to the public. The sprawling structure encompasses physicians offices a level two emergency department including a level three trauma center, a level three Neonatal 
Intensive Care Unit, and a cancer treatment center. There are 3,400 patient visits through the Emergency Department and 1,200 patient discharges from the hospital each month. The corporation employees $600 \mathrm{RNs}$ at combined sites (Director of Education, personal communication, January, 4, 2007 [names are not included in order to protect anonymity of subjects]). The hospital offers the region's only comprehensive cardiac program and performs approximately 250 open-heart surgeries each year (Director of Education, personal communication, January 25, 2007). The hospital, whose campus extends across approximately two city blocks, presents an impressive countenance.

Even at an early morning hour the hospital flourishes with activity as I enter the Outpatient Department. Many patients and those accompanying them sit in the beautifully decorated lobby on plush sofas and chairs, watching television; the smell of brewing coffee wafts down the hall. Iospital volunteers, identified by the designated color smocks they wear, as well as receptionists, work behind a glassed-in desk. Patients summoned to the desk at intervals provide intake information before their scheduled surgery or procedure. Families of patients also report to the desk as progress reports become available. Patients and families converse in whispers, indicating the personal nature of the occasion. As I leave the Outpatient area, the bustling activity on the first floor continues as techs dressed in scrubs transport patients in wheclchairs and on stretchers to locations within the hospital for diagnostic tests or upstairs to patient care units for admission. Many other employees walk through the hallways, all wearing scrubs, which makes identification of their role in the hospital difficult. As I proceed through the hospital corridors, I greet several employees and nursing students that I know. Several visitors waiting at the elevator make small talk with each other. I hear Braham's Lullaby played over the public address system, signifying the birth of a baby. I 
eventually wind my way through the hospilal until I reach the cafeteria. the lab's meeting place. The cafeteria, open very early in the moming, serves breakfast to employees and visitors; appetizing aromas fill the air. In the crowded cafeteria, people enter the food lino through one door and exit through another after paying the cashicr. Nursing students take scats at tables according to their clinical lab group, and I locate my chosen lab group. Because nursing students often faint while observing surgeries, deliveries, or other procedures due to low blood sugar, the practice of beginning the clinical day in the cafeteria evolved to encourage students to eat. Starting the day in this manner creates a relaxed atmosphere and conveys concern about students' well being. I greet the students already present, some eating pancakes, biscuits and gravy, or eggs and bacon. The students, fresh looking in their clean, white uniforms, lab coats, and white shoes, appear surprisingly alert for the early morning hour. $\Lambda$ patch, sewn on the sleeve of students" uniforms and lab coats, along with a nametag, identifies the university and nursing program affiliation. Students pour over numerous sheets of paper spread out in front of them: care plans and drug information--all required preparation before clinical begins.

The care plan, very important in clinical preparation, serves as the blueprint for patient care; therefore, a detailed description follows. Each student must prepare a care plan for his or her assigned patient before every clinical lab. The care plan, made up of all pertinent nursing diagnoses, differs from the medical diagnosis made by the physician because the former addresses the patient's response to the medical problem, and not the medical problem.

For example, the patient with a lung disorder called COPD (chronic obstructive pulmonary discase) receives the nursing diagnosis, "activity intolerance," meaning the patient lacks energy sufficient for activities of daily living due to inadecuate oxygenation. 
The patient becomes tired because oxygen needs exceed supply. The nurse then develops a plan. which meets the patient's needs, within the nurse's scope of practice. The nurse addresses the patient's response to the medical condition by spacing out the patient"s activities and allowing a rest period after the bath or before ambulation, thus minimizing fatigue and conserving energy. The nurse monitors signs and symptoms of decreased oxygenation, such as skin color, breathing pattern, vital signs, results of lab tests, and ensures the administration of breathing treatments and oxygen. In addition to addressing the patient's needs and responses through the care plan, the nurse must carry out the physician's orders for treatments and medication. This care plan, a vital part of clinical preparation for nursing students, provides the rationale for all nursing care. On mornings before clinical, students confer with each other and hastily put finishing touches on care plans in anticipation of presenting the report in preconference.

In addition to assisting each other in completing assignments, such as care plans before clinicals, students engage in other socialization as well. Popular topics of discussion include recent tests and debate over the correctness of answers selected, as well as concerns about upcoming tests. Other topics of discussion include personal childbirth experiences. The lab group seems very close, like family. The students remark that they like meeting in the cafeteria because the discount on food helps their "poor income." Soon. all of the students in the lab, as well as the faculty teacher. arrive and the day begins. A total of 10 nursing students make up this clinical lab.

A pre-conference, a sort of debriefing, takes place before the students go to the medical-surgical unit, the setting for the study. The students, directed by the faculty teacher, leave the cafeteria and proceed down the hall while she locates a place for the preconference. The large numbers of clinical labs held in the hospital make reserved 
locations for pre- and post-conferences impossible. The faculty teacher uses any private area, an empty room, even a quiet corridor where she can talk to the students. We follow her throughout the hospital, like ducks in a row; we turn here and there and finally end up in the employees' break room in the Outpatient Department. The students jokingly express doubt about finding their way out of the maze of hallways.

When everyone takes a seat, the faculty teacher announces the alternate assignments in locations besides the unit. During the semester each student receives an alternate assignment at the Outpatient Department, the Cancer Center, Radiology, or the pediatrician"s office for observation and performance of available skills. All other students report and provide rationales for planned patient care. The faculty teacher alternately quizzes students and provides teaching points. She often says. "Look that up." The atmosphere in the pre-conference fecls comfortable and nonthreatening. The faculty teacher actually says, "Remember, no stress today!" The faculty teacher often gives assignments or "jobs" for the day, something the student must investigate for discussion in post-conference. She says, "You be the investigator." The students excitedly talk about their assignments for the day. Everyone seems prepared, and we leave for the unit.

The clinical lab converges on the unit; the troops have landed! We enter single file, all in white; staff at the nurses" station look up as we go by. The phrase. "angels of mercy" enters my head as we proceed down the hall. Several physicians, nurses. lab technicians, respiratory therapists, and other employees mill about the busy unit. Physicians making rounds on their patients occasionally confer with a nurse, then sit at the nurses" station writing progress notes on the chart and greet other physicians jovially. $\Lambda$ unit secretary sits at the nurses' station, the "nerve center" of the 24 bed medicalsurgical unit. The unit secretary mans the phones and fax machine, runs errands, directs 
traffic, and enters physicians' orders per computer. The unit secretary calls out to a nurse, "K, it"s Dr. . calling you back." A chart rack holds patients" charts that fit neatly into individual cubicles. Color-coded tape on each chart corresponds to specific physicians. Monitor techs, stationed on another floor, constantly observe the cardiac monitors on each side of the nurses" station. A large nameplate on the wall in the nurses" station displays the Unit Manager's name. Usually, three RNs. three nursing techs, and the unit secretary work on each shift. A marker board at the nurses" station indicales the nurses and techs assigned to cach patient room.

The students proceed to the break room. Nurses and other staff use the room to "get away" briefly when eating or charting, and students gather here briefly when arriving on the unit. The students put their belongings away and leave because the small room quickly becomes very crowded. It contains a small table with four chairs, a few lockers in one corner, a patient bedside table, a small refrigerator, and a bathroom. $\Lambda$ bulletin board posts announcements and important information such as, "Heart failure document reminders," "Alarm alert," "Cover your cough," "Medication missing," and "Wash your hands." Students disperse on the unit, beginning the routine of clinical lab. A line forms at the Pyxis (automated medication dispensing system) as students wait to obtain patients ${ }^{*}$ medications scheduled for administration. $\Lambda$ typical clinical day begins.

Case $\Lambda:$ Ann

A description of Ann includes the following characteristics: third-semester nursing student, married, age in early thirties, chin length medium brown hair with bangs, and brown eyes. From the interviews, $\Lambda \mathrm{n}$ discussed how she chose nursing as a second career; the opportunity came about after the factory where she worked for scveral years closed without much warning. She qualified for a government program for displaced 
workers, which paid for the education necessary for a new career. Ann always thought she wanted to become a veterinarian but decided against pursuing this goal because of the lengthy preparation time required. She investigated majors offered by the university in pursuit of other options:

... and so whenever I got laid off, the plant closed down. I was looking at the stuff that __ [the university] offered and I was like ... I bet nursing is pretty neat. So. it's not too different, caring for animals. I mean at least they [people] can spcak back to you where animals can't. That's kinda how I ended up where I am now. Interviews and documents demonstrate that Ann faced some obstacles along the road to the nursing program. After making the decision to pursue nursing, her lirst attempt at admission to the associate degree nursing program proved unsuccessful. She attended the university some years earlier and during one semester stopped attending classes without officially withdrawing, resulting in failing grades and consequently a low GPA (grade point average). She enrolled in the university again and began nursing prerequisite courses. Ann received excellent grades but could not overcome the effects of the earlier poor semester. She initiated a mecting with an academic advisor regarding the best course of action to improve her GPA. Consequently, she took academic renewal, a university procedure that voided the semester with failing grades. Ann applicd a second time to the nursing program and with her new GPA of 4.0, gained admission. Ecstatic about this, she relates checking the mail every day until she received the [italics added to show emphasis given by $A n n]$ letter. She said that she knew from other students that a big letter, containing admission paperwork meant acceptance, a small letter, bad news. Ann seized the opportunity to begin a new career after losing her previous job. Her new role as a nursing student presents a sharp contrast from her background as a 
factory worker. She demonstrated courage, determination, and hard work in starting over in the new world of nursing. I)ata from interviews, observations, and documents form the following description of Ann as she learns in the hospital clinical learning environment.

I greet $\Lambda \mathrm{nn}$ in the cafeteria; she remembers me from the day I administered the selection questionnaires. Ann received previous notilication of her selection as a sludy participant, and I thanked her again for her willingness to participate. She replied, "I didn't think you "d want to talk to me [italies added to show emphasis given by Ann|." She seems surprised and smiles, as if pleased at the honor of participating in the study, and receives approving glances from the other students. Ann presents a well-groomed appearance: her pant suit uniform and shoes clean and white. She carries a canvas bag imprinted with the name of the nursing program. The bag contains needed supplies for clinicals: a clipboard, paper, pen, stethoscope, and completed assignments. I sit at the table next to her, in the middle of the entire lab of nursing students. Fveryone acknowledges me, and although we exchange pleasantries, my presence, a new element thrown into the normal day, seems a litle awkward at lirst.

The faculty teacher arrives and signals that we should leave for pre-conference. The faculty teacher"s appearance seems incongruous with her position of $\Lambda$ ssistant Professor. Young and pretty with her long blonde hair pulled back in a ponytail, she looks like a nursing student herself. The faculty teacher as an experienced, knowledgeable nurse as well as an educator soon becomes apparent. $\Lambda \mathrm{nn}$ interacts positively to the faculty leacher, who responds to students in a warm and comforting manner. When we arrive at the preconference room, $\Lambda$ nn gives a detailed report about her assigned patient. She tells the group her plan of care for the patient as well as the medical diagnosis and medications ordered. Ann reports in her soft spoken manner and self- 
consciously glances around the room as she speaks. She seems well prepared and answers the faculty teacher"s questions adequately. Relief shows on her face at the conclusion of the report and questioning session.

After pre-conference, Ann, the other students, the faculty teacher, and I take the elevator to the unit. Ann leaves her bag in the break room and goes out in the hall to find the clinical staff nurse caring for her assigned patient. The nurse provides a patient report and answers all of Ann's questions. The clinical staff nurse also tells Ann about other patients that require skills that Ann may want to perform. She finds the tech assigned to the patient and asks about how much help the patient needs with a bath. Ann seems comfortable interacting with the unit staff and thoroughly collects information necessary to begin patient care.

Ann invests a great deal of time and effort in preparation for each clinical lab. Students may choose the option of acquiring assignments the day before or early the day of the clinical lab. Ann goes to the hospital the day before clinical to get her assignment: I come the night before, when we get out of class, like yesterday I was here [hospital] a little after 2; I get out of class at 1:30 and I was here about $20^{\circ} \mathrm{clock}$ and I'll stay 'til about 3:15 getting my assignments and stuff.

The faculty teacher posts the pink assignment form in the medication area of the unit, out of public view for protection of private information. Ann finds her assigned patient's name and room number posted on the assignment sheet. She reads the chart if available; if not, she must wait until she can review the chart for laboratory tests, $x$-rays, physician`s progress notes, and nurses notes. In this way, she obtains an overview of the patient since admission. She writes down the medications ordered for her patient from the medication administration record (MAR). If any of these are new drugs to her, she must 
look up the indications for using the drug, the normal dosage, and side effects before the clinical lab. If available, Ann talks with the patient"s assigned clinical staff nurse, receives a report on the patient, and asks questions about anything needing clarilication.

$\Lambda$ fter $\Lambda$ nn obtains the neecssary information, the real preparation work begins when she returns home. Ann usually spends about three hours in preparation of paperwork and the rest of the night studying for tests. Interviews and documents show that she must look up every medication new to her, including drug actions, indications, and major side effects. Ann also completes a care plan before clinical. Even though the faculty teacher sometimes permits submission of the care plan the day following lab, Ann always comes to clinical with her completed care plan in case the faculty teacher collects the assignment at that time.

Documents show that in addition, Ann must prepare patient assessment forms before clinical. Information for these often lengthy forms comes from combing the chart for patient information such as lab values and past medical history as well as data received from the patient during clinical. Completing necessary preparation work requires much of $\Lambda$ nn's time. The interviews and observations reveal that in addition to the time commitment, all preparation work for clinicals potentially becomes the subject of quizzing by the faculty teacher. Ann's faculty teacher confirms the importance of clinical preparation and the consequences for the unprepared student:

Well. if they don't know their medications when they come to the Pyxis or we're getting ready to give the medications, they get fired and they're kicked out. So they don't get to come back and get their medications until they are prepared. I won't go with them to give the medicine until they are prepared--they don't want to be fired. They don"t want to hear the words. "You're fïred." It's embarrassing if" 
everyone around them hears it.

The interviews and observations reveal that Ann follows a routine in clinical, beginning with receiving a patient report. Next, she goes to the patient's room and makes the initial contact. The patient, in her seventies, looks frail and thin. A nasal cannula delivers oxygen and an IV infuses in her arm. Ann introduces herself and carefully explains the care she plans to provide. She seems a little quiet at lirst, using few words, but completing her mission. Ann quickly warms up and speaks more fiecly with the patient as the day progresses as if assessing the patient's reaction to her before she becomes more at ease. Ann verbalizes feeling somewhat uncomfortable around patients, uncertain if they want her there. She admits feeling self-conscious with an acute awareness of her patient's comfort when performing skills:

... I used to feel like I was just violating them totally by ... wanting to look ... to feel every--their pulse rhythm, their abdomen... I felt like I was ... like they didn't want me in there...

Not surprisingly, $\Lambda \mathrm{nn}$ says that she feels the demands of elinical preparation consume her time. With the two afternoons each week when she obtains her assignment from the hospital and two days each week for the actual clinical lab, Ann goes to the hospital four days a week: "Seems like I study all the time, and I feel like I don'1 study enough. Or l'm doing some kind of homework, and it just seems like l'm alwalys ... struggling." The rigors of clinical preparation overwhelm $\Lambda$ nn at times. While she works on one assignment, she worries about other assignments she must complete. Often when Ann looks over her weekly planner at all the tasks that lie ahead. she asks herself, "I Iow am I gonna do this; how am I gonna do this?"

Ann also describes overwhelming experiences during clinical labs as well. During 
her lirst clinical of the semester, she came out of her patient's room where she had spent an extended period of time, and saw no one in her lab anywhere in sight. She looked around the unit, walked to the nurses's station. and still seeing no one in her group. became alarmed:

And I was thinking, "my gosh, they left me, they forgot about me!"... It was almost like slow motion, and I was like, of course the nurses and stall were there, I was like, "I can't believe they forgot about me!"... I guess at the time I was overwhelmed.

The faculty teacher decided to leave the unit at a different time than usual and thought that all of the students received the message. When the faculty teacher realized she left one student on the unit, she returned to find a tearful Ann.

Ann describes another unsettling clinical experience in which she struggled to cope with an aspect of paticnt care which she found dificult--unpleasant odors. She relates her response when faced with this reality in nursing. Returning to the unit from lunch, Ann found her assigned patient responding to a laxative administered earlier. Ann felt overwhelmed not only by the odor but by her response:

... I don't know if it was because I had just eaten or what, but I came up and I thought I was gonna throw up! And I thought, "I can't do this; I can't do this." He was still on there [bedside commode], thank goodness. I kept walking out in the hallway; I was walking in circles. I was like, "take a deep breath, take a deep breath; you don"t need to throw up. you're the student nurse: you don't need to be the one to get sick." But, I mean, I guess it's just something that I eventually"ll get used to, but it's not happened yet.

The faculty teacher confirms the overwhelming nature of some clinical 
experiences: "... it's like jumping into a pool, you know, and learning how to swim.... For a student I think it's like sensory overload." The faculty teacher also describes how students react to overwhelming clinical situations: "I've seen them cry. Their face gets red or you can see when somebody is not able to concentrate or focus because they re thinking so many other things."

Ann identifies other aspects of clinical labs she finds challenging. A situation, seemingly insignificant, became a great concem for Ann. In some clinical labs students must change from their uniform to scrubs, provided by the hospital. The hospital requires all personnel, including students, to wear scrubs for observation in the delivery and operating rooms. In the locker room, the changing area, few scrubs in limited sires may remain for nursing students because hospital employees who arrive carlier, get first choice. $\Lambda \mathrm{nn}$, fearing the unavailability of scrubs in larger sizes, faced the embarrassment before each clinical of finding scrubs that fit her: "I was so afraid. I knew they switched outfits, and I was so afraid... What if they don't have an outfit that would fit me? And I don't want to be in that situation." In an attempt to prevent such a situation, Ann approached the faculty teacher and asked il she could purchase her own scrubs for clinical. The faculty teacher cleared the issue with hospital unit managers who gave permission for $\Lambda \mathrm{nn}$ to buy her own serubs in the approved colors, provided she transport them in a plastic bag to ensure cleanliness.

Another event causing great concern and discomfort for $A$ nn occurred during her first surgery observation. Although treated well by the surgery staff, Ann lelt out of place and disillusioned by what she perceived as the assembly-line approach to patients.

I felt that they have all this sterile stuff here. and I didn't really want to mess anything up. I wanted to be out of the way, but I wanted to see. I just felt so, like 
out of place... It's like it's not even a body there. I guess it is second nature to them "cause this is what they do everyday, and I'm sure it gets old ... but to me I'm like. "that's a body there." I mean, they re talking about selling their house and doing this and I'm thinking, "you're taking this woman's insides out and you're talking about real estate?"

The interviews and observations also point to other situations that $\Lambda \mathrm{nn}$ perceives as challenging. These involve attending to patients' needs, performing personal care, and performing skills, especially for the first time. The nature of nursing clinical experience prohibits students from functioning independently because the provision of most patient care requires close supervision. Ilowever, the constant dependence on the laculty leacher or clinical staff nurse often hinders students from performing patient care in an eflicient manner. Ann recounts an occasion that caused her frustration and delayed patient care. In the middle of bathing a patient, Ann realized she needed another item besides the one obtained earlier from the Pyxis. Unable to retrieve the needed item on her own, Ann interrupted the patient's bath while she searched for assistance with the Pyxis. $\triangle$ few minutes passed before Ann found help and resumed the patient's bath.

When Ann interacts with patients while performing care and skills, she often leets uncomfortable and insecure. Performing physical assessments necessitating the invasion of patients' personal space scems awkward and disconcerting for $\Lambda \mathrm{nn}$ :

... I felt like ... they didn't want me in there, which they may not. I don't know. I get so nervous and then start to sweat. l'm like, "I don't want to sweat on my patients." I do feel my confidence level is still not where I would like it to be but I am starting to slowly, like a turtle's pace. but slowly I am starting to feel a little more comfortable going into the room and just doing the assessment... I really 
need to build my confidence, I need to ... be able to go into a room and not think that, "Am I doing this right, am I doing this right?" I always wonder, "What do they think about me when I go in there?"

Closely related to such discomfort and insecurity, $\Lambda$ nn also fears causing pain or discomfort to patients when performing certain skills:

I don't want to do anything that could harm my patient. I an so afraid that every time that, every time that something drops, something falls or if ... I don t want to hurt them. I feel like I'm always asking. "Are you ok? Does that hurt? ( an I help you with anything?"

The first time performance of a skill compounds $\Lambda$ nn's concern of causing harm or pain to patients. Ann becomes apprehensive with just the anticipation of performing a skill:

Tense, I'm just ... inside my whole body leels like, you know, I just lear the day I'm gonna have to start an IV. I've done it, l"ve checked off on my little arm (model arm) and you know, I've performed it for my instructor. But even when I come up here to get my assignment, I'm thinking, "wonder when that IV was changed? Am I gonna have to change it on my shift?" I mean. I just ... I just get so nervous over the simplest things.

One day in clinical the clinical staff nurse asked $\Lambda \mathrm{nn}$ to administer flu vaccine to a patient. At the thought of performing this first time skill, Ann wrestled with anxicty as she thought. "... I had never given a vaccine before. What am I gomna do? I've never done this before? Just ... just tense."

When Ann gave an injection for the first time, she describes the process of obtaining and checking the medication with the instructor and preparing the drug for administration: 
And I'm thinking ... "I don't know ... il's like would it not hurt as much if you went slow in or if ... I don't know." You practice ... I have a little spongy thing ... the little stress ball like thing. I practice on it at home and I was like ... you don't really know how it feels and I don't want to hurt anybody more than what it is already gonna hurt. But he /patient / couldn't have told me if it would have hurt him or not, so I guess it was a good lïrst timer.

Along with the fear that she might cause harm to a patient, $\Lambda$ nn states the major concern of feeling incapable of performing any skills without assistance: ". . but you know, you want to be able to do it on your own, and I hate to have to go to ___ [laculty teacher| every time. You know, to not be able to do it myself."

In addition to the fear of causing pain to a patient is the stress of being questioned by the faculty teacher:

Every time I get a medication, she"s like, "what's that for"? Now what s that for"? What's the side effects of that?" I always want to have it... I even have a little flip thing that I write all my stuff down in case she asks me something. so I don I have to ... 'cause the very lïst time I give an IV push medication, she said, "what"s the llow rate?" And I"m thinking, "I don t know." So I had to go look it up. I felt so stupid "cause I should've known that.... Another time when Ann might be questioned by the faculty teacher is during preconlerence: I don $1 \mathrm{know}$ if she really knows the answers or if she's just asking us to see il we know. I'm not sure why she"s asking questions, but then she"ll say. "we"ll get together and we'll follow up on it."

The faculty teacher talks about the practice of questioning students to verify adequate preparation: 
I quiz them. Anytime there's down time or we have their [the patient] chart, even when they re giving their report before they leave the floor,... they have to bring me their chart, they have to bring me their MAR, and you know we kinda talk for a few minutes one-on-one about the day and if at any time there is something that was unclear from pre-conference, we're able to discuss it and grab the chart and I'll ask questions, "what about this; did you ever find the answer to this? Well, what about this?"

The faculty teacher also described her intentions for the post-conference. During post-conference, the faculty teacher leads students in a discussion of what they learncd during the morning clinical. The faculty teacher incorporates the topics of critical thinking, communication, psychomotor skills, and organization into discussions, while students talked about their experiences with each other that day.

The discrepancy between school lab preparation and the realities of working with real patients in hospital clinicals also concerns Ann. Students first prepare for hospital clinical labs in the school lab with simulated skills and patient care. The school practice lab, although helpful in acquiring skills and handling equipment, cannot compare to performing care for real patients. The reality that working with real patients greatly differs from the school practice lab inspires a sense of dread:

... the one-on-one with the patients ... the real life ... the realness... We ... have our clinicals at school. but you just don't get a response from a manikin... I haven't had the opportunity yet to have ... a MRSA [infection] patient ... or have a patient that was maybe closer to death or something like that and ... my day is coming. I'm sure it will happen.... It's just the realness of it all. 'That's like with the IV, my very first time, I did it all day long (in school practice lab). I practiced 
several times. I went into that lab and practiced and practiced. But you know, you don't get a blood return. You don't know that you're not in the vein....

Other causes for concern regarding clinical include learning the unique language of medicine and nursing and fear of interacting with physicians. Ann related a humorous incident when she did not understand the meaning of an abbreviation written on a chart: ... on the chart it had OBT in reach and I'm like, "what in the world is OBT?" I asked ___ [other student], "What is this?" And she was like, "I"ve seen it before, but don't know what it is either." I'd seen that the nurse had signed off that it was in reach, and I'm thinking,... I'm looking around the room ... and I'm like.

"What"s in reach?!" It was the table ... overbed table!

Ann describes her fear of interacting with physicians:

... the doctors ... I don 1 know ... I guess I feel like I'm so inferior to them....

I've never really had to talk to a doctor, of course one's never talked to me cither.

Whenever I see a doctor. I'm like, "wow," you know, it's like ... I don't know;

I've never really had to communicate with a doctor, and I just fear it.

Although Ann feels that she is progressing in clinical performance, she occasionally has doubts and becomes discouraged:

... there has been a couple times that on my way home after clinical or something. I'm thinking, "I'm not even worthy to scrub the toilets in that hospital." I get down ... and I think. "why do you even try?" I just feel like ... "is this really what you think you can do?"... and I really question.

Despite the concerns and doubts, Ann relates rewarding clinical experiences as well. Ann, along with other students in the lab, cared for a patient over several weeks and shared in his joy as his condilion improved. The patient, previously paralyzed, regained 
his lecling and progressively began to move parts of his body.

... we just all cheered, and he was smiling. He was so happy. and we went down and got some little stuffed animal ... and took it in there for him and he was just so happy! Of course, he had no family here, and maybe, we made ... that man's day today....

Students cannot survive the rigors of clinicals without support systems. Ann's sources of support include her husband, mother, the faculty teacher, the clinical staff nurses, students in the same clinical lab, and other friends in the nursing program. Ann's husband and mother lend support by making themselves available and listening when she needs to ventilate. The faculty teacher offers Ann support as well. During the previously mentioned experience when Ann felt she had been left alone on the unit, the laculty teacher came to her rescue. When Ann saw the faculty teacher walking down the hall, tears welled up in $\Lambda$ n's eyes from relicf. The faculty teacher pulled $\Lambda n n$ into a quict corner and reassured her. Ann also feels supported by the faculty teacher" s praise and positive atlitude. At the beginning of the clinical day, the faculty teacher often says, "no stress, that"s our goal." The laculty teacher uses her favorite phrase. "That's labulous!" when Ann does well or accomplishes something new. The faculty teacher also frepuently exclaims, "That"s my girl!" to show praise.

Ann also describes the clinical stalf nurses as a source of support. Ann interacted with a different clinical stalf nurse on each observation day. Working with different clinical staff nurses adds to the complexity of the clinical experience. Ann says that the staff nurses nover fail to offer help with skills, answering questions, or obtaining supplics and equipment: "Every one of them's been helpful. if I ask a question. I need something" out of the Pyxis, or sometimes they just voluntecr." 
One of the clinical staff nurses working with $A n n$ described in the interview her understanding of what the clinical is like for students.

I try to help them oul as much as I can. "cause you know what. I've been in their place twice [LPN and RN preparation] and it's a hard thing ... it's hard enough to take your time away from your family. You have to put your stuff all in school and you're having to work a full-1ime job. You know, they're [students] stressed to the max and then have to do something totally different and each day they walk up here. it's a totally new experience.

The same clinical stalf nurse discusses her role in student learning during the clinical:

I just think that we try to do our best when they come up here and we try to make them feel welcome, that they can ask us questions and think that we're not going to degrade them or put them down.... I think a lot of it, it's just being nice to them, being friendly.... I've been on floors. they re not too friendly. so you ic scared to ask any questions. I think, being open, and saying, "IIi, how are you doing?" opens the door... They feel more comfortable that they can come to you. The second clinical staff nurse, the only male nurse on the unit, and a recent graduate of the nursing program, describes a similar philosophy of working with students:

Well. whenever I have a student, I try to make sure that when I'm doing something, that they can either watch, or they can participate ... just try to get them as much experience and knowledge and seeing things that they possibly can ... with the little time you have with them... I tell them experiences l"ve had, and I do ask them questions and just try to show them [how to do things]. I think it 
really helps them if you tell them specific things that have happened to you ... so they can build upon experiences that you have already gained... They could be taking care of my relative or family member down the road. I think any kind of help you can give them is beneficial.

In an interview, one of the clinical staff nurses speaks of supporting students: "You pep them up and talk to them and say. "You know you can do it." She responds to a student who is upset: "I try to go over and ask if there is something I can do, tell them to go sit down. get a drink. relax. because they're following me. and it will be all right." The second clinical staff nurse relates how she supports students in difficult limes:

Typically, you just try to let them know that other people have been there. Especially, I like to do that because you know. I've been there: I haven't graduated very long [ago] and let them know that there were things that were bad about the day, but things get better; there are better days.

Support also comes from fellow students in $\Lambda \mathrm{nn}$ `s clinical lab, friends in other semesters in the nursing program, and patients and their families. Ann related the story of being abandoned on the unit to a friend, also a nursing student, but in a different semester in the nursing program. The friend helped Ann see the incident in a humorous way and they laughed together: "... it did make things seem not so bad." Ann relies on other nursing students, both in her clinical lab and in other clinicals as much as she does her husband. The common bond shared among fellow nursing students promotes a deep understanding of clinical experiences: . ... we are going through ... maybe not the exact same thing, but they're in clinicals themselves... They seem to sense my anxicty sometimes, and they're like, "You're doin' good. You're doin' great, Just calm down." Ann also receives support from students in her clinical lab who also work in the hospital 
and possess helpful information. Ann feels comfortable asking these students simple questions: "... I feel like I can come to them and even if it's a stupid question. I wouldn't feel like they're [saying]. "She didn't know that?"."

Patients and their families provide welcome support and encouragement as well. Ann remembers a patient that left her beaming. Ann cared for a patient who showered her with praise: “... when I left, she complemented me and gave me the bighead! I mean she was telling me how good of a nurse I was gonna be, how sweet I was, just all kinds of stuff. When I left, I really felt she put you on cloud nine."

The faculty teacher relates an incident in which the patient and his wife were the source of support for a student who successfully started an IV:

So we go in and the patient... [said]. "You know I want you to start this IV." Well, she [the student] got it! And the wife [said], "I'm so proud of you!" and the patient [said], "I'm so proud of you!" At post conference, we just cheered her [the student] and clapped.

Entering the new world of nursing impacts Ann's personal relationships resulting in changes in her life, including decreased time spent with her husband. Since Ann's husband works alternating shifts, they see little of each other through the week but try to spend more time together on weekends. Ann relates that studying consumes so much of her time that little remains for anything else: "Seems like I study all the time, and I feel like I don't study enough." She says that she does not see how the students with children do it because even without children she finds little time remaining for anything exeept study. She says that her husband jokingly says, "Nice visiting with you." when she does interrupt her studies for a few minutes.

Ann reports a change in other personal relationships as well. The time she once 
spent with friends radically decreased after starting the nursing program. One friend, in particular, actually called her and said. "You never call me anymore: do you not like me?" Ann`s lack of time impacts family members as well. She used to visit her mother. who lives in another town, about once a month. Now, Ann talks with her mother by phone and visits infrequently.

\section{Patterns of Themes}

The previous narrative chronicled $\Lambda$ nn's journey in the clinical learning environment. Ann's perceptions, experiences, and responses along the way impacted her learning in the hospital clinical environment. Several predominant themes emerge from the story. The following section presents the identified trends.

\section{Life Becomes the Clinical}

From the interviews. $\Lambda$ nn relates her feeling that clinicals, along with the beforehand preparation, consumes all of her time. When she goes to the hospital unit the day before clinicals to get her assignment, she spends a couple of hours there and in addition, several hours more looking up drugs and writing a care plan after she goes home. The documents show that since clinical labs meet twice a week, $A$ nn goes to the hospital, either for preparation or clinicals, four days a week. Ann relates that she feels like she constantly either studies or does homework and struggles to accomplish everything even though she has no children or outside job like many students do. If she had these additional responsibilities, Ann feels that could not do everything required of her. The time consuming nature of clinical work affects Ann's personal relationships as well. She has little time for her husband, family, or friends, who all comment about her decreased time spent with them.

Someone to Lean On 
The interviews show that it is the support that $\Lambda$ nn receives from different sources that provide the means by which she copes with the demands of elinical. Ann obtains support from her husband, who helps by listening to her concerns. I Ier mother and friends outside the nursing program offer her support and encouragement, even though they do not have a complete understanding of $\Lambda$ nn's experiences during clinical. Although her relationships with friends and family changed due to the demands placed on her time since beginning the nursing program, she continues to talk with them occasionally. Ann's husband, mother, and friends listen to her and provide encouragement. During clinical, Ann and friends asks questions, conlide problems, and share successes together. The small circle of friends support cach other on good and bad days. She feels safe and unthreatened with these friends because she can ask them things without feeling stupid when she does not know the answers. Ann receives support from the patients she cares for as well. Each time she elicits a smile or praise from patients; she feels validated. These positive patient encounters reinforce Ann's decision to go into nursing.

The interviews and observations show that the faculty teacher and the clinical stalf nurses provide support to Ann as well. She feels that she can go to her faculty tcacher if she has a problem during elinical. She does not hesitate to consult with the faculty teacher concerning the welfare of her patients. The faculty teacher praises Ann when she does something well and applies critical thinking to solve a problem. The faculty teacher advises Ann of the "no stress" policy in clinical. When $A$ nn felt abandoned on the unit and became upset, the faculty teacher took her aside and showed concern for her well-being. The faculty teacher did not make Ann feel silly because of her emotions or belief that everyone left her on the unit; she provided comfort and 
support.

The clinical stafl nurses show support to Ann during clinicals. Ann interacted with a different clinical staff nurse on each observation day. I laving to work with different clinical stalf nurses during each clinical day adds to the complexity of the clinical experience. $\Lambda n n$ leels that all of the clinical staff nurses, without exception, make themselves available to her and show an interest in her. $\Lambda$ nn readily turns to the clinica! staff nurse in charge of her patients when she has questions or concerns, such as administering an "as needed" medication. The clinical staff nurse also accompanies $\Lambda$ nn when she performs certain skills, such as checking a blood glucose level with the glucometer, or applying monitor leads. The clinical staff nurse offers new skills for $\mathrm{Am}$ to perform. such as how to read and implement a physician's order written on the chart. Contributors to Self-doubt

Self-doubt emerged as a theme from feclings of fear, anxicty, apprehension, and dread. Ann expresses fear of harming or violating patients. She relates that during any interaction with a patient she becomes acutely aware that harm might come to them during her care. When $A n n$ realizes that she must perform a skill, such as an injection, she expresses anxiety at the possibility of inflicting pain on the patient. Because performing a skill or procedure on a real patient lacks congruity with the school lab practice, she experiences anxicty that her inexperience will cause more pain than usual to the patient. Apprehension also arises from Ann's fear ol violating patients when she performs assessments which necessitate that she invade patients personal space. She also feels that she may violate the privacy of patients when she enters a room and they may not want her there.

In addition to her fear and apprehension about causing harm to a patient when 
performing a skill, $\Lambda \mathrm{nn}$ dreads being asked to do an actual procedure for the first time in the hospital clinical lab. Ann describes this sense of foreboding and apprehension when she is assigned a patient with an IV. She begins to feel a sense of trepidation that she may have to restart the IV and immediately checks the chart to see if this will need to be done while she is caring for the patient. She describes herself as tense with the anticipation that the day will come when she might have to perform a new skill. Since the sehool practice lab provides a very different experience from performing skills on actual patients, Ann expresses feelings of dread about the reality of giving injections and starting IVs on real people instead of manikins. Whether or not techniques practiced in the school lab prove adequate when performed on a patient remains an uncertainty.

The interviews show that $\Lambda \mathrm{nn}$ is overwhelmed at the amount of work that lies before her and questions her ability to get it all done. She stares at the numerous upcoming assignments written on her weekly planner and asks herself how she can possibly accomplish all the tasks at hand. Ann sometimes asks herself why she even tries. Documents verify the large body of knowledge that Ann must learn and practice. In another situation, $\Lambda$ nn relates that she was unable to figure out what an abbreviation on a chart meant. After asking other students, and discovering the meaning, she felt that she should have known something so simple. Learning the skills, procedures, theory, and critical thinking necessary to perform well in clinical presents a daunting and overwhelming task for $A$ nn.

Some personal experiences during clinical also proved overwhelming for $\wedge \mathrm{nn}$. Thinking that everyone in the clinical lab had abandoned her on the unit reduced her to tears. Though physically an adult, Ann`s developmental level in clinical nursing practice at that time, no doubt, only reached infancy. Another overwhelming experience involved 
Ann's reaction to an unpleasant odor. She became nauseated, left the patient's room, and while walking in the hall, she told herself to take deep breaths to avoid vomiting. This strong reaction could possibly render her unable to care for a patient properly. These detailed situations describe times when $\Lambda$ nn questions herself and reproaches herself. All of the feelings of fear, anxiety, apprehension, and dread from overwhelming experiences contribute to self-doubt.

\section{Initiative}

Taking the initiative emerges as a theme during the interviews. Ann provides an account of obtaining her own scrubs for hospital clinicals during her Maternal-c hild and Surgery rotations. Rather than waiting until the clinical lab and taking a chance that scrubs in her size may not be available, she demonstrated self-direction by taking the initiative and talking to her faculty teachers about her concern. $\Lambda \mathrm{nn}$ had a specific goal in mind, to pass the clinical labs in question. Ann realized that successfully passing clinicals meant that she had to meet the scrubs requirement. Rather than facing embarrassment if none were available, she took the initiative and asked for permission to purchase her own scrubs in the required colors. She discussed this matter with both faculty teachers, who in turn discussed the issue with the clinical managers in the areas where she would need to wear scrubs. The clinical managers granted permission for Ann to bring in her own scrubs, provided that she transported them to the hospital in a clear plastic bag to keep them from getting dirty. Ann, alone, recognized the potential problem which could ultimately interfere with passing clinicals. No one else involved, even the faculty teachers, anticipated this problem, but $\Lambda$ nn took it upon herself to become proactive rather than reactive.

From the interviews, Ann also exhibited self-direction in gaining admission to the 
nursing program. When the factory where she worked closed, Ann explored the majors that the university offered. She sought advisement from faculty in the nursing program in determining the requirements for admission. She had a low GPA due to the fact that years earlier she stopped attending classes without withdrawing, resulting in failing grades on her academic transcript. Despite the fact that her low GPA created a barrier in entering the nursing program, due to its selective admission policy, Ann showed self-direction in pursuing her goal. The documents show that through the university academic advising services, she discovered that with the process of academic rencwal, the failing grades could be voided. Ann's goal remained clear: admission to the nursing program. She acted on her own behalf to achieve this end. By demonstrating self-direction, Ann achieved her goal.

\section{Case B: Kathy}

Kathy, a third semester nursing student in her mid-20s, is married with two children. Her dark brown, almost black hair falls to mid-neck length and contrasts sharply with her porcelain white skin and large, sky blue eyes. Kathy originally wanted to become a pediatrician, but that changed when she became a parent. When her children were sick and received nursing care, she saw what nurses actually do to assist, support, and help the children and help the parents. She recognized that physicians have brief contact with patients while making a diagnosis, whereas nurses develop a closer patient relationship by remaining with patients, explaining and teaching. Of the nurse s role, she says. "I just love that ... nursing is ... just what I feel in my heart that I want to do."

Kathy did not take a traditional path to the nursing program. Married and pregnant with her first child in her early teens, the principal did not allow her to finish high school with the rest of the students. She obtained a GLD and finished the high school 
requirements carly. Gaining admission to the nursing program proved more dillicult than Kathy thought. She applied the first time to the nursing program and was disappointed that she was not accepted. She continued to work toward her goal, and after completing all required support courses, the next attempt proved successful.

On the first observation day with Kathy, I join the lab in the cafeteria and find her having breakfast. I initially met her when I informed her of her sclection for the study. I thank her again for agreeing to participate in the study. Kathy's personality seems naturally a little guarded; she in fact, acknowledges, "I have a problem trusting people." She does not talk much unless directly addressed. Kathy says that she is most comfortable with just a few of the students in the clinical group. She says that because she fecls at ease with these friends, she can ask questions or tell them anything without embarrassment or fear of looking stupid. Since the students share the clinical experience, they each understand the situation. Nthough Kathy has these friends, and she conlides in them, she is somewhat wary of others. She explains that there are a couple of students in clinical that just don't get along with everybody, "'They try to make everybody look bad." Kathy follows through with the nursing program expectations as evidenced by her pristine white uniform and shoes. Prepared for the day, she carrics a stethoscope, required paperwork, notebook, and black pen. She and other students commiserate about a test taken carlier in the week. 'They say that students in previous semesters used books and notes while taking the test, and the new approach that no longer allows book use seems "unfair."

I receive a phone call from the faculty teacher saying she would be a little late because she has an appointment at her child's school. After informing the students, they launch into another discussion about associate versus baccalaureate nursing degrees. One 
student says she took offense when she read a text book that classified associate degree nursing as a technical degree and the baccalaureate nursing degree as the professional degree. I discuss the Post-RN program at the university that allows associate degree nurses to obtain the baccalaureate nursing degree in approximately 1 year. Several of the students already completed prerequisite courses for the baccalaureate nursing degree and plan to enter the Post-RN program after graduation from the associate degree program.

When the faculty teacher arrives, Kathy and the other students give a report on their assigned patient, including ordered drugs and care plan. Kathy gives her report in a somewhat mumbling, rapid speech pattern with statements that ends in a questioning lilt, as if holding her breath until the faculty teacher deems her satisfactorily prepared. She lets out a deep breath when the faculty teacher, having no further questions of her, goes on to announce alternate assignments for selected students. Other students, familiar with the assigned locations, volunteer to serve as escorts to these sites. Kathy, other students, the faculty teacher, and I go upstairs to begin the day.

Kathy locates her patient's nurse and receives a status report. She discovers that her assigned patient's medications have already been given. I accompany Kalthy when she introduces herself to her patient: a thin, 78-year-old woman who sulfered a stroke but remains alert and verbal. Kathy also greets the patient's granddaughter who is present and evidently assisting with decision making regarding her grandmother's care. Kathy and the granddaughter discuss the fact that the patient will soon be discharged to a rehabilitation hospital. The granddaughter tells Kathy of her concern that her grandmother has not received some of her routine medications for 3 or 4 days. Kathy responds that she will inform the nurse. The nurse explains that the patient's medications were possibly changed by the physician. The granddaughter tells Kathy that the technician on duty 
already gave the patient's bath and changed the bed linens. Apparently, no one communicated to the technicians that the nursing student assigned to the patient would perform all care. Kathy obtains the vital sign machine and after going back to the patient's room, discovers that the machine does not function; the blood pressure cuff does not inflate properly. She finds another machine and proceeds to obtain the patient s blood pressure and pulse, then manually takes the patient's temperature and counts respirations.

Although Kathy seems to take the changes from the expected routine in stride, this represents a lost opportunity to practice clinical skills. At first, she worries that sho would have little to do during clinical, but she notilies the nurse that her patient's medications have been given as well as the bath and linen change. The nurse takes an interest in Kathy and provides an alternate patient for whom she may perform tasks. She delights in this opportunity to work closely with the nurse and says that this situation feels more like a "real" nursing experience.

The staff nurse instructs Kathy that her alternate patient needs medications and obtains these from the Pyxis. One sign posted on the refrigerator, amid many posted reminders, reads, "Kentucky state law states that IV fluids are medications. They must be documented on the MAR when administered." Kathy reviews the medications with the faculty teacher and proceeds to the patient's room. The patient. around 50 years old. had a cardiac catheterization three days earlier. Kathy cheerfully introduces herself, checks the patient's identification band, asks her to state her name, and gives the medications. She leaves the room and initials on the MAR the time she gave the medications and also writes her signature on the document.

Because her assigned and alternate patients will leave the unit, Kathy completes the necessary discharge forms with the guidance of the staff nurse, and together they go 
first to the altemate patient's room to explain the instructions. Kathy reviews the medications to be taken at home and hands her the prescriptions but finds a discrepancy; one of the ordered medications did not have a written prescription. Because she feels uncertain of how to respond to this problem, Kathy turns to the staff nurse for guidance. The staff nurse instructs the patient that since she has this medication at home, she should continue using the medications and call the doctor"s office when she needs a refill. Assisted by the staff nurse when needed, Kathy continues the steps for the discharge. She cautions the patient to notify the physician if any chest pain, skin rash, muscle or leg cramping, or weight gain over two pounds in a week occurs and requests that the patient sign the form stating she has received the instructions. Kathy gives the patient a copy and kecps a copy for hospital records.

$\Lambda$ fter finalizing placement in the rehabilitation hospital for the first patient awaiting discharge, the social worker, accompanied by Kathy, notifies the patient and her granddaughter of these arrangements. After the social worker leaves the room, Kathy continues to talk with the patient's granddaughter, who seems to view Kathy as a support person. The granddaughter tells Kathy that she worrics that her grandmother will not cat at the rehabilitation hospital because she is a picky eater. Kathy reassures her that the dietician there will assist the patient with food selection.

Usually in clinical, much of what Kathy does relates to the performance of routimo tasks, such as bathing, changing linen, and taking vital signs. However, when situations deviate from the expected, she must use critical thinking to solve problems. She depends on the faculty teacher and clinical stafl nurses to lead her in this process. An observation illustrates Kathy's guided critical thinking development when she obtains an elevated blood glucose level on a patient: 
... the one they did this morning was ... like 102 (normal 70-110). And her daughter says it runs kind of high at home ... she hasn`t been on any of her medicines and stuff since she has been here, but I thought 428 was beyond extreme. so I wanted to check that again... And I checked it again, and it was a little bit lower. So, 292 was still high ... I just wanted to make sure I did it right. because I didn't want to give her too much insulin and ... cause more problems The following narrative details how Kathy receives guidance in addressing this emerging problem. Alarmed at the high reading, she reports it to the nurse. The nurse suggests that she repeat the test because the wrong button on the glucometer could have been hit by mistake. Kathy returns to the patient's room with the equipment and explains that she needs to repeat the test. The patient good-naturedly accepts this even though she must have another finger prick. Kathy dons gloves and inserts the reagent strip into the glucometer and turns it on. She wipes the patient's finger with an alcohol pad, then attaches a lancet to the spring injector, and presses it against the patient's linger to draw blood. She places a blood droplet on the reagent strip and waits a lew seconds to obtain a reading from the machine. When finished, she leaves the room to conlier with the nurse on the result of the glucometer reading.

This time the reading is lower but still elevated. Together, Kathy and the nurse look at the MAR to determine the insulin dose. The patient should receive six units of regular insulin. Kathy seems a little nervous at the prospect of this task because the faculty teacher will surely question and scrutinize her during preparation of the insulin. Kathy goes to the faculty teacher who gets the insulin out of the Pyxis and helps Kathy select an appropriate syringe.

The teacher says, "Why are we giving this insulin'?" Kathy explains that the $M \wedge R$ 
indicates an order for this amount of insulin for the patient's blood glucose reading.

The teacher asks. "What kind of syringe do we need?"

Kathy replies. "An insulin syringe."

The teacher instruets her that although an insulin syringe is needed, the best type is a low dose syringe, because the small amount of insulin is easier to visualize in the low dose syringe with larger markings. After Kathy prepares the insulin, the teacher examines the syringe and verifies the accuracy of the dose. The elinical stafl nurse also checks the syringe to confirm the correct insulin dose.

Kathy, the nurse, and I go to the patient"s room where Kathy puts on gloves and checks the patient's identification band, and asks the patient to state her name as a second method of identity confirmation. Because the patient's record does not indicate the location of the last injection and sites must be rotated, Kathy asks the patient where she: received her last injection. The patient does not remember, and the stalf nurse instructs Kathy to give the insulin in the right arm. Kathy removes the cap from the needle and tears open an alcohol sponge. With her left thumb and forefinger, she pinches up a bit of skin on the patient's right upper arm. swabs the area with the alcohol sponge. inserts the needle at a 45 angle, and injects the insulin. She deposits the used syringe and needle in the sharps container, removes her gloves, and washes her hands. She goes out to ehart the medication on the MAR, where she initials next to the time of the dose and signs her name.

Kathy practices some critical thinking on her own, when she needs to place monitor leads on a patient's chest. They are color-coded for correct placement. After she applies an adhesive patch to each area of the chest to which the leads will attach she says to herself, "White is right and smoke over fire" 10 remind herself that the white lead goes 
on the right side of the chest and the red lead goes under the gray lead on the left side of the chest.

The faculty teacher identifies evidence of critical thinking when she reviews the patient's chart with the student and asks questions linking information, such as lab work and $x$-rays to form a total picture of the patient. This activity verilies students" critical thinking ability and their capacity to see the totall picture. The teacher states. "... if they "re not getting the basics, they're not able to critically think."

Because the clinical staff nurse knows the patients well, she attempts to foster critical thinking in students. She guides students in connecting important patient information. The clinical staff nurse explains:

Well, when they get the meds, I always tell them to look at their vital signs lirst. watch that blood pressure and heart rate because ... we might have to hold them. I try to explain that and tell them to watch for that, just steps that you need to do every time.

Nursing students received constant evaluation by the faculty teacher. Kathy confided that her greatest fear concerning clinical is making a mistake:

... whether I mess something up. Some of the nurses are glad to have us up here and some of them aren't and they can be just kind of mean. And so I try to stay on their good side, and that is the main thing I am worried about, is just messing up. Kathy especially becomes concerned about making a mistake while performing a skill. During an interview she describes this situation:

When I am doing my skills, just remembering to do them right. I know, like I have it in my head, but then when I go in there to do it, just like hanging a piggyback or ... something simple, an IV or ... flushing it. I am alraid I'm going 
to ... not clamp something or have it unclamped, and it is just going to leak out everywhere and just forgetting to do something.... When I go in there and I just think, "What do I do next?" And ... make sure that I do that so that I don't cause an error.

Kathy admits that although she has made the right decision to go into nursing, she also expresses some disillusionment with the reality of clinical. During an observation in another area of the hospital, she became troubled when she witnessed a paticnt receiving cold treatment from a nurse and other staff. The patient was ignored and not addressed. Kathy also heard the nurse and other personnel gossiping about this patient. She became more upset when "one of the clients was sitting in the hallway and the guy / stall] came up behind her and was just ... running his mouth and being hateful to her | the patient |." Kathy reports that because she was so upset about what she witnessed, she unloaded on the faculty teacher during post-conferenee. The faculty teacher calmed her by listening to her and sharing her outrage.

Kathy also verbalizes disillusionment from the realization that the routine of clinical can at times become monotonous. When she is in clinical the whole day, she expresses how tiresome just doing the same things over and over again becomes. She reflects, "... when I really get out there, this is what I'm going to be doing, then I really don't want to work on a floor like this my whole life. I think ... "do I really want to do that all the time?".

Kathy also describes a disconnection between skills presented in the school learning lab and the reality of performing them in clinical. She speaks of how the school lab prepares her for clinical:

Most of the time, it's pretty on track and you really aren't going to get it until you 
actually get to do it. Because on IV insertions, I have not got to do that in clinical but I've got to watch a couple of the nurses doing it, and they don't do it like... we have learned in lab or on the video. And I mean, it's not the same materials ... and both times l've tried it in the lab. It's not the same.

The positive experiences, however, offset the occasional disillusionment with the reality of clinical and reinforce Kathy's decision to go into nursing. During the first nursing course, Kathy was very nervous about her first clinical in a nursing lome. She felt uncomfortable at first, but the patient's reaction to her was uplifting and encouraging: ... she was just so thrilled about having me there, and she had me sign a book for her, and we just talked. She didn $t$ have any family or have anybody to come visit her and she just made me feel that I could really do it.... I don't think she was ... all there completely, you know, mentally, but I mean she was really sweet. She just made me feel like I could do my job. I didn't have any confidence back then. During an observation, Kathy cares for another patient who transforms a routine day into a day filled with humor. This 91 -year-old man lost consciousness at home, fell and hit his head on the sink, which badly abraded the skin from his arm. He lhas a black eye and walks with a cane, yet he is not a typical "old man." He appears much younger and Kathy remarks that he does not look his age. He says with a smile that he looks much younger because he has no children. He tells us about his "lady friend." When Kathy asks about her age, he replies that she would have to be a younger woman since there are no women available as old as he. Therefore, he explains, the choice of a younger woman has already been made for him. During the assessment, he tells Kathy that he has to urinate every 30 minutes and that his skin is so dry that you could make cracklings, crisp pieces of pork skin from rendering of lard, out of him--.he pronounces this "cracklin"s." Later. 
when the clinical staff nurse visits the patient to auscultate his abdomen, she asks, "Is your belly awake; did you feed it?"

He responds. "Yes, and I took it to the bathroom too!"

When Kathy begins to change his dressing, he jokingly says. "I'm scared of those scissors; they 're pointing right at my eyes!" As Kathy bandages the several areas of tom skin on his arm, he points to one area and says, "Cover this one, and you're liable to get a promotion." This patient's humor and friendliness visibly lightens Kathy`s mood, and she seems to relax. This type of positive interaction with patients increases Kathy's comfor: level in the clinical and provides her with support as she learns in the hospital setting.

In clinical, the faculty teacher and the clinical staff nurse measure Kathy's progress, but she also measures her own work. Kathy acknowledges her growth and development as a nursing student and says that she feels much more confident interacting with patients and performing skills now than when she lirst began. At first, she struggled with basic skills, such as bathing patients and taking vital signs. Now she fecls that she easily completes these basic skills and others, such as medication administration, and eagerly seeks additional and more advanced tasks. Clearly, the more she accomplishes, the more she envisions herself when she finishes school--a real nurse.

The faculty teacher says that she can see dramatic progress in students ${ }^{\circ}$ performance after only a few wecks into the present third semester. At the beginning, students seem scared, timid, and unable to organize their time. By the end of the semester, she notices that they are putting everything together, and she can see them really developing. She says, "I love this semester."

The clinical staff nurse also speaks of behaviors in students that signal growth and development. She states that when students start clinicals, they are unsure of themselves. 
However, when students get closer to the end, they take the initiative and do not hesitate to perform skills. She observes. "You can see a big difference."

Even though Kathy's life has been positively impacted by nursing education. her personal life has drastically changed since she began the nursing program. "I really don" have a social life," she says. Before beginning the nursing program, Kathy could spend as much time with her family as she wished. Now, she has a 1-hour round-trip drive every day to travel to elasses and clinicals. On clinical days, she must get up at 4:00 in the morning to arrive on the hospital unit to receive her patient assignment at 6 a.m., review the chart, look up drugs, and prepare a care plan before clinical begins. Kathy says that all of her responsibilities make it more difficult to concentrate on the important people at home, and she sometimes feels that she neglects her marriage or the children. She says that she and her husband argue a lot over "stupid stulf," and this has worsened since she started school. Kathy says that she just does not have time to "... sit down and deal with stuff... I don't have time for this, I've got to go." She explains that she feels that she is either neglecting school or her family. Of this situation, she says "... il' I don't get something done when I'm supposed to, then there is not time to do it again." Kathy sums up how her life has changed from the increased demands on her time: "... I want to be with them [family], but l've got to study or ... go to ... something at school. I just want to have leisure time... Once I got in [nursing program], then there is no leisure time. It"s all work."

Kathy experiences financial strain as well. During an interview, Kathy revealed the state of her linances:

... we live about 30 minutes away and so coming over every day and then the gas ... and trying ... to get money to eat lunch and stuff. Then I ve had to borrow 
stuff from my grandma, and my husband hasn't been working hardly at all ... so. financially ... stuff hasn't been easy. I get one scholarship. and then I have got probably about $\$ 20,000$ in loans already...

When the stresses of clinical gets to her, Kathy's main source of support is her husband. After a demanding clinical day, she turns to him to ventilate her leelings: “... he listens to me and ... we just take a walk at night, and I let my frustrations out. I figure we gotta walk back home, so we might as well talk about something."

Kathy describes her current faculty teacher as a great source of support during clinical. She feels comfortable going to her for help or reassurance. For example, she goes to the teacher when she does not understand questions on a test or for assistance in clinical and says that the teacher, "just kind of gets me going." She describes this support during the performance of a skill. When Kathy had difficulty changing an IV bag, the teacher's words, "We'll do this, I'll help you do this," were comforting to her. Kathy said the faculty teacher held the IV bag for her and walked her through the procedure: *... making sure that I didn't mess up. We kinda got it done together." Kathy further describes the support she receives from the faculty teacher:

... you can ask her something, and she will explain it through and she kind of helps you to understand ... instead of ... sitting there watching you and saying. "well, you should already know that." She is really open to you. She wants to help you learn. She is really good at that.

Post-conference also provides a time for the faculty teacher to ask students about their comfort level in clinical. This gives students an opportunity to share their feelings about their growth and progress. During post-conference, the faculty teacher praises students for improvements in giving report to the clinical staff nurse and recording on the 
MAR.

Kathy divulges that in past clinicals, however, some faculty teachers were not as supportive or available to her:

... my teacher, she just didn't seem like she wanted to show me anything. and I really didn't get to do anything. Or anytime when I would like go and give a shot or try to get the medicines out, and I didn't know ... just trying to get everything together and ask somebody for help.... They just look at you like, "You should know how to do that."

Kathy interacted with one clinical staff nurse during the observations, and describes how she receives support from this clinical staff nurse, as well as previous clinical staff nurses with whom she has worked. Kathy speaks of the especially positive experience when the nurse listened and assisted her with difficult situations and reassigned her to an alternate patient. She says of one nurse in particular, "... [name of nurse] is one of my favorite nurses. She just takes you around and lets you do everything.... I ... just helped her through her day, and I like that because it feels like more of a real experience."

Kathy especially appreciates this nurse and the many like her. She describes the development of a relationship of trust with these nurses which leads to being allowed to do more and learn more in clinical. Of relationships with nurses overall, Kathy says, "Some of them are there to help you learn, and some of them just don "t want to fool wilh you." She describes uncomfortable situations with other nurses:

... when I have to ask her something. I just feel really like I don't get what I need when I do it, because she doesn't want to be bothered or seems preoccupied. She's running off in the middle of me talking. I will be trying to chase her around, 
ask a question; she is always agitated. She won't look at me. She is always doing other things, and she keeps running off from me.

The clinical staff nurse says that lack of time often hinders the ability to effectivcly work with students. When things become hectic, she says. "We don t have the time." The clinical staff nurse says that she enjoys helping students and feels pleased when she hears a student say about working with nurses, "I get to work with a good one. that nice one." The nurse states she sees her role in clinical with students as helping them with "hands on" tasks and learning the "real world" way in the hospital. She states. "I hey learn the most basically in the real world. I mean, how they are secing it here is not what you are going to learn in school... You might have six patients, and it leels like a hundred."

The clinical staff nurse who worked with Kathy describes how she typically supports students who are having a hard time with skills performance or are upset during the clinical:

I just tell them all, "Don't worry about it." I tell them, "By the time you do it a thousand times. you're going to be better." I try to reassure them ... cut up with them and ask them when they are going to be back... If I see that they are having problems with doing certain things, I try to help them with that one thing, and hopefully, if I'm here the next week. well, I probably won't get the same one, but if I ever come across that person again, you know, help them.

During post-conference, the faculty teacher asks students to talk about their favorite nurse. One post-conference activity consisted of asking students to list the characteristics of a good nurse. The many adjectives mentioned by the students included caring, compassionate, competent, courageous, humorous, professional, attentive, 
observant, sweet, ever learning, sharing, and strong. This exercise helped instill the positive traits of the nurse into the students ${ }^{\circ}$ minds and increased awareness of the characteristics the students should emulate.

\section{Patterns of Themes}

Kathy's story, presented in Case B, provides a rich description of her experience in the clinical setting. Predominant themes emanate through this account. Presentation of the identified patterns follow in the next section.

\section{Professionals as Shepherds in a Structured Context}

Kathy began clinicals working according to a routine, meeting her patient, giving medications, and performing assessments. Her capability to grow beyond this basic level does not occur spontaneously. She depends on the clinical staff nurses and the faculty teacher to guide her. In addition, she must draw from previous clinical and classroom experiences. Kathy learns to think critically when she encounters something outside the routine. An example where Kathy is led through a eritical thinking situation is emphasized through a detailed description in her narrative. For example, when she obtained an abnormal blood glucose reading for a patient, she turned to the nurse and the teacher who led her through the critical thinking process. The nurse assisted Kathy in determining the amount of insulin to give the patient and how to troubleshoot problems with the glucometer. The teacher questioned her about why insulin was administered and led her through the process of critical thinking by guiding her in relating knowledge she already possessed. Critical thinking is the process of examining and analyzing a problem, based on one's knowledge and experience to reach a solution. Part of learning critical thinking is hearing others verbalize this mental process. The nurse and the teacher shared their thoughts with Kathy, thereby demonstrating the act of critical thinking. 
Kathy receives intense, one-on-one attention from the faculty teacher and the clinical staff nurse. This assistance does not occur on a superficial level. When Kathy performs a skill or requires guidance in critical thinking, the faculty teacher or the clinical staff nurse devote uninterrupted time by her side. The teacher or nurse, sometimes both, lead Kathy step by step through the procedure or problem solving siluation. During the pre-conference, Kathy is led by the faculty teacher in critical thinking exercises. As Kathy presents the patient she will care for during the day, the faculty teacher interjects and explains her own thoughts, thereby verbalizing the critical thinking process.

Kathy also gauges her personal growth and development by the fact that she has increased confidence in working with patients and the ability and desire to accomplish as much as she can in the clinical. The faculty teacher and clinical staff nurse confirm that Kathy`s increased confidence as well as her ability and desire to perform skills in clinical definitely signify her progress toward becoming a nurse.

\section{Idealism Versus Reality}

This theme lirst arose from interviews when Kathy discussed how clinical work greatly decreased her time with family and friends. Previously, she had only observed what nurses do when her children were cared for in the hospital. After entering the nursing preparation program, she had to deal with the reality of the time demands. Now, in her preparation, she has less time for lamily and friends. Again, she realizes that she musl deal with the reality that clinical work lacks perfection. For example, at times, she observes unkind behavior by nurses toward patients. She also mentions the situation when she was disappointed that she heard the staff and a nurse gossiping about a patient. She also faces the reality that working everyday in the clinical setting can become boring and confining at times, which caused her to ask herself if she really wanted to do this 
work.

In addition, Kathy sees a discrepancy in the classroom simulations. Some of the skills demonstrated or shown on a video in the school lab differ from the way clinical staff nurses perform the skills. Students practice textbook, proscribed procedures in the classroom, but sometimes observe modifications in the practical clinical setting. Adding to this discrepancy, differences in equipment and supplies between the school lab and the hospital clinical can cause distress.

Issues of Trust

Evidence of this theme is apparent when Kathy verbalizes, "I have a problem trusting people." During clinical experiences, Kathy exhibits guardedness when relating to some peers, past faculty teachers, and clinical staff nurses. She voices discomfort relating to some peers who she says "try to make you look bad." Therefore, she becomes cautious in her relationships with other students and has only a small circle of friends with whom she feels accepted. Observations confirm that Kathy is guarded when relating to others as seen in her somewhat questioning, mumbling speech pattern and the fact that unless directly spoken to, she speaks very little. Although she is very comfortable relating to her present faculty teacher, she did not feel the same way about past teachers and felt uncertain about depending on them for help. She expresses wariness when working with some clinical staff nurses. She also feels that sometimes nurses do not want her on the unit and that she is in the way. Therefore, before trusting others in the clinical setting, she remains reserved, while carelully gauging their attitude toward her.

Kathy acknowledged that not everyone in clinical helped her. She discusses being somewhat guarded with people and having only a select group of friends that she feels safe going to for help. Although she has good rapport with the present faculty teacher, 
she recalls less than supportive relationships with previous teachers. In addition, she does not readily interact with clinical staff nurses because she feels that some do not want to bother with her. However, she highly values the positive relationships she has established with nurses in the clinical. Kathy interacted with the same nurse during the observations and especially enjoys working with this nurse. After developing a trusting relationship with this clinical staff nurse, Kathy was allowed to perform additional skills under this nurse"s supervision and reports that she feels more like a real nurse.

This theme was also evidenced from the observation of Kathy caring for the elderly man. Clinical experience can be a somber occasion, but this patient's humor and lightheartedness created a relaxed mood and brought laughter and pleasantness to her day. The patient's funny remarks provided a welcome respite from the usual sedateness accompanying skills performance, such as the dressing change. The humor became infectious and spread to Kathy, the faculty teacher, and the clinical staff nurse, which in turn. seemed to buoy Kathy's spirits as she worked under their supervision. Even though Kathy provided the same conscientious care for this patient as for other patients, the gaiety of the patient produced an atmosphere that temporarily eased the pressure of clinical work and allowed her to feel somewhat relaxed.

During clinical, Kathy follows an expected routine, but when any disruption in the routine occurs, she may be thrown off balance briefly. Whether the clinical stafl nurse or faculty teacher facilitates her learning or ignores her determines if she maintains her work routine. If ignored or unsupported, she has difficulties.

\section{Life of Perseverance}

Kathy's remarkable accomplishment of entering the nursing program seemingly was against the odds. This theme emerged in interviews when she revealed that due to 
marriage and pregnancy in her early teens, the high school principal did not allow her to linish school with her peers. Although this would have presented an insurmountable life changing event to many, Kathy, at such a young age, had the foresight to earn a GED, then go on to enter the university and take nursing prerequisite courses. This presented another obstacle, paying for tuition. Unable to work while going to school and caring for, by then, two children, and her husband not regularly working, she received one scholarship and has already borrowed $\$ 20,000$ in loans.

Kathy overcomes each obstacle in her path in order to succed in the clinical. She must perform many personal tasks before she laves home for the clinical. She rises at 4:00 a.m., dresses in her uniform and wakes up her children to take them where they need to go for the day. She drives 30 minutes to the hospital, early enough to allow time 10 go to the unit, receive her patient assignment, review the chart, look up drugs, and prepare a care plan, before the elinical begins at 7:30 a.m. She overcomes her lack of money by borrowing gas and lunch money from her grandmother. She does what she needs to do in order to arrive at the hospital on time. Overcoming these obstacles presents no easy task; yet Kathy continues, day after day, finding a way to accomplish her arduous work. In addition, she now has no leisure time for herself.

\section{Case C: Susan}

Susan, a 23-year old, single, third-semester nursing student, has short, curly dark brown hair, an upturned nose, and gray-blue eyes that seem to sparkle with vitality when she speaks. She began college at another school as a traditional student and followed the pre-med curriculum for 3 years. IIer plans were to become a pediatrician because she loved children, but she realized how much time and work this educational track would involve: finishing college, medical school, and a residency. She also realized, from 
obscrving a pediatrician, that physicians had only limited patient interaction. She wanted to spend more time with patients and enjoy getting to know them. She really changed her mind about becoming a physician when she heard so many people say that when they were sick, they remembered the nurses who cared for them. She transferred to her present school located away from her hometown and remembers hearing students in her classes discuss the stress of gaining admission to the nursing program. Alter hearing stories of unsuccessful admission attempts, she became apprehensive and waited on "pins and needles" for the results of her application to the nursing program. Documents show that because her GPA was extremely high, she achicved something that she later found out rarely happened--she was aceepted into the nursing program on her first attempt.

Although Susan was certainly accustomed to the rigors of academic work, she was still not prepared for the changes in her life that occurred upon entering the nursing program. She laughingly told her family to just pretend that she was in a coma for 2 years until she completed the nursing degree. Having less time to spend with her family has been a sacrifice for her because she describes herself as a "close-knit family person." Now she must travel to visit the family and feels her immersion in nursing studies costs her family time. She feels that she is no longer as close to some family members and has noticed that these relationships have changed because she has little in common with them and little to talk about anymore when she visits. Family members have difficulty relating to her discussions about nursing of which she says, "That's my life now."

She once enjoyed just sitting at a park, unburdened, but now nursing is always on her mind. She explains. "I have to think about the next test or the next assignment. and it's a lifestyle. You can't just do it halfway." She also reports that she no longer has time for her photography hobby or personal time to reflect on things which she calls "me 
time."

Susan has experienced linancial stress as well. With the demands of classes and clinicals, she has few hours left to work and earn money. Although she receives a scholarship, she must also work to meet her expenses. She reduced the number of work hours because nursing studies placed great demands on her time. Now she makes just cnough to cover her bills. Even if time permitted, she lacks the money to go out and do the things she once did. Overall, Susan thinks the state of her life is a step back; she likens it to a "mudslide" that she cannot get on top of but is carried away. Iowever. she: expresses hope for the future and looks toward graduation when her life will be better without the constant worry of the next test. She describes her life now, "You know ... everything has taken kind of a pause in life right now."

Despite the negative effects that studying nursing has had on her personal and family life, she recognizes positive changes as well. She has learned to use critical thinking, introduced and emphasized in nursing, not only to solve nursing problems but to solve problems in all areas of her life. She says that this ability enables her to view situations from different perspectives and explore all possible outcomes. Before the nursing program, she tended to jump to conclusions without exploring all options. In addition, she has learned to manage her time more effectively using the principles of prioritization, management, and delegation stressed in the nursing curriculum. She also learned to discipline herself to study for the long periods of time required in nursing.

During observations and interviews, Susan articulates her experiences, carefully using proper grammar. She often exudes youthfulness and excitement about learning in the clinical setting and frequently smiles and laughs. For example, she expressed her joy in starting an IV for the first time by stating: .... it is the greatest fecling in the world.... I 
think it's just as amazing every time that I do it." She freely and eagerly shares new clinical experiences with her fellow students. For example, during an observation, the clinical staff nurse working with Susan said to her, "I need a I oppler on the left arm.."

"What's a Doppler?" Susan asked herself. She went to the faculty teacher, who demonstrated the use of the Doppler, an electronic amplification device used to obtain audible pulses that are too weak to palpate. Susan invited other students into the patient's room to share this new skill. She salys of this experience:

My patient was so amazing, and she loved having people come into the room, the more the merrier, and I learned a hands-on skill that I shared with my other classmates. which was ... a big thing for us and if we're doing something that not everybody else is seeing, then we pull them in the room and say, "Look at this." Susan does not show the worry that others seem to show in the clinical setting. In fact, what others perceive as challenges, Susan views as opportunities to fearn. Susan exhibits this enthusiasm for everything she does in clinical and enjoys sharing her experiences with other students, even clinical staff nurses. In one situation, after watching a pacemaker insertion, she excitedly discussed this observation with other students and a nurse, who asked Susan to explain details of the procedure that she had never seen. From interviews she says that sharing experiences is extremely valuable because everyone does not have the opportunity to see every procedure, and she feels that learning from the experiences as well as the mistakes of others can help each student be the best nurse possible. Susan keeps up with fellow students during clinical and asks how they are doing. so that she can judge how she can best help them. She says. "... if I have some free time. I want to be available to help somebody else because ... they help me a lot." Susan's strong feelings about nursing have not waned since beginning the nursing 
program three semesters ago. In an interview, she relates:

I think the desire and the passion is still there and because it ${ }^{\circ}$ so close to the end and ... all the hard work is starting to pay off, and you can see the light at the end of the tunnel. I think my passion is just getting stronger and actually doing the hands on stuff in clinical has made me want it more and be more excited. It's not just book knowledge but actually getting out there and being able to do it and seeing the results of your care. It makes it that much more exciting for me.

Susan's apparent enthusiasm and joy in learning exemplifies the type of behavior that her clinical staff nurse believes is characteristic of students who succeed in clinical. The clinical staff nurse states: "... they really jump in and try to learn things, the want to learn. and they're very confident."

Clinical experience provides a unique type of learning. 'The faculty teacher confirms the power of clinical experience:

It's hands-on for the students.... They can't get everything they need from lecture, and we can talk about things, and until they see it, they can't remember it and apply it. It also teaches them the art of nursing. They can read about the science in a book. but ... to learn about caring, they ... need to experience it with a real live person.

Susan and the other students especially enjoy one particular clinical day:

Halloween. After planning for a week, students in the lab arrive in the cafeteria before clinical laden with bags and bags of candy, wicker baskets, and plastic orange pumpkins. One student wheels in a cart holding dozens of orange iced cupcakes; cach contains a sign attached with a toothpick that reads, "Complements of |raculty teacher's lab|." The students excitedly discuss their plans for dispersing the treats to different places in 
the hospital where they wish to show appreciation to the staff for working with them during the alternate experiences and on their regularly assigned unit. After the faculty teacher arrives, we leave for post-conference and proceed to the Outpatient Department breakroom. The students dump the bags of eandy on a large table and begin filling baskets and plastic pumpkins; there is a fun, festive mood in the air. They prepare a special wicker basket shaped like a pumpkin for the manager of the unit where they spend most of the clinical time. They laugh and say they should attach a note that says, "Thank you for letting us practice on the patients." When everything is ready. the whole group goes out to make their deliveries.

We turn to enter another corridor and one student spies a physician entering the doctor's locker room and says, "There he is!" The faculty teacher marches up to the door and knocks, amid giggles from the students. After a minute, and a second knock, the door opens and a puzzled looking young doctor peers out to see nine nursing students, the teacher, and myself staring at him. A student says, "Happy Halloween; be nice to nursing students!" The doctor looks uncertain, but finally breaks into a smile, takes the bag of candy offered to him and thanks them. From there, the students proceed through the hospital delivering baskets of goodies to various departments. Surprisingly, several employees pass by dressed in costumes: a werewolf, Mimi from the Drew (ary television show, Joe Dirt from the movie of the same name, a pirate, and a Hell's Angel. The students wonder out loud how patients respond to the nurses in costume. The mood remains high and several students break out singing a harmonious, "My. Girl ..." as wo walk through the halls. In an interview, Susan reflects on this experience:

I would say that today was probably one of my favorite days because ... we went around and passed out candy, and that was fun because ... I hate being tied dow'n 
to one thing and just a monotonous schedule... I like mixing it up.... I was living off of adrenaline but knowing that we went around and handed out candy to everybody and got to go to different places in the hospital and I got to see my pediatrics again, which is my favorite, just getting to do that beforc going straight into clinical work.

After walking throughout the hospital, we linally arrive on the unit to begin clinical. The students, still in good spirits, appear pink laced and glowing with perspiration. The group delivers the final baskets to the staff and the unit manager. The students. more settled now, get down to business, find their patient's nurse and receive report. The faculty teacher gathers the students briefly in the break room and instructs them that their focus for the day is nutrition.

Susan and I go into her patient's room: a middle-aged black man who appears very sick, lethargic, and barely responds when addressed. He has an N(i (nasogastric) tube and an IV, each connected to an infusion pump. She goes out to the nurses' station where the faculty teacher reviews the patient's x-rays on the computer screen. Together they read the radiology report which describes a mass on the KUB (kidneys, ureters, and bladder) $x$-ray. The teacher interprets the $x$-ray on the screen. "There is a small bowel obstruction, an ileus. That is when your bowels don't move alter surgery: they are paralyzed." The teacher points to an area in the bowel impacted with leces; the outline of the patient's NG tube is visible. They review the physician's orders lor this patient and lind an initial order for soap suds enemas every six hours. The clinical stall nurse completed the order, but the bowels were still impacted. A clinical stall' nurse tries to retrieve medications from the Pyxis that Susan needs for this patient, while the teacher instructs Susan to review NG tube medication administration. 
Due to a system malfunction, the clinical stall nurse cannot open the Pyxis drawer, so she calls the pharmacist who must come and reset the system. In the meantime, two other students, experienced with the NG tube process, helpfully review with Susan the technique of giving medications through the NG lube. Susan has only performed this procedure on a manikin in the school lab. After a few minutes, Susan obtains her patient's medications. As she compares each medication to the $M \wedge R$, she places a dot next to the drug listed on the MAR. The clinical staff nurse on duty says that she devised the dot system which other nurses and students found helpful and began using the system also. We turn to the background sound of two women from housckeeping laughing and singing, "This Little Light of Mine ...," as they clean a room. Before Susan administers her patient's medications, the teacher pulls her and three other students into another patient's room for a teaching session on NG tube care and medication administration. Susan secures the medications during the teaching session to return to them later. This patient, an elderly woman, has an NG tube through which she receives intermittent feedings. She also has a Foley catheter, an IV, and wears a special hose to prevent blood clots. Although the patient lies in bed with open eyes, she appears unresponsive and apparently unaware of her surroundings as a student bathes her. The entourage of teacher, students, and I interrupt the bath when the teacher begins the question and answer session. Everyone gathers around the bed, intently watching the patient and the teacher as she speaks. The teacher asks, "Tap water or normal saline?"

"Tap water," one student says.

The teacher replies, "Right answer. what do we do first?"

"Check placement of the tube," another student voluntecrs.

In this extended example of helping students learn to think critically, the teacher 
asks, "What with?" and she continues, "Put it on hold; this is a three-way stop cock," and points to the three-way valve connected to the NG tube. The valve serves as an adaptor which may be turned to the on and off position facilitating medication, water, or feeding administration. With gloved hands, the teacher holds the device and demonstrates as she says, "This way is off; this way is open."

"Which way is off?" a student asks.

The teacher shows her again as she commands, "Look at her belly. Get your stethoscope ready. Put in air with the syringe and listen. Do you hear it?"

A student places her stethoscope over the patient's stomach while she injects air through a syringe, hears the gurgling sound, smiles and says, "Yeah."

The teacher asks the other students if they want to listen, and they respond that they do and proceed to take turns listening.

The teacher says. "Check residual--remember how to do it?"

"Aspirate," a student offers.

"We want less than $200 \mathrm{CCs}, "$ the teacher confirms.

"What happens if she has more than 200?" a student queries.

"Call the doctor," the teacher responds.

When a large amount of residual aspirates from the patient's stomach. further feedings need to be held for a while to allow the patient time to digest the contents of the stomach properly. The teacher praises the student checking for residual stomach contents, "She is doing a great job; she's gonna make a great nurse."

Susan helps the student performing the skill by holding the tube for her. The student announces 205 as the amount aspirated, and the teacher directs her to replace the stomach contents back into the patient through the tube. The faculty teacher asks the 
group whether the large volume of medications followed by the considerable amount of water required should be given at this time. The danger of overloading the patient with excess fluid exists because of the patient's slow digestion.

The faculty teacher and students agree that medications should be held at this time, since 205 C Cs residual was obtained. The teacher goes to tell the nurse who soon returns to the room. The clinical staff nurse obviously disagrees with the teacher about holding the patient's medications and says to the students, "There"s nursing and there"s reality to me; I'm sorry." The clinical staff nurse tells the students that each medicine does not have to be followed by a large flush of water like the text book says; they can be given all at once and flushed with a lesser amount of water afterwards. The clinical staff nurse mixes the medications in a plastic medicine cup, draws them up in a syringe and pushes them through the tube. The clinical staff nurse discusses this apparent difference of opinion between the faculty teacher and herself during an interview:

Because they had a residual greater than 150, and they didn't want to overload her ... and their thing ... with the students is that they put water in the med and then they have to flush $30 \mathrm{CC}$ every single time. And she has multiple meds and so that would be well over, putting almost 400 to $500 \mathrm{CC}$ of fluid in her at least and plus the Miralax of 240 , so that would be way too much for that patient to tolerate. Their policy is that they have to do one med, one med, one med; where we put all of our meds in and let them dissolve and give them, and the instructor said they can't do it.

The faculty teacher discusses the above type of situation that occurs in clinical when she has a difference of opinion from the nurse:

... I explain my views to the student, I don't want to tell the nurse that they're 
wrong... Now if it was something about patient safety of course, I would question it .... but if it's just done different ways. in post-conference. we'll talk about it. I try to reinforee the student to think, "Why's she doing it like that?" But then I explain to my students why I think, what I think, and why that might be better.

I laving been sidetracked by the teaching session, Susan is now ready to provide care for her assigned patient. She seeks out three other students who have not yet seen this skill. She, the three students, and the faculty teacher go into the patient's room to administer his medications by NG tube. Susan puts on gloves as the teacher reminds her, "Check for placement; even if you did it 10 minutes ago."

Susan presents a recitation of the medications and justilication for giving them as she auscultates over the patient's stomach and injects air into the tube. Alter she hears the confirmatory gurgle, the teacher instructs her that she does not need to cheek for residual since this patient receives continuous feedings per pump. Susan confidently places each medication in a plastic medicine cup, mixes it with water, injects the medication into the tube with a syringe, flushes with the required amount of water, and clamps the tube for 30 minutes. Nex1, she is ready to hang the IV medication, but the teacher notices no date on the IV lubing, and they go together to get new tubing from the Pyxis. The teacher needs to help another student, and the clinical staff nurse goes with Susan to hang the IV. After attaching a tag to the lubing with the date and her initials, Susan, assisted by the nurse, primes the IV tubing with the bag of medication, connects it to the patient, and sets the pump for the length of time the medication should infuse. She records the administration on the $M \wedge R$ and bathes the patient and changes his bed linens with the help of another student. Alterwards she checks blood glucose with the glucometer and also records the 
result on the MAR.

Susan worked with a different clinical staff nurse on each of the observation days. The possibility of working with a different clinical staff nurse during each clinical creates an additional element with which she must contend. One of the clinical staff nurses with whom Susan interacted explains her philosophy of working with students in the cliniea and how she provides support for student learning:

I think that we give demonstrations of ... how to do things. They can follow and see how you handle situations ... $\mid$ so $\mid$ they can get a first-hand vicw of what happens, as opposed to what you can get in a [school] lab... I just try to always be there and answer their questions. I try to be patient and not impatient.

The second clinical staff nurse who worked with Susan also provided her views on working with and supporting students during the clinical:

They have to get a reality check. What you get in a book, you can be book smat and be absolutely stupid with patients.... If they don "t listen to patients, then they won't be able to help them... You know it's not all Fllorence Nightingale ... it's life... I'll assist them with putting ... Foleys in, making sure IV sites and NG tubes are in the correct spot... Just mainly. they've got the knowledge, it's just breaking it down and finding what they do know.

Susan goes into the break room with the patient's chart and MAR and documents what she has done during the day. She indicates her patient's skin breakdowns by marking these locations on the anatomical figure. She carefully reviews all documents, and the faculty teacher comes in and verifies that all notations are correctly made. The teacher praises her by saying, "Looks like you're rockin' and rollin today!"

During an observation, one of the students complains of not feeling well but she 
does not want to go home and miss a clinical. The faculty teacher allows her to remain in the break room most of the day. Intermittently, during clinical, students come into the break room to check on her; they know she experiences recurrences of a particular condition periodically and plans to see her doctor today. I learn that at this student's request, Susan went into the break room and prayed with her.

One student says to Susan, "You pray so well, how did you kearn to do that?" Susan replies, "It just comes naturally."

Evidently, Susan is known for her spirituality and during interviews she discusses relying on her belief in a higher power in times of need. She relies on this belief during times of pressure and stress in clinicals. For example, she recalls an unsuccessful first attempt at starting an IV, and the dread of having to try again. When she knew that she was assigned to an area that required her to start IVs before patient procedures, she lelt nervous. When asked what she does when laced with these problems and concerns, she responded:

Pray, I'm a ... believer that ... prayer changes things, and it has helped me at times.... I've kind of learned to remember to pray ... before I do a skill and ... if something goes wrong, just try again. If you don't get the IV. just try again... I think it just brings a calming sensation over you, and it helps you to be calm, and it also helps the patient, because if you're stressed out. that patient is going to be stressed out....

Susan not only prays for the patience and ability to perform skills, but for the patient who may be in pain from procedures. She prays that whatever she does will help the patient and asks for God's will in that situation.

Susan's brother serves as another source of support for her. Whilc carcfully 
maintaining patient confidentiality, she relates her accomplishments and challenges about clinical experiences to her brother. Susan's brother celebrates with her when she excitedly shares successfully performing a new skill or procedure. When discouraged from a clinical in which she lacked the ability to complete a task successfully, she turns to her brother for support. She describes how her brother, after hearing her describe a bad day in elinical, possesses the ability to emphasize the positive and minimize the negative aspects of her experiences. He says, "Well, what did you learn though?". This helps her put the day into perspective.

Susan also depends on the laculty teacher for support. She states that the faculty teacher is, in fact, her one most valuable relationship in clinical. Susan feels that in addition to being very knowledgeable in patient care, the teacher takes an interest in what is going on with her, inside and outside of school. She says that the teacher cares about what she is doing in her life, even if she is getting enough sleep. She feels that the teacher holistically cares for students and compares the teacher"s role to that of "Mom." It was the faculty teacher who escorted her to her assigned alternate area and told the nurses that Susan needed to start an IV that day. The nurses there took Susan under their wing and provided great reassurance to her and explained that no one was successful in starting IVs all the time. They also emphasized that no one is perfect and to expect days when you are "off."

Facing her fears proved a very valuable experience for Susan. She described how one day she learned and gained conlidence from successful accomplishments:

... I did two IVs that day, and it helped to build my confidence ... seeing how I had come from being so nervous and so stressed out about it and just picking myself up and going with it and not allowing that to get me down .... 
Susan describes in detail the intricate expcrience of starting an IV:

The hardest part about the IV is finding ... a vein. because it's not something you can always see. It's about feeling and knowing what a vein feels like and that was my biggest concern... It's not nice to have a needle stuck in your arm ... and I'm causing pain to that patient ... but once I put the tourniquet on, it's amazing ... it's like the vein just appears out of nowhere and you can feel it and know exactly where it is and follow it from the angle you need to go in and how deep it is.... I tell them to take a deep breath and ... I just stick it in their arm... Then seeing the blood flash back in that chamber, it's like, "I hit it!" but you can't lose your cool. You know you ve got to go a little bit further with the needle and get the catheter in and just feeling the catheter slide right into that vein and knowing that you actually hit it is the greatest fecling in the world because you don't have to stick that patient again. I think it's just as amazing every time that I do it.

Completing tasks in clinical within a certain time frame becomes an additional source of challenges. This semester, the faculty teacher emphasizes time management and prioritization of care. During an interview, Susan describes a situation when she was put to the test:

... I had a patient that was going down for surgery, and it was my responsibility before that patient went down to get ... all these things done... Once surgery calls and says they're ready, you can't wait. you have to be ready for them... In a span of two hours, I think, one day I had finished a bed bath and all the oral care and skin care and the medication passing... Getting that preop checklist done and making sure that patient was ready to go when surgery was ready for them ... was very, very stressful. 
Susan explains that she sometimes has problems with time management, not necessarily because she is unable to prioritize, but because when other things happen on the unit she runs in and out of other patients rooms to see new procedures.

During post-conference at the end of one day, the faculty tcacher invited a clinical staff nurse, a former student as well, to post-conlerence. The faculty taacher told the students. "I told you I kept in contact with my |former] students and I want $\mid$ nurss | to talk to you and give you some encouragement." This guest nurse talks about her experiences in the preparation program and tells the students that they will make it through the program just as she did. Iler presence demonstrates that students can be successful. At the conclusion of her remarks, this guest nurse tells the students that when she was in the faculty teacher's clinical lab, she and her fellow students did cheers in post-conference like the ones on the TV show, In Living Color. The laculty teacher asked her to go ahead and show the students how to do the cheers. The nurse proceds to do some cheers, which are both funny and a little racy. The students erupt in laughter because the cheers were silly, but refreshing.

Afterwards, the faculty teacher led students in a discussion of a topic divided into pieces of a paper "pie" given to them that moming in preconference. The facully teacher told the students that morning. "We're having apple pie today." This piqued their interest as she gave each student a "slice" of the paper "pie" with instructions written on the back to find information on a patient's condition. Each student reads the condition and reports their findings. Susan also reports her information correctly.

\section{Patterns of Themes}

Through this recountal, several prominent themes arise. The following section elucidates these with respect to Susan's clinical experience. 


\section{Collaborative Learning}

This theme is evidenced from observations and interviews as Susan seizes the opportunity to share learning experiences with her peers. She takes the initiative and brings other students in to patient rooms, so that they may benefit from any new skill or procedure. She seems to make this her responsibility so that other students benefit from new experiences because all learning opportunities are not available to all students. She seeks out her peers when she has a patient or skill of interest to share. For example, she sought out other students who had not used a Doppler before and brought them into her patient's room to observe and perform this new skill. Susan sees these shared experiences as learning to become a better nurse. She also views these shared experiences as an opportunity to learn from one's mistakes and the mistakes of others. She makes a point to notice other students' progress with clinical tasks so that she can offer her help. Susan also shares her belief in prayer with her peers when requested. When another student in the clinical lab was ill, she asked Susan to pray for her. Susan offered a prayer for the student in the breakroom of the unit.

Susan also collaborates easily with the faculty teacher and clinical staff nurses. Susan interacted with two different clinical staff nurses during observations. She approaches these professionals without reservation or fear. She assumes that the faculty teacher and clinical staff nurses do want to help her learn and frecly turns to them for guidance. When faced with a critical thinking or psychomotor task, she initiates dialogue with the teacher or nurse and joins in a discussion about how best to provide patient care.

Susan seems to view the clinical as a social experience for learning. I he clinical becomes a quest for knowledge and insight from anyone who might provide answers for her questions. She shows persistence in her search for answers; she will not give up until 
she knows the correct way to perform in clinical. She learns not only from the faculty teacher and clinical staff nurses, but physicians, technicians, and patients. She views all of these people as participants in her clinical learning experience.

\section{Constancy of Purpose}

Susan demonstrates the ability to stay the course, to strive for her best elinical performance, and to persevere toward completion of the nursing program. Even though she has experienced dramatic changes in her life, such as less time with family, little leisure time, and strained finances, she maintains her resolve to complete the program of study. When stressed because she failed to start an IV the first time she tried, she persevered, kept going, and did not allow this setback to keep her down. Susan also demonstrated perseverance in learning prioritization and time management in clinical activities, even when she felt pressured for time.

\section{Positive Energy}

Through Susan`s story, her enthusiasm and cheerfulness pervaded in whatever she participated within the hospital. For example, Susan exuded excitement on Halloween when she delivered baskets of candy and cupcakes to areas all over the hospital. This activity spread cheer to the recipients as well as to Susan and the whole lab. The hospital employees initial surprised looks were soon replaced by broad smiles as they received a visit from the students. This activity proved uplifting to Susan. The enthusiasm from this event seemed to invigorate her for the rest of the day and positively affected the patients and staff she encountered.

During clinical activities, when Susan is faced with a dilemma or is uncertain about how to deal with a situation, she linds assistance from the elinical staff nurse or the faculty teacher and goes on to her next task. She appears to "go with the flow" and does 
not become bogged down with small deviations from normal and states that she learns from her mistakes. Susan maintains a positive perspective when she confirms her decision to enter nursing. She feels that she is close to the end of the nursing program and all of her hard work is paying off when she says, "You can see the light at the end of the tunnel."

Susan's positive outlook stems from her faith in a higher power, the driving force in her life. $A$ firm believer in prayer, she depends on her faith to help her in times of difficulty. She discusses how her faith and prayer also guide her daily activities in clinical. She prays before performing a skill in clinical, such as starting an IV. She prays not only to have the patience and ability that she needs but for the patient as well. She says prayer gives her a sense of calm. Although not overbearing, Susan freely shares her beliefs with anyone who requests it. When a fellow student was sick, she asked Susan to pray for her. Susan is apparently recognized for her ability to pray in an expressive manner because other students comment on how well she prays.

Susan's interactions with patients also provide positive energy from which she draws to gain confidence in her role as a student. She vicws every patient contact as an opportunity to make a difference in someone's life. She receives positive energy from her brother as well when he helps her to see the positive aspect of clinical situations.

Susan also expresses faith that she will succeed in the nursing program. Although the journey is not easy, she looks forward to the time when she completes her program of study. This vision of the future keeps her motivated because she has faith in a positive outcome when her life will be better and she no longer faces the rigors of life as a nursing student.

Susan, as a learner, exudes excitement and enthusiasm for learning in clinical. She 
emits energy for all clinical activities. She says that she is very eager to leam new handson skills such as understanding what a Doppler is and actually using it to take pulses for a patient. She describes in great detail the experience of starting an IV and calls it amazing. She relates new experiences to other students. Susan says that her passion and desire for nursing is even stronger than when she began the nursing program and that has made her even more excited about what she does in clinical. She states that the opportunity to apply knowledge from the classroom in clinical makes it that much more exciting.

\section{Confident Frame of Reference}

This theme is evidenced when Susan stated that by satisfactorily performing skills, she gains confidence. When she started two IVs after a failed attempt, her confidence was greatly boosted. From observations, Susan seems confident when she performs skills under the watchful eye of the clinical staff nurse or the faculty teacher. She confidently asks questions and engages in discussion with the clinical staff nurses, the faculty teacher, and peers when she needs information or help. She gained confidence in her ability to apply critical thinking not only to nursing situations, but to all areas in her life. This skill enabled her to explore all options in a given situation rather than jump to conclusions. She also gained confidence in her management, prioritization, and delegation skills. Finally, Susan expressed growing confidence in her decision to enter nursing.

\section{The Rescarch Question Considered}

What is the nature of the socialization experience during the clinical laboratory that prepares the associate degree nursing student to enter professional practice? This multiple-case study reports the story of the socialization process of each student. These three cases address the research question and subquestions in story form. 
The themes represent strong threads across each of the student cases. The Ilinshaw Socialization Model $(1976,1986)$ provided a lens for analysis of the emphasis on social learning inherent in the central rescarch question and the subquestions.

Overall, the findings from this study are in agreement with the Hinshaw Socialization Model $(1977,1986)$. Yet the final level of internalization of the standards and values of the role of the nurse, internalization, was not completely achieved. The narratives support that the students accepted the norms and standards of their new nursing role. However, because the three students, at the time of the study, had not completed their nursing preparation program, the students had not yet fully assimilated these norms and standards into their value system. The internalization level (Kelman, 1961) in the last phase of the Hinshaw Model states that the standards and norms of the new role have been incorporated into one's value system. Data from the narrative reports did not demonstrate that the three students in this study had fully developed this level of professional values.

The researcher found that, as in the first phase of the Ilinshaw Model (1977, 1986), Transition of anticipated role expectations to the role expectations of societal group, the three students had entered their nursing preparation program with no previous experience in nursing. Themes from the three cases that illustrated this were Life becomes the clinical, Someone to lean on, Professionals as shepherds in a structured context, and Collahorative learning. For example, the prior learned roles of college student, spouse, mother, sister, and daughter prepared each of the students with a perspective for evaluating the new role of nursing. Fach of the three brought with them their own beliefs about what nurses do and how they act, mainly from observations of nurses who cared for sick family members. In addition, all of the women willingly sought to become socialized 
into the new nursing role when they entered the nursing program.

The three students all demonstrated behaviors consistent with phase two of the Hinshaw Model (1977, 1986), Attachment to significant others/label incongruencies. Again, specific themes from the student cases provide empirical confirmation, Someone to lean on, Professionals as shepherds in a structured context. Idealism versus reality. and Collaborative learning. All students connected and attached themselves with the faculty teacher or a clinical staff nurse in the clinical setting. The students clearly report instances where they identify or label situations that are contrary to what they were taught in the classroom or school laboratory. These situations elicited strong emotional reactions in the students, such as witnessing uncaring treatment of patients.

In the third and final phase of Hinshaw's Model (1977. 1986), Internalization of role values/hehaviors, not all levels (Kelman, 1961) were completely evideneed in the narrative report. This phase incorporates the three levels of opinion change as defined by Kelman: compliance, identification, and internalization. Once again, the themes conlim Hinshaw's Model. For compliance behaviors, Someone to lean on, Professionals as shepherds in structured context, and Collaborative learning demonstrate how all three students carefully performed correct behaviors in order to receive positive responses from the faculty teacher and the clinical staff nurses. The themes, Someone to lean on, Idealism versus reality, Life of perseverance, Constancy of purpose, and Confident frame of reference, demonstrated the behaviors of the three students in the identification level. The students adopted the role behaviors of members of the profession, the faculty teacher, and the clinical staff nurses. The students continue to receive exposure to these role models for the duration of their nursing preparation program. Finally, from the case reports, only some of the behaviors in the third level, internalization. were achieved by 
the three students. Themes that expressed this incomplete transition to the nursing role include Contributors to self-doubt, Issues of trust, and Confident frame of reference. As previously discussed, while the students recognize and emulate the standards of their new role, they have not yet incorporated these standards and norms into their own value system.

\section{Subquestion A}

How does the student experience the social, psychomotor, and critical thinking skills in the clinical laboratory?

The themes in Case A, Life becomes the clinical, Someone to lean on, and Contributors to self-doubt illustrate the manner in which the student experienced the social, psychomotor, and critical thinking skills in Subquestion A. The themes in (ase B, Professionals as shepherds in a structured context, Idealism versus reality, and Issues of trust also answer Subquestion A. Likewise, in Case C, the themes, Collaborative learning, Positive energy, and Confident frame of reference address Subquestion $\Lambda$.

The three students had to collaborate and interact with other students in the clinical group in order to succeed through the clinical educational experience. The narrative report reveals that all three students vicwed the elinical as a shared experience. While Ann and Kathy turned to fewer students during the clinical than Susan, all received and provided assistance to other students during the clinical, even to those who were not their closest friends. All three students practiced independently in the school practice lab with other students and quizzed each other on their skills performance.

The faculty staff nurse and the clinical staff nurses guide the students in the clinical setting. In the school practice lab, the faculty teacher taught psychomotor skills, supervised student practice, and tested students for competency. In the clinical, the 
faculty teacher and the clinical stafif nurses work side by side with the students on an individual basis, directing them step-by-step through nursing care procedures. Through these experiences, the students benefit from role modeling by these nurses and learn the way of the nurse. During these interactions with the faculty teacher and clinical stafl nurses, in addition to learning socialization behaviors and psychomotor skills, the students are also guided through the critical thinking process. Through hearing professional nurses verbalize the critical thinking process, the students learn how to analy\%e clinical problems and arrive at solutions. Incidents in the cases ol both Kathy and Susan specifically illustrate efforts by the faculty teacher and clinical nurses to focus on their students" critical capacities and the students' reactions to these opportunities.

\section{Subquestion B}

What support systems sustain the student during the clinical laboratory experience?

The theme in Case $\Lambda$, Someone to lean on answered subquestion B. In Case B, the theme, Professionals as shepherds in a structured context responds to Subquestion B. The theme, Collaborative learning addresses Subquestion B. in Case C. These themes relate to support systems in the clinical. Sources of support within the clinical were identilied by the students as other students in the laboratory, the faculty teacher, and the clinical staff nurses.

Additionally, all three students identified sources of support outside of the clinical. Through the narratives, the students stated that family members and friends were the people they turned to for support and encouragement outside of the clinical. In addition, the students received reinforement from patients.

\section{Suhquestion C}


How do the faculty teacher and the clinical staff nurse influence student learning in the clinical setting and interaction in the clinical setting?

Themes in Case $\Lambda$, Someone to lean on and Initiative answer Subquestion C. In Case B, the themes, Professionals as shepherds in a structured context, Idealism versus: reality, and Issues of trust respond to Subquestion C. The themes in Case C,

Collaborative learning, Positive energy, and Confident frame of reference answer Subquestion C. Both the faculty teacher and the clinical staff nurses serve as role models to students and structure the clinical to facilitate student learning. The faculty teacher plans and organizes student lcarning in the clinical setting, making clinical assignments according to the students' needs and serving as a student advocate. The faculty teacher may assign a student to work with a particular clinical staff nurse because the faculty teacher believes the student will benefit from this experience or to a patient with a diagnosis that correlates to classroom topics. The faculty teacher represents the nursing program and upholds the ideals taught in the classroom while guiding students in reconciling theory-practice incongruencies. Finally, the faculty teacher plans learning in the postconference where students are debriefed after the clinical experience.

The clinical staff nurses represent the real world of nursing practice and practitioners in the nursing profession. Clinical staff nurses supervise patient care and often mentor students. In addition, the clinical staff nurses assist with student supervision in the performance of psychomotor skills when the faculty teacher is not available.

\section{Across Case Analysis}

Data in all three cases show a growth process from student toward becoming a nurse. Each of the three students shows strong determination, from gaining entry into the nursing program to continued perseverance in completing the program. Ann, Kathy, and 
Susan work diligently to complete their program of study. None of the three students stand still, but proceed dynamically toward their goal of becoming a nurse. Although each case faces challenges, all successfully progress through the clinical. Ann worries during the clinical that she will somehow harm a patient; Kathy experiences great family demands and financial concerns; and Susan experiences a loss of personal time with her family. All make personal and professional sacrifices, but each set their sights on a common goal--completing the nursing program. All three students possess a support system which serves as their source of strength during the journcy through the clinical experience. The following sections detail similarities and differences between each of the three cases.

\section{Background}

Ann, Kathy, and Susan all come to the nursing preparation program with no previous knowledge in nursing. These students came into nursing with an idealistic image of the nurse and the nursing profession solely from observations of nurses. All of these students began their role as student nurse as novices. Caring for patients' intimate needs. interacting with clinical staff nurses, physicians, and other personnel in the clinical setting constituted new experiences for all three students due to their lack of familiarity with professional nursing practice. Therefore, interaction with professionals in the clinical setting represents the means through which these three students learn the way of the nurse and become socialized into the culture of professional practice.

\section{Transitioning into Nursing Role}

Ann, Kathy, and Susan all experience a transition from student nurse toward nurse. The clinical experience represents a journey through which the student learns the way of becoming a nurse. The three students recognize their own progress by the small 
victories they celebrate. When they are successful while performing a skill, learning a procedure, or understanding a difficult concept, they take a step toward becoming a nurse. The clinical experience takes over, to the exclusion of their personal lives. Ann, Kathy, and Susan made great sacrifices to complete the nursing program, but did so willingly. They are single-mindedly dedicated to their goal of becoming a nurse. Therefore, they are committed and willing to persevere because at this time, becoming a nurse necessitates this way of life.

\section{Determination}

Ann lost her job in the factory and entered a new world when she enrolled in college and began the nursing prerequisite courses. She did not give up when her first application attempt to the nursing program proved unsuccessful. She consulted with the academic advising office at the university and discovered how she could overcome her poor academic record from the past. She declared academic bankruptcy, which wiped away her poor grades. She gained admission the second time she applied to the nursing program. Ann continues to show the same determination to succed in her nursing studies. She demonstrates willingness to do whatever she needs to do to succeed. She comes to the hospital the evening before the clinical to obtain her patient assignment, review the patient's chart, and complete necessary paperwork. Then, when she returns home, she looks up drugs, writes a care plan, and in addition, studies for several hours. She anticipates obstacles, such as making sure her scrubs fit in preparation for the clinical.

Even though Kathy did not finish high school, she showed determination to obtain an education and completed the GED requirements. She kept trying to gain admission to the nursing program after one unsuccessful attempt. She completed all nursing 
prerequisite courses and successfully applied a second time. Although she lives 30 minutes away from the clinical site, she arrives on time for the clinical. She must rise very early in the morning and make arrangements for her children's care before leaving for clinical. With little money and her husband often unemployed, she borrows money from her grandmother for gas to drive to clinical and for lunches. In addition, her student loan debt approximates $\$ 20,000$. She arrives at the hospital before clinical to allow time to receive her patient assignment, write the care plan, and look up drugs.

Susan transferred from another school and moved away from her hometown to attend nursing school. She works as much as possible in order to cover her expenses. She misses the closeness to her family. Now she must travel when she wants to visit them. She does not allow a discouraging day in clinical to get her down; she keeps trying and tries to keep a positive perspective. She possesses the attitude that she and her peers experience the clinical together and shares her new experiences freely.

\section{Support Facilitalors}

The three students depend on their own support systems to sustain them through the rigors of the clinical experience. During the clinical, all three turn to the faculty teacher for assistance, guidance, and moral support. The faculty teacher offers praise when the students perform well in the clinical and provides support when they experience difficulty and become discouraged. The faculty teacher views the purpose of the clinical as the opportunity for student nurses to apply theory to practice. She sees her role in the clinical as a facilitator to ensure that the needed information and knowledge is obtained. The faculty teacher describes the clinical as fun and relaxed, but educational. She likens the clinical experience to jumping into a pool and learning how to swim. The faculty teacher is empathetic to students and realizes that they often experience sensory overload 
because of all of the demands placed upon them. When students experience difficulties during clinical and become overwhelmed, she talks to them to see if she can help. While kind and understanding, she also has rigorous expectations of students. Iler standard response to unprepared students is "You're fired!"

The clinical staff nurses also provide support and encouragement to the students in the clinical setting. Ann and Susan interacted with two different clinical staff nurses on each observation day, while Kathy interacted with one nurse during the observations. A more detailed account of Kathy's interaction with a clinical staff nurse was provided in the narrative to illustrate how she was led through a critical thinking situation. The clinical staff nurses accompany the students when they perform skills or procedures and provide assistance and confirmation that the students are learning the norms of nursing. The clinical staff nurses also demonstrate to the students that perfection is not always expected in clinical performance by assuring the students that the clinical staff nurses themselves continue to face challenges in working with patients. The five clinical staff nurses all demonstrated strong similarities in their view of their role in working with students. All of these clinical staff nurses recognized that their contributions to student learning in the clinical are very important and represent a significant impact on student learning. Through interviews, these nurses expressed caring and understanding of students as they experience the clinical. 'They also demonstrate a genuine desire to support and facilitate students as they learn in the clinical setting.

Fellow students in the clinical play a significant role in providing the support necessary to sustain the three students during the rigors of clinical experience. Lach freely turned to one another and other students when assistance with patient care or an answer to a question was needed. Although the students have certain friends with whom 
they have closer relationships, they envision themselves as a collective unit, ready to come to each other's aid.

Interactions with patients in the clinical setting also serve as a source of support for the three students in the study. When these students receive praise, a smile, or affirmation from patients, this reinforces their confidence that they are becoming a nurse.

Outside the clinical, Ann finds support from her husband who helps just by listening to her concerns and allowing her to ventilate her feelings. Kathy's husband provides her main source of support outside of the clinical. She unburdens herself about the clinical day when they take walks together. Susan turns to her brother for support outside the clinical. He helps her to see the positive aspect in situations she encounters. She also possesses a deep faith in a higher power and turns to prayer when she needs help in clinical.

\section{Idealism Versus Reality}

Each of the three young women must face the reality of clinical practice. Ann feels that the school practice lab does not always realistically prepare her to perform hospital skills. She becomes disillusioned at the impersonal, insensitive treatment of patients she has witnessed. She must cope with some unpleasant aspects of working closely with patients, such as offensive odors. She also worries that some patients do not want a student nurse and may reject her.

Kathy faces the reality that some clinical staff nurses may not want her on the unit and may not want to help her learn. She also witnessed cold and impersonal tratment of patients by nurses and other hospital stafl.

Susan faces the reality that she may not be able to perform skills the first time she tries. For example, she unsuccessfully tried to start two IVs one day in clinical. Susan 
possesses a positive attitude and keeps trying to be successful. She will nol give up until she can perform a skill adequately. She demonstrates confidenee that she will succed. Because of all of the demands of nursing preparation, Susan must also cope with lack of time to spend with her family.

\section{Changes in Social Interactions}

Ann lacks time to spend with her family and friends. Ilowever, she receives a full scholarship for her nursing studies, which alleviates financial concerns. Kathy's decreased personal time causes her to feel neglectful of her two young children and husband, and she no longer enjoys leisure time for herself. She must make childeare arrangements before driving 30 miles to class or clinical. Susan expresses concerns because she no longer lives close to her family and misses them. Time constraints allow her no leisure time for herself and she no longer enjoys time for hersell when she can just reflect. She must continue to work as much as possible to meet her expenses. Ilowever, she barely makes enough to pay her bills and cannot work as much as she needs for entertainment moncy.

Interviews and observations also revealed differences in findings between the three cases. The following section presents the prominent differences in the stories of Ann, Kathy, and Susan.

\section{Individual Perspectives}

Ann feels anxious while performing skills. She fears that she will somehow harm the patient or invade their privacy. When questioned and closely supervised by the faculty teacher, she fears that she may be incapable of performing each skill correctly. She worries about being judged by some pecrs in clinical.

Kathy, by her own admission, does not readily trust others. She fears that the 
clinical staff nurses may not welcome her on the unit. She also expresses concern that her peers, past faculty teachers, as well as the clinical staff nurses have not always wanted to help her. Because of this concern, she becomes guarded in her relationships.

Susan demonstrates confidence that she will succed in the nursing preparation program. When she faces difficulty in the clinical, she immediately regroups and prepares to try again. She does not allow a setback to immobilize her. She has the attitude that she will do whatever is necessary to suceced.

\section{Relationships in Clinical}

Ann turns to the faculty teacher and fecls safe approaching her when she needs assistance in clinical. Ilowever, Ann sometimes feels discomfort when questioned and watched by the faculty teacher. The faculty teacher provides Ann with comfort and reassurance during stresslul times. $\Lambda \mathrm{nn}$ also depends on selected pecrs in clinical when she has a question or needs help with a patient.

Kathy admits difficulty in trusting others. She interacts only with a small circle of peers in clinical. Although she feels comfortable with the present faculty teacher, she expresses reluctance to interact with teachers in the past. Kathy warms up to clinical stall nurses who show an interest and help her learn. However, she watches and waits until she determines their intention before she trusts them. Susan interacts easily with all of her peers in clinical, the clinical staff nurses, the faculty teacher, patients, technicians, and physicians. In fact, she seems to thrive in the clinical, which she views as a social setting. She shares her ideas and asks questions of her peers and professional stalf without reservation.

\section{Summary}

Findings from this study represent the experiences of three students in the clinical 
laboratory as they learn to become nurses. Each case presents a picture of a student's personal life as well as the life of a student nurse. The within-case themes highlight the specific individual personal experiences of the students. The across-case themes emphasize similarities that become strong indicators of the clinical experience for these three students. The differences across the cases also point to how different people with different problems and perspectives continue to succecd.

\section{Case A: Ann}

Ann entered the nursing program as a second career, after the factory where she worked for several years, closed. During her transition to the new world of nursing, she faced some obstacles. After a second attempt, she gained admission to the nursing program. Ann's life changed dramatically when she became a student nurse. Her time was consumed with preclinical preparation, the twice weekly clinicals, classes, and studying for tests. She was left with little time for family and friends. $\Lambda \mathrm{mn}$ seemed to experience anxiety and discomfort during the clinical experience and worried that she would somehow harm a patient. She demonstrated a strong determination to succeed in the clinical. She relied on the faculty teacher, the clinical staff nurses, and selected peers for support during the clinical. Outside of the clinical, Ann's husband was her main source of support. An overview of the within-case themes follow.

\section{Life Becomes the Clinical}

Ann was required to attend clinical twice a week in the hospital in addition to classes at the university. Before each clinical, she went to the hospital the day before the clinical to obtain her patient assignment. After spending a couple of hours on the unit, recording pertinent information and reviewing the patient's chart. she returned home. where she spent several more hours, looking up the drugs she was scheduled to 
administer, writing a care plan, and beginning the physical assessment form. With the study time required in her elasses, she felt that all of her time was consumed by nursing, preparation. As a result, $\Lambda \mathrm{nn}$ 's personal relationships were affected because she had little time to spend with her husband, family, and friends.

\section{Someone to Lean On}

To sustain her during the demands of the elinical, $\Lambda \mathrm{nn}$ turned to selected peers, the faculty teacher, and the clinical staff nurses. These peers were people with whom Ann felt safe asking questions, without the fear of ridicule. She viewed the faculty teacher as a constant source of support and assistance during clinical. She received praise and consolation from the faculty teacher when she needed it. The faculty teacher"s "no stress" policy enabled $\Lambda \mathrm{nn}$ to feel more comfortable in the clinical. The clinical stafl nurses made themselves available to her to offer advice and to accompany her to perform psychomotor skills when the faculty teacher was busy with other students.

\section{Contributors to Self-Douht}

Ann's feelings of apprehension, anxiety, and dread regarding patient interactions and skills performance led to her self-doubt. She feared that she would somehow harm a patient when performing a skill or violate their privacy as she provided personal care. She dreaded the possibility of performing skills and experienced self-doubt that she could adequately perform the skills correctly. $\Lambda \mathrm{nn}$ expressed that she was often overwhelmed by the amount of work that she had to complete, which also added to her feelings of selfdoubt.

\section{Initiative}

Ann demonstrated initiative when she identified and headed off difficulties associated with the clinical experience. When she recognized that she might not have 
scrubs to fit her, she went to her faculty teacher to investigate the possibility of purchasing her own scrubs. She also showed initiative when she was unsuccessful in gaining admission to the nursing program the first time. She contacted the Academic Advising Office at the university and discovered that she could void her poor grades with academic renewal.

\section{Case B: Kath}

Kathy was married, with her first child, when she was in her early teens. She did not complete high school, but earned a GED instead. She overcame multiple barriers to enter and remain in the nursing program. She was not accepted on her lirst application attempt, but reapplied and was successful. She lived 30 miles away from the hospital and the university. This meant that she needed to rise at 4:00 in the moming on clinical days to prepare herself and her children and make childcare arrangements before leaving home. Kathy also faced financial hardships in order to pay for her education. She had significant student loans and had to borrow additional money from a family member. By her own admission, she did not readily trust others. Consequently, her relationships in clinical were guarded. The within-case themes are elaborated on in the following section. Professionals as shepherds in a structured setting

Kathy depended on the faculty teacher and the clinical staff nurses, not as only an available resource, but to provide intense, one-on-one guidance in clinical activities. The faculty teacher and the clinical staff nurses accompanied her and led her step by step through a procedure or problem solving situation, focusing on critical thinking as they did so. Kathy credits her growth and development as a student nurse to this mentoring and guidance she received from these nursing professionals.

Idealism Versus Reality 
Kathy describes several areas in her life where she perceived a discrepancy between what she thought becoming a nurse would be like and what she found in reality. Before entering the nursing program, she only had observations of what nurses do to rely on. She had to reconcile that idea with the reality of the huge amount of time required to become a nurse. She had much less time to spend time with her husband, children, and friends after she began the nursing program. She also had to deal with the reality that clinical work lacks perfection. When she witnessed uncaring treatment of patients by nurses, she felt disappointed that this behavior was not according to her ideals of what nursing would be like. In addition, Kathy perceives a discrepancy between the way she learned skills in the school practice lab and the way the skills were performed during clinical.

Issues of Trust

Kathy was guarded in her relationships in clinical because she had a problem trusting people. As a result, she carefully selected peers with whom she reacted during clinical. Although she had a good rapport with the present faculty teacher, she recalled less supportive faculty teachers in past clinicals. She also did not readily interact with all clinical staff nurses because she felt that some did not want to be bothered with her. However, she developed positive relationships with a few clinical staff nurses because she felt that they showed an interest in her.

\section{Life of Perseverance}

Kathy demonstrated perseverance in entering and remaining in the nursing program. She was married and pregnant in her early teens and was not allowed to finish high school. She had the foresight to earn a GED and enter the university to take the nursing prerequisite courses. By then, she had two children and was unable to work. Her 
husband was often out of work as well. This forced her to apply for student loans, which eventually totaled over $\$ 20,000$.

Because of her daily commute to the hospital and the university, she had to rise very early in the moming on clinical days to prepare herself and her children before she left home. She was still forced to borrow money from her grandmother for gas and food.

\section{Case C: Susan}

Susan, a traditional college student, transferred from another school to enter the nursing program. She was accepted into the program the first time she applicd, due to her high GPA. She moved away from her family to begin nursing studies and could no longer spend as much time with them as she liked. Although experiencing some anxiety when faced with challenges in the clinical, she displayed a positive, confident outlook. She viewed the clinical as a social setting for learning and freely interacted with all of her peers, the faculty teacher, the clinical staff nurses, and patients. Her major source of support for the rigors of the nursing program was her brother. A discussion of the withincase themes follow.

\section{Collaborative Learning}

As stated earlier, Susan seized any opportunity to share learning experiences with her peers. She sought out fellow students when she thought they could benefit from observing a skill or procedure on her assigned patient. Susan approached the faculty teacher and the clinical staff nurses without reservation when she needed help or guidance. She freely asked questions and initiated a dialogue with these nursing professionals. She showed persistence in learning the correct way to perform procedures and solve problems. She exhibited determination in learning and included the faculty teacher, the clinical staff nurses, patients, technicians, and patients as participants in her 
learning environment.

Constancy of Purpose

Susan demonstrated determination to stay the course and to strive for excellence in her clinical performance. She would not give up when faced with challenging situations in the clinical. She realized what she needed to do and did not allow any setbacks to keep her down.

Positive Energy

Susan's enthusiasm pervaded all that she did in the clinical. She showed excitement in all clinical activities and was an inspiration to other students because of her positive outlook. This perspective stemmed from her belief in a higher power and she relied on her faith to sustain her through challenging times. She viewed every patient contact as an opportunity to make a difference in someone's life. In addition. she received positive energy from her brother who helped her to see the positive aspects of clinical situations.

\section{Confident Frame of Reference}

Susan gained confidence with each successful skill or problem solving attempt in the clinical. As she learned to perform skills under the guidance of the faculty teacher or the clinical staff nurses, she confidently asked questions and engaged in discussion. She gained confidence in her ability to apply critical thinking, not only to clinical situations, but to all areas of her life. She gained confidence in exploring all options in a given situation, rather than jumping to conclusions.

\section{The Research Questions Considered}

The central research questions and the subquestions are addressed in the following section. 


\section{The Central Research Question}

What is the nature of the socialization experience during the clinical laboratory that prepares the associate degree nursing student to enter professional practice?

This multiple-case study answered this question by reporting the socialization process of each student. The IHinshaw Socialization Model $(1976,1986)$ provided the lens through which the central research question, as well as the subquestions were analyzed. The three students demonstrated behaviors consistent with the IInshaw Model. Iowever, it could not be determined if the internalization level (complete socialization), the last phase of the model, was fully attained by the students because their professional value systems are not yet completely developed, due to the fact that their nursing preparation was not finished. This study examined a segment of time within the preparation and does not follow the student through the completion of the course or program.

\section{Subquestion A}

How does the student experience the social, psychomotor, and critical thinking skills in the clinical laboratory?

The three students collaborated with other students in the clinical setting. In addition, the students were guided step by step through clinical procedures and critical thinking activities by the faculty teacher and clinical staff nurse. Through these experiences, the students benefited from the role modeling from these professional nurses

\section{Subquestion B}

What support systems sustain the student during the clinical laboratory experience? 
Sources of support in the clinical setting were identified by the three students as other students, the faculty teacher, the clinical staff nurses, and patients. In addition, understanding and concern from family members was crucial in each case in order to meet the pressures inherent in a demanding course of study and the acquisition of new skills in dealing with patients in a profession in which decisions can literally have life or death consequences.

Subquestion $C$

How do the faculty teacher and the clinical staff nurse influence student learning in the clinical setting and interaction in the clinical setting?

Both the faculty teacher and the clinical staff nurse serve as role models to the students and play an important role in structuring the learning environment. The faculty' teacher makes clinical assignments according to student needs and to correlate with classroom topics. The faculty teacher upholds the ideals of the nursing program and guides students in reconciling theory-practice gaps and in mastering the critical thinking that underlies the nursing curriculum. The clinical staff nurse supervises and mentors students in the clinical environment and represents the real world of nursing.

\section{Across-Case Analysis}

All three cases provide evidence that the students are in the transitional process of becoming nurses. Ann, Kathy, and Susan showed determination and perseverance in entering and remaining in the nursing preparation program. $\Lambda 11$ made sacrifices and possess the common goal of successfully completing their education and becoming nurses. All describe support systems that sustain them during the rigorous clinical experience.

The narrative report included similarities between the three students. $\Lambda$ ll had the 
common background of entering the nursing program with no previous knowledge in the field. They all had a preconceived, idealistic view of the nursing profession. The clinical experience and the interactions during clinical represent their socialization process (while not complete) into the culture of the nurse.

The students experienced a similar transitioning into the role of the nurse. They each identilied and recognized their progress in becoming nurses by their successes, which signified their progress toward learning the day-to-day routines of nursing. The clinical experience took over, to the exclusion of everything in their lives, yet they remained committed in their work in order to become a nurse.

The students exhibited strong determination to succeed. In spite of challenges in beginning the nursing program or the setbacks they encountered during the clinical, they each found a way to continue and refused to give up.

All students had support facilitators that enabled them to persevere during the clinical. In the clinical, the faculty teacher, peers, the clinical staff nurses, and patients provided encouragement and assistance. Outside the clinical, cach student had a family member who supported them by listening to their concerns and allowing them to ventilate their frustrations as well as share their victories in the elinical.

The students all faced reality versus idealism when they had to adjust to the fact that actual clinical practice did not always correspond to the ideal of classroom learning. The students expressed shock and disappointment regarding their experiences in the clinical setting.

All students experienced changes in their social interactions after beginning the nursing preparation program. While some students had more personal responsibilities, all experienced a lack of time to spend with significant others. In addition, none of the 
students had time for leisure activities.

There were differences in the individual perspectives of the three students. Ann felt the most anxiety in the clinical setting. She feared that she would somehow do something to harm a patient. Iler feelings of anxiety contributed to her feclings of selfdoubt. Kathy experienced difficulty trusting others and this feeling was reflected in the relationships she developed in the clinical. Because of past experiences, when she perceived that others did not want to help her, she remained very selective in her interactions. Susan demonstrated confidence in her ability to succeed. She possessed the attitude that despite setbacks, she would persevere. When she faced difficulty, she regrouped and tried again.

Other differences surfaced between the three students in the relationships they developed in the clinical. Although Ann approached the faculty teacher when she needed help, she sometimes felt uncomfortable when questioned and scrutinized by the faculty teacher. She had a small circle of peers with whom she interacted. Because Kathy admits that she did not readily trust others, she also formed relationships with a small circle of friends, the faculty teacher, and selected clinical staff nurses. Susan, on the other hand, freely interacted and established relationships with everyone in the clinical setting. 


\section{CHAPTER $V$ \\ DISCUSSION AND CONCLUSIONS}

\section{The Study in Brief}

Previous studies have focused on various aspects of clinical nursing education (e.g., Chapman \&: Orb, 2000; Dunn \& Burnett, 1995; Jacobson, 1966; Massarweh, 1999; Thorell-Ekstrand \& Bjorvell, 1995; Windsor, 1987). The clinical portion of nursing education comprises twice as many hours of the nursing curriculum as the classroom portion (Vollman, 1989). Student nurses who work with actual patients in the clinical practice setting have the potential to make serious mistakes that can cause injury or death (Chapman \& Orb, 2000). Yet this "real world" experience is essential to student learning. For this reason, clinical education represents a vital but complex environment.

Clinical nursing education not only provides students the opportunity to apply theory learned in the classroom, but serves as the setting that contributes to the socialization of students into nursing practice (Hinshaw, 1976, 1986: Thorell-Ekstrand \& Bjorvell, 1995; Windsor, 1987). Members of the profession mentor students to show them the ways of the nurse (Hinshaw, 1976, 1986; Jeffreys, 2004). Although clinical education remains crucial to nursing preparation, the beginning nursing student confronts many problems and works under a number of constraints during clinical experience (e.g., interpersonal relationships with patients, performing psychomotor skills, and developing critical thinking ability) all while under the scrutiny of both the faculty teacher and the clinical staff nurses (Chapman \& Orb, 2001). The complexities and challenges of the 
clinical learning environment are reported in the literature as contributing to students" dropping out of their preparation programs (Boyle et al., 1996; Pringle \& (jreen, 2004).

The critical part the clinical component plays in nursing preparation makes understanding the clinical environment important, especially in light of the current nursing shortage $(\Lambda \Lambda C N, 2001,2002,2005)$, with an estimated need for more than one million new and replacement nurses by 2012 (United States Bureau of Labor Statisties, 2005). Previous research (Norman et al., 2005; Vollman, 1989) suggests that further study of the clinical environment is needed to shed light on improving retention in nursing programs, and ultimately addressing the current nursing shortage. Therefore, the present study explored the experiences of nursing students in the clinical and addressed the central research question, "What is the nature of the socialization experience during. the clinical laboratory that prepares the associate degree nursing student to enter professional practice?"

Nursing program administrators, faculty teachers, and clinical stalf nurses may obtain a clearer understanding of what happens to nursing students in the clinical setting from the findings of this study. This new knowledge may aid in the development of nursing programs that are sensitive to the needs of students. The Hinshaw Socialization Model (1977, 1986), which proposes an explanation of socialization into the professional nursing role, provided the theoretical framework to guide this study. Within the context of this understanding of the socialization of student nurses, the purpose of this study was to describe three associate degree nursing students in the clinical setting. This study was a qualitative, multiple-case study design. $\Lambda$ fter observations, each student nurse expressed her views of clinical experience during the research interviews. The views of the faculty teacher and clinical staff nurses in the hospital learning environment also provided 
multiple insights within each case and offered a wider range of information about the clinical experience.

$\Lambda$ fter meeting Institutional Review Board requirements for human subjects at the University of Louisville and Western Kentucky University, the researcher obtained permission to conduct the study from the nursing program direetor and the hospital administration. The researcher met with the clinical lab to explain the study and asked for volunters to participate. These students completed a screening questionnaire developed by the researcher. In order to gain consensus regarding the "typical cases" for this study. a list of criteria for selection of the students based on professional experience was developed and submitted to three associate degree nursing faculty members. These faculty members reached agreement on the appropriateness of items. Based on this list, the researcher developed a student screening questionnaire to identify the cases, those most likely to disclose information about their clinical experience, and those who had the intent to remain in the study until the conclusion. Three students, plus an alternate, were selected to participate in the study. These four students received notification of their selection in person.

Following an observation of each student in the clinical setting, the researcher conducted the first interview with each student (all names in case studies are pseudonyms). Subsequently one interview was conducted with the faculty teacher who supervised all three students following the first student interview as well as the clinical staff nurses who interacted with each student during the lirst observation. Following a second observation with each student in the clinical setting, the researcher interviewed each student for a second time. Additional elinical staff nurses were also interviewed when any of the three students interacted with a different clinical staff nurse during the 
second observation. The semi-structured interview questions, developed by the researcher, followed the guidelines of Merriam (1998) and Spradley (1979). The less formal, open-ended questions allowed the participants to select how to present the information as well as the type of information (Merriam). All interviews lasted approximately 45 minutes to 1 hour, were tape recorded, and transcribed. Documents, such as course syllabus, clinical assignments, and student academic transcripts were also examined. Field notes were recorded during observations and mining of documents.

At the end of each data gathering session, the researcher processed that information by typing field notes, transcribing interviews, as well as writing in the reflexive journal. The researcher began coding the data by dividing the prepared text into segments of meaning. Using the constant comparative method, the researcher began open coding by placing the cards into categories that related to the research questions. Each segment of meaning was compared to the previous segment and assigned to an established category or new category. When all cards were assigned to a category, the researcher examined, arranged, and rearranged the cards within the categories as necessary.

Next, the researcher began axial coding by determining links between categories. as related to the research questions. Lastly, using the ideas generated from the linkages in axial coding, the researcher constructed an explanation or story that identified themes or patterns of meaning that indicated how the categories addressed the research questions. From the categories, the researcher constructed case stories. These cases report the socialization progress of each student during the clinical and address the purpose and research questions. Across-case analysis was performed in order to draw conclusions about the similarities and differences across the three cases. This enabled the researcher 
to develop conclusions regarding the clinical experience in nursing.

\section{Discussion}

This qualitative, multiple-case study included the perspectives from the nursing students, the faculty teacher, and clinical staff nurses, and provided a comprehensive picture of the experiences of students in the clinical environment. The findings represent a departure from narrowly focused quantitative studies as well as qualitative studies of single cases. This study presents findings from the rich, descriptive account of the lived experience of clinical experience. While other studies report categories, percentages, and focused variables, this study focuses on three individuals, their personal lives, their work in the clinical setting, and the post-conference.

Most previous studies on nursing clinical experience used quantitative methodology, thus limiting subjects' responses to pre-existing categories on questionnaires (e.g., Jacobson, 1966; Kim, 1997; Knox \& Mogan, 1987; Kushnir, 1986; Timmins \& Kaliszer, 2002; Wong, 1978, 1979). The quantitative researchers asked participants to choose from a list of items. Participants could only select from choices given. The researchers expressed the findings in percentages related to these pre-existing categories. Many of these studies centered on nursing students' perceptions of the clinical teachers who guided the clinical experience (e.g., Cooper, 1982: Jacobson, 1966; Kiker, 1973; Lowery et al., 1971). Others included both the perceptions of students and the perceptions of the clinical teachers (e.g., Mogan \& Knox, 1987; Pugh, 1988). Few studies included the role of the clinical staff nurse in nursing education (e.g., Campbell et al., 1994; Dunn \& Hansford, 1997).

Although extending knowledge in nursing clinical experience, these research findings did not allow for an understanding of experiences from individual perspectives. 
In this qualitative study, interview questions encouraged cach student nurse to tell about the clinical, using her own choice of words. Students expanded and explained each query as they perceived necessary to describe their situation. For example, when Ann was asked to describe a typical clinical day, she revealed her feelings of tenseness and fear of having to perform a skill in clinical.

Several other studies in the literature contained qualitative elements, which described specific aspects of nursing student clinical experience (e.g., Beck, 1995; Williams, 1993). However, only three case studies (DiGiacomo, 1993; Glover, 2000; Hamill, 1995) were identified that focused on the nursing student in the clinical setting and only one included the faculty teacher (DiGiacomo). No studies were identified that included students, the faculty teacher, and clinical staff nurses. Glover interviewed students regarding their perceptions of feedback from the staff registered nurse and the clinical teacher. Hamill investigated students' stressors in the classroom as well as the clinical environment. DiGiacomo cxamined the clinical cxperience in one facility.

The present case study adds comprehensive knowledge to the body of research on the nursing student's clinical experience. This multiple-case study research provides a more intensive, holistic description of their lived experiences. The students gave firsthand accounts of their time inside and outside of the clinical. Previous research utilized only the single-case design. This study dramatizes the lives of the three nursing students, along with information from the faculty teacher and clinical staff nurses and relates what the students are thinking, feeling, and learning. This study represents the only identified multiple-case study that explores an on-going clinical experience of students with the inclusion of multiple sources--the faculty teacher and the clinical staff nurse--at the same time. In addition, this multiple-case study provides greater variation across the cases and 
a more powerful interpretation of data than the single case allows (Merriam, 1998)

Utilizing the student nurse as the primary unit of measure, plus the nursing faculty teacher and clinical staff nurses, provided data that more fully inform each case. The three narratives, plus the perspectives of three students, one faculty teacher, and five clinical staff nurses, led to a richer, more comprehensive description of clinical nursing experience than obtained from a single case study.

Previous research (e.g., Admi, 1997; Beck \& Srivastava, 1991; Klechammer et al., 1990; Kushnir, 1986; Pagana, 1992; Williams, 1993) focused mainly on problems experienced by nursing students in clinical experience. Participants selected problems from a list of items, but were not provided an opportunity to elaborate on causes and difficulties. In this multiple-case study, the students told their stories in their own words, without prompting. They shared their positive, as well as negative perceptions about the clinical experience.

This case study emphasizes the importance of the relationships with the faculty teacher and clinical staff nurses. Through the intense, one-on-one guidance provided by these professionals, students learn psychomotor skills and learn the routines and attitudes of the nurse. As the faculty teacher and clinical staff nurses verbalize their thoughts, stepby-step, while problem-solving or performing a skill, the students develop and strengthen their critical thinking abilities. The close relationships that students develop with the faculty teacher and the clinical staff nurses and the way that critical thinking evolves is introduced, but not explored and emphasized in the literature.

The researcher identified specific themes for each case. In the following sections, these themes are introduced, described, and analyzed.

Case A 
Through observations, interviews. and mining of documents, a narrative of Ann's experience in the clinical was developed. The within-case themes emerged from this narrative and are discussed in the next section.

\section{Life Becomes the Clinical}

Ann's story describes the all-consuming nature of the clinical experience. $\Lambda$ similar finding was identified in Williams' (1993) study focusing on concerns of beginning nursing students. Difficulty of clinical work was cited by students as a major concern. Kim (1997) also found that students cited pre-clinical preparation as a major source of anxicty. Beck (1995) found that students described clinical work as physically debilitating and causing them to feel as if they are drowning and unable to keep their heads above water. Kane (1998) cited long hours of study as one of the most highly rated sources of student stress in nursing preparation. Jones and Johnston (1997) reported lack of free time as a student source of stress. Beck (1995) noted that students felt engulfed by demands and time pressure. The findings from these previous studies are consistent with the theme, Life becomes the clinical.

\section{Someone to Lean On}

Ann describes support systems that sustain her within and outside the clinical experience as fanily, friends, peers in clinical, the faculty teacher, and the clinical stall nurses. Students in a study by Carter (1982) cited availability and use of significant others as means of coping with stress. Hamill (1995) found that students developed supportive networks with peers more so than with family members in stressful situations. Students in Hamill's study reported that discussing stress with peers and comforting each other was helpful.

\section{Contrihutors to Self-doubt}


Ann describes the cycle of anxiety, fear, and apprehension that lead to doubting herself. Previous studies cited similar findings. Kushnir (1986) found that students develop psychological symptoms of impaired memory, loss of cognitive control, crying, and inability to respond in stressful situations. Kleehammer et al. (1990) report anxiety regarding nursing procedures, fear of making mistakes, and use of hospital equipment as anxicty-provoking clinical experiences. Pagana (1992) found that feelings of inadequacy in students were related to their lack of knowledge and experience. Williams (1993) reported that students rate the fear of doing something wrong to a patient and learning clinical procedures as main concerns in clinical experience. Admi (1997) cited similar concerns of students as averse and embarrassing sights, causing pain and suffering to patients, and inadequate knowledge as stressors in the clinical. In this study, Ann specifically cites an averse sight as embarrassing. Timmins and Kaliszer (2002) cite a major student concern regarding clinical experience as involvement with a patient's death, a point that illustrates how situation-specific the clinical experience is; Ann did not mention this situation because she did not encounter it. 'This implies that it is unlikely that any given student could ever experience all of the possible problems or circumstances that a professional nurse must be prepared to handle. The clinical practicum is simply rot long enough nor varied enough to cover every eventuality. Another common anxiety is students" fear of making a mistake and talking to physicians in the clinical (Kim, 1997). Ann specifically stated that she experienced apprehension about talking to physicians.

\section{Initiative}

In Ann`s narrative. this theme demonstrates how she handled challenges. This ability enabled her to foresee barricrs to her success in the nursing program and in the clinical. She was proactive in her response to these barriers by taking the action needed to 
change a situation when possible, so that hindrances to her success could be overcome. For example, $\Lambda$ nn foresaw that she would have a problem obtaining scrubs that fit and took it upon herself to make arrangements, so that she would always have uniforms that fit. No research could be found that had explored student initiative as an element conducive to success in clinical.

This finding has considerable potential with respect to the "empowerment" of student nurses. Previous themes discussed for Ann--Someone to lean on and Contributors to self-doubt, as well as the literature cited in those sections--make clear the fragile nature and lack of self-confidence of student nurses in the clinical setting. Ilelping them to take greater ownership of and become more assertive about their own growth may be a productive approach for nursing educators. Literature on empowerment and selfdetermination from the fields of disabilities and gender studies could be a useful starting point (e.g., Sands \& Wehmeycr, 1996; Stein, 1997; Zimmerman \& Warschausky, 1998).

\section{Case B}

Kathy's story emerged from observations, interviews, and document examination. From her narrative, the within-case themes emerged and are reviewed in the following section.

\section{Professionals as Shepherds in a Structured Context}

The close supervision and mentoring of students and the provision of step-by step guidance. as described in Kathy's narrative, emerged as a finding not previously identilied in the literature. Kathy's narrative describes how the faculty teacher and clinical staff nurses function as role models of the profession and shepherd her in a very structured manner. Although this close supervision of students by the faculty teacher as a positive, monitoring transaction was not grounded in the literature, previous studies 
identilied the importance of the laculty teacher as role model (Cooper, 1982; I ee et al., 2002; Mogan \& Knox, 1987; Nehring, 1990; OShea \& Parsons, 1979). Further, there is an extensive literature on mentoring per se (c.g., Grindel et al., 2001; Ilinshaw, 1976, 1986; Jeffreys, 2004), although that is beyond the scope of this analysis. Kathy's account emphasizes how the close, uninterrupted attention from the faculty teacher and elinical staff nurse contributes to the growth and development of the student nurse. Through this close relationship, Kathy developed her critical thinking ability when the faculty kacher and the clinical staff nurse verbalized her thoughts about what she was doing. However, several studies identified the instructor"s close supervision during clinical as undesired by students and source of stress and anxiety (Admi, 1997; Kim, 1997; Kleehammer et al, 1990; Kushnir, 1986; Pagana, 1992; Wong, 1978). That finding was echoed in the theme, Contributors to self-doubt, under Ann's case, above. The "double edged sword" of this close supervision--significant growth and learning coupled with the anxiety inherent in this process--has never previously been identified in the same study.

\section{Idealism Versus Reality}

Kathy was confronted with excessive demands on her time, disillusionment with witnessing poor treatment of patients by nurses, and discrepancies in skills performance in the clinical that did not reconcile with previous learning in the school practice lab. $A$ theory-practice gap was cited as a student concern in several studics (Chapman \& Orb, 2001; Elliot, 1993; Elkan \& Robinson, 1993; Wong, 1979). Melia (1987) noted the need to learn the unwritten rules in the elinical setting, indicating this was diflicult for students to understand.

This implies that, because students become confused when they are taught one way in the classroom and they encounter a different approach in the clinical setting, they 
must learn critical thinking skills to solve these dilemmas as they arisc. Furthermore, nursing educators may want to give some thought to helping nursing students learn explicitly about the unwritten codes of nursing practice precisely because they are tacit (Polanyi, 1967); not all persons are equally adept at picking up on these cues. Schlechty and Noblit (1982) note the importance, and difficulty, of making the obvious obvious, i.e., helping people reach the "aha" moment when what they know at a tacit level actually becomes explicitly recognized.

\section{Issues of Trust}

Kathy discussed her reticence to trust others in the clinical environment. It took a long time for her to decide to whom she should talk to ask questions. Kathy had first to persevere through obstacles before obtaining her education. This concept of trust was not identified in the literature. However, this theme has many to similarities to both Initiative, and Someone to lean on, from Ann's narrative. Elements of all three of these themes imply that the element of trust is very important in establishing relationships in the clinical that are conducive to learning. Likewise, the theme, Professionals as shepherds in a structured context from Kathy, above, raises the issue that so many students find the close supervision of the faculty teacher and clinical staff nurses anxiety provoking. Lack of trust could be a significant aspect of this dynamic.

\section{Life of Perseverance}

In Kathy's narrative, she relates how she has overcome several obstacles in her path toward becoming a nurse. No similar constructs were identified in previous literature. However, the theme, Initiative, in Ann's within-case analysis, represents a similar finding. Again, the connection to the empowerment and self-determination 
research is clearly relevant here (e.g., Sands \& Wehmeyer, 1996; Stcin, 1997; Zimmerman \& Warschausky, 1998).

\section{Case C}

The within-case themes developed from Susan`s narrative are discussed in the bollowing section.

\section{Collaborative Learning}

Susan freely interacts during the elinical experience. She views learning as a collaborative effort. Elements of this theme were identified in the Ilinshaw Model of Socialization (1976, 1986). Also, the theme, Someone to lean on in Ann's within-case themes is similar, as is the theme, Professionals as shepherds in a structured context, in Kathy's within-case analysis. The literature cited in the discussion of those themes, above, is also relevant here.

\section{Constancy of Purpose}

Susan demonstrated the characteristic of staying the course and not giving up when confronted with demands in the clinical. She possessed the attitude that although she might experience challenges during the clinical, she would eventually succed if she continued to try. This theme has commonalities with the theme, Initiative, from Ann's within-case analysis and Life of perseverence, in Kathy's within-case analysis. This concept was not identified in the previous literature. Once again, the connection to the broader literature on empowerment and self-determination may be germane (c, g. Sand; \& Wehmeyer, 1996: Stein, 1997; Zimmerman \& Warschausky, 1998).

\section{Positive Energy}

Susan's story demonstrated how positive energy helped her deal with difficulties. The enthusiasm, cheerfulness, and apparent delight in all aspects of clinical activity, as 
well as her strong faith in a higher power, seemed to play an important role in Susan's success in the clinical. This construct was not identified in the previous literature. However, elements of this can be seen in the themes, Initiative (from Ann), Life of perseverance (from Kathy), and Constancy of purpose (from Susan) and the literature cited therein.

Confident Frame of Reference

Susan's narrative revealed her confident nature, which increased as she satisfactorily performed clinical skills. This quality helped her to deal with daily challenges. The concept of confidence was not identificd in the previous literature. Again, however this theme overlaps with specific elements of other themes in this study, notably Professionals as shepherds in a structured context (from Kathy's case) and Positive energy (immediately above).

\section{Across-Case Analysis}

Drawing from the narratives in the three cases, and the strong themes within each case, the following across-case themes were identified.

\section{Background}

The three students in this study came from a background of no previous knowledge in nursing and began as novices. Benner (1984) previously identilied this stage in her work on nursing professional development. Ilinshaw (1976, 1986) identificd this phase as well in her model of socialization. $\Lambda$ corresponding within-case theme was Initiative, from Ann's within-case themes.

\section{Transition Into Nursing Role}

All three students in the present study were experiencing a transition from student to nurse. The clinical experience represents an important part of a journey through which 
Ann, Kathy, and Susan learn the culture of nursing. All of these students recognize their own transition along the way by their successes. Fach time they successfully perform a clinical skill or procedure represents a step forward in that process. Although not specifically identified as Transition into mursing role, several studies addressed transition into the nursing role through the student nurse socialization process (Boyle et al., 1996; Hinshaw, 1976, 1986; White \& Ewan, 1991; Windsor, 1987).

All of the within-case themes contributed to this across case theme because they highlight the experiences of the three students that demonstrate transition from student to nurse. From Case A, these within-case themes are, Life becomes the clinical, Someone to lean on, contributors to Self-doubt, and Initiative. From Case B, the contributing withircase themes are Professionals as shepherds in a structured context, Ldealism versus reality, Issues of trust, and Life of perseverance. From Case C, the within-case themes contributing to Transition into nursing role are Collaborative learning, Constancy of purpose, Positive energy, and Confident fiame of reference.

\section{Determination}

The theme, determination, from the across-case analysis, corresponds to the following within-case themes: Case A, Initiative, Case B, Life of perseverance, and Case C, Constancy of purpose. Narratives from all three students in this study reveal a strong, determination to succeed in the nursing program, specifically in the clinical. Ann and Kathy faced obstacles in entering the nursing program when they were not accepted the first time they applied. However, they identified strategies to increase their likelihood of admission, tried again, and were successful the second time they applied. Susan showed determination to learn the clinical skills well and practiced until she felt satisfied with her performance. 
All three students made great sacrifices in order to remain in the nursing program. These students persevered through challenges such as financial constraints, loss of timc: with family, and lack of personal leisure time. Kathy contends with the additional responsibilities of caring for her two children, commuting to the clinical site, and making childeare arrangements for her children before leaving for the clinical. In addition, she experienced financial concerns. All three students in this study demonstrate unrelenting, determination to continue, despite the barriers they face. Only one study cited financial concerns as a stressor to nursing students (Timmins \& Kaliszer, 2002). No studies identified in the literature explored the concept or related concepts of determination.

\section{Support Facilitators}

The within-case themes that correspond to this across-case them are as follows:

Case A, Someone to lean on, Case B, Professionals as shepherds in a structured setting, and Case C, Collaboraive learning. Although a few studies (c.g., Biggers et al., 1988; Carter. 1982; Hamill, 1995) included some findings that mentioned students personal support systems, no previous studies emphasized the role that students" personal support systems play in succeeding through the clinical. The present study provides more extensive information regarding the people from whom students receive support outside of the clinical setting. Ann and Kathy received personal support from their husbands, while Susan received support from her brother. These three students revealed that this support greatly contributed to their success in the clinical.

Relationships occurring during clinical experience have been explored in the literature (e.g., Attack et al., 2000; Glover, 2000; Jackson \& Mannix, 2001). However, this study expands these findings to offer a more comprehensive picture of these relationships and the impact on students' clinical experience. The three students in this 
study describe, through the narratives, the great impact of working one-on-one in the clinical with the faculty teacher, clinical staff nurses, and patients. There is little mention of the clinical staff nurses in the literature and no studies were identified that reported the support that patients gave to student nurses.

All three students report that their learning in the clinical setting hinges on the positive relationships they form with these significant people. The Case B theme, Professionals as shepherds in a structured context, describe how the faculty teacher and the clinical staff nurse shepherd these three students through each step of performing psychomotor skills and critical thinking situations. This intense, interactive relationship forges the environment conducive to learning, not only the skills involved in the practice of nursing, but also insights to what nursing is about.

Interviews and observations supported the impact that patients had on the socialization of the three students. The support and encouragement offered by the patient contributed to the students transition into the nursing profession. Each of these students cited the desire to care for people as influencing their decision to enter nursing. Kathy and Susan also cited the experience of observing the role of the nurse as opposed to the role of the physician as an additional reason they chose to enter nursing. These two students stated that the nurse's role allowed the most interaction with patients and became the deciding factor in entering nursing.

\section{Idealism Versus Reality}

Themes from the within-case analysis that have similarities to this across-case theme are Case A, Contributors to self-doubt, Case B, Idealism versus reality, and Case C, Collaborative learning. All three students expressed concern and confusion when practices in the clinical were different than what they had learned in the school practice 
lab and the classroom. In addition, the students voiced disillusionment when they witnessed patients treated in an uncaring manner. Several studies identified similar findings related to incongruencies in learned and observed content (Chapman \& Orb, 2001; Elkan \& Robinson, 1993; Elliot, 1993; Turkoski, 1987; Wong, 1979).

\section{Individual Perspectives}

Individual perspectives emerge through the narrative report for each of the three students. The theme, Contributors to self-doubt in Case A clearly expresses Ann's anxiety and discomfort with the clinical experience, which in turn led to feelings of selfdoubt. In Case B, the theme, Issues of trust, reveals that Kathy does not readily trust others and as a result is somewhat guarded before establishing relationships in the clinical. In Case C, the themes, Constancy of purpose, Positive energy, and Confident frame of reference demonstrates Susan's view about her ability to succeed in the clinical and determination to succeed even in the face of adversity.

The constructs or related concepts of students" unique perspectives. reticence in trusting others, positive attitude, and confidence were not identified in the literature. However, findings regarding anxiety in nursing students represented a prominent theme: in the literature. Quint (1965) revealed that students are concerned about doing something in the clinical that causes personal discomfort and embarrassment. Admi (1997) cited fear of causing pain and suffering to patients, averse and embarrassing sights, and inadequate knowledge as stressors in the first clinical experience. Pagana (1992) reported threatening or challenging initial clinical experiences for students such as fear of making mistakes that could harm a patient and feelings of inadequacy related to lack of knowledge. Williams (1993) cited the top concerns of students as the fear of doing something wrong to a patient and learning clinical procedures. Kim (1997) also found that students rank the 
fear of making mistakes as a leading concern. Iamill (1995) found that lack of practical skills was a top concern for students in the clinical setting.

Ann's narrative clearly reveals these same concerns as contributing to her anxicty and discomfort during the clinical. Although Kathy's and Susan"s overall perspectives of the clinical experience do not focus on stress and anxiety as much as Ann's. they also report discomfort and stress during skills performance. All three report pressure to complete clinical assignments on time, also a finding in Pagana's research (1992).

The fact that the three students in this study reported both similar and different experiences from the clinical setting parallels the broader literature. Nlthough the overwhelming sense of the research seems to be that clinical expectations are both extremely challenging and anxiety provoking, what also comes through is the wide variance in specific emotions that are described. Perhaps the best way to understand idiosyncratic feelings such as guardedness, confidence, prayer, self-doubt, etc., is to recognize that all of these are subsumed as specific individual reactions to the broader pattern of stress and anxiety.

\section{Changes in Social Interactions}

The within-case themes corresponding to this across-case patterns are Life becomes the clinical and Someone to lean on, in Case A. Similarly, Life of perseverance in case $\mathrm{B}$ and Collaborative learning in Case $\mathrm{C}$ reflect these changes in how and with whom they spent their time. The narratives reveal that all three students experience alterations in their social interactions. All reported decreased time for lamily, friends, and Icisure activities. Similar findings were identified in the literature. Beck (1995) found that interpersonal relationships with family, friends, and pets are negatively affected by stressors in nursing education. Beck compared nursing and liberal arts students? 
experience of stress found that both groups of students reported maintaining relationships with two or less friends and two or less relatives with whom they felt close.

\section{Central Research Question}

In this section, the findings from the present study are synthesized to answer the research question and the subquestions. The central rescarch question is: What is the nature of the socialization experience during the clinical laboratory that prepares the associate degree nursing student to enter professional practice?

The Hinshaw Socialization Model (1977, 1986; Blais et al., 2002) provided a theoretical framework for understanding the socialization process within the clinical learning environment. Hinshaw's model also provided a lens for analysis of the research questions. Findings of the present study reveal initial socialization behaviors in the three nursing students consistent with those proposed by Hinshaw.

\section{Phase I. Transition of Anticipated Role Expectations of Societal Group}

The students in this study demonstrated the behaviors of phase one of the Hinshaw model, Transition of Anticipated Role Expectations to the Role Expectations of Societal Group. The three students entered into the world of nursing as lay people, with no previous experience in the field. Each chose to enter into this new role voluntarily and willingly. All three had previous roles of mother, daughter, wife, student, sister, and/or factory worker. These women are making the transition from their preconceived ideas of the nursing role to the expectations that the gatekeepers of the profession have of them. The narratives, exemplified by the themes, Someone to lean on (Case A), Professionals as shepherds in a structured context (Case B) and Collaborative learning (Case C), reveal evidence of this transition process when the three students look to the faculty teacher and the clinical staff nurses to learn the role of the nurse. 
Phase II. Attachment to Significant Others/Label Incongruencies

As in phase two, Attachment to Significant Others/Label Incongruencies

(Hinshaw, 1977, 1986; Blais et al., 2002), the students in this study formed attachments: to the faculty teacher and the clinical staff nurses. This attachment did not occur by choice at first, but by necessity. In order to pass the clinical satisfactorily, these students maintained a dependent relationship with the faculty teacher and clinical staff nurses.

Later, the students in this study seemed to form a special bond with certain clinical staff nurses with whom they felt most comfortable. This attachment is evident when the students did not hesitate to turn to the faculty teacher and clinical staff nurse when they needed assistance in clinical or for moral support. One student said that the faculty teacher in the present study cared about her total well-being and not just her clinical performance. These findings in the present study about the close relationships developed between students and the faculty teacher and the clinical staff nurses were in agreement with previous research by Boyle et al. (1996), Clark (2004), Cohen (1981), Chun-Heung and French (1997), Davis (1966), Kelman (1961), Knowlton (1985, Kramer (1974), Moore (1970), White and Ewan (1991), Waugaman (1981), and Windsor (1987).

The narratives, e.g., the themes of Contributors to self-doubt, Idealisn versus reality, and Constancy of purpose, show that all of the students in the study identilied or labeled feelings of conflict when they identified clinical situations that deviated from what they were taught (Blais et al., 2002; Hinshaw, 1977, 1986). The students in this study cited confusion regarding discrepancies in equipment used for skills learned in the school practice lab as opposed to those skills performed in the hospital. Two of the three students in this study responded with strong emotions to conflicting expectations between the classroom and the clinical when they observed unprofessional and unkind patient 
treatment by nurses and staff. Previous studies addressed similar findings of theorypractice gap, being expected to know concepts they had not been taught, and reality shock (Chapman \& Orb, 2001; Clark, 2004; Elkan \& Robinson, 1993; Lilliot, 1993; Knowlton, 1985; Turkoski, 1987; Waugaman, 1981; Wong, 1979).

Phase III. Internalization of Role Values/Behaviors

To describe the third phase, Internalization of Role Values/Behaviors. Ilinshaw (1977, 1986) incorporated the three levels of values orientation defined by Kelman, (1961): Compliance, Identification, and Internalization. lior all three of these phases, the evidence was drawn from the holistic cases rather than from specific themes.

Compliance. This level oceurs when a person demonstrates the expected role behaviors only to obtain positive reactions from others. Observations and interviews reveal that the three students in this study demonstrated the expected behaviors of the compliance level. The three students exhibited the expected behaviors to please the faculty teacher and clinical staff nurses. These students carefully performed correct behaviors when demonstrating skills under the watchful eye of the faculty nurse and the clinical staff nurses. Observations revealed that maintaining the appearance of competence and reciting all critical elements of a skill remained the focus for the three students. Clark (2004), Knowlton (1985), and Waugaman (1981) presented similar lindings.

Identification. In this level, the person selectively adopts the role behaviors acceptable to that person rather than the values associated with these behaviors Identification behavior usually changes with exposure to different role models (Blais et al., 2002; Hinshaw, 1977; Kelman, 1961). The three students in this study did not demonstrate all behaviors of the identification level because exposure to new role models 
will continue until they complete the nursing program. Although the students in the study have adopted the role bchaviors of the professionals introduced to them thus far, such as performing skills and how to act like a nurse, the ongoing induction of new nursing role models will continue to impact identification. The faculty teacher and clinical staff nurses, as unique individuals, each tend to stress the values associated with different behaviors within the profession. Therefore, these students have demonstrated the identification of expected behaviors of their new role but have not yet completely accepted the associated values. The three students identify and mimic the behaviors of the professional nurse, the faculty teacher, and clinical staff nurse and try to emulate the nurses' actions.

Internalization. Finally, none of the three students in this study achieved this level (Kelman, 1961). These students have not yet simultaneously accepted all standards of the new role and incorporated them as part of their own value system. Observations reveal that these three students were continuing in the process of assimilating the standards of the nursing role into their own value system. Uncertain responses from these students during post-conference discussions about the values of the nursing profession indicate incomplete internalization. While these students recognize and practice the values and ideals demonstrated by the faculty teacher and staff nurses, they did not yet sec themselves as full professional nurses. These findings conform to those of Kelman, who states that individuals may demonstrate one or a blend of these three levels (Blais et al., 2002). Clark (2004), Knowlton (1985), and Waugaman (1981) presented similar findings. While the three students demonstrate the socialization behaviors of first two phases of the Hinshaw Model (1976, 1986), the phase three level, Internalization, was not yet realized because the students had not completed their educational preparation. 


\section{The Empirical Subquestions}

The evidence cited below reflects both the cases as a whole as well as sclected themes. For all these subquestions, the analysis focuses on investigating both descriptive information and the insights that were gleaned from the experiences of Ann, Kathy, and Susan.

\section{Subquestion A}

How does the student experience the social, psychomotor, and critical thinking skills in the clinical laboratory?

From the narratives, developed from observations, interviews, and documents, all three students in the study experienced the clinical as a shared learning activity. Ann and Kathy had a smaller circle of close friends in the clinical than Susan. However, all freely interacted with other students in the clinical laboratory and viewed themselves as united with the commor goal of succeeding in the nursing program. Before entering the hospital clinical setting, collaboration and assistance began for $\Lambda$ nn, Kathy, and Susan in the school practice lab. The faculty teacher taught the psychomotor skills in the school practice lab, then guided and supported the students as they practiced these skills. These three students spent many additional hours in the school lab helping each other learn the psychomotor skills. After practice, the students were evaluated individually on their performance of these psychomotor skills by the faculty teacher. When the students began hospital clinical labs, they continued to ask for and received assistance with tasks or skills from other students, the faculty teacher, and clinical staff nurses. The faculty teacher and clinical staff nurses provided one-on-one supervision to these students when they performed psychomotor skills during the clinical.

Susan, especially, viewed the entire clinical experience as a learning opportunity 
and made a practice of seeking out other students to share in her new learning experiences. For example, when she performed a new skill for the first time, she pulled other students into her patient's room so they would not miss a new learning opportunity. Before pre-conference, these students discussed assignments, care plans, and medication facts with all other students present in a shared effort to prepare for clinical. These students showed kindness and concern to others in the clinical even though they were not their closest friends. For instance, when another student became sick, Ann, Kathy, and Kathy were very solicitous of her needs. These students worked together on elinical projects such as making Halloween baskets for hospital personnel. The three students in the study modeled the idea that they were all in the experience of clinical together.

The students in this study practiced critical thinking skills as they worked one-onone with the faculty teacher or clinical staff nurse as reflected in the themes, Life becomes the clinical, Professionals as shepherds in structured context, and Collahorative learning. As the student performed a skill or interacted with patients, the faculty teacher or the clinical staff nurse guided them in learning critical thinking. For example, when a student obtained an abnormal blood glucose reading, the clinical staff nurse directed the student through the process of critical thinking to address the problem. By hearing the faculty teacher or clinical staff nurse verbalize their mental processes in analyzing the situation, the student learned the critical thinking process. The students in this study did not learn to think critically on their own; they were led in the process by the faculty teacher and clinical staff nurses in the social setting of the clinical. When the students needed guidance in performing a psychomotor skill or solving a clinical problem, they turned to the faculty teacher or clinical staff nurse. These professionals did not simply tell them what should be done or give the students directions. Instead. the faculty teacher or 
clinical staff nurse remained with the student, closely monitoring them as they performed the skill, correcting, teaching, and affirming each step taken by the student. In addition. the faculty teacher and the clinical staff nurse shared their reasoning and thought processes with the students by verbalizing what they were thinking and connecting lacts, principles, and experiences with the students. Examples of the students learning critical thinking were during pre-conference and during the clinical when the faculty teacher challenged them to state verbally and apply their knowledge in response to questions she posed to them. When they faltered, the faculty teacher linked previously learned information to address patient care. This recitation of facts by the students under the direction of the faculty teacher helped the students Iearn to think critically and is described by Benner (1984) and In fante (1975)

Many previous studies explored the clinical experiences of nursing students (e.g., Admi, 1997; Beck \& Srivastava, 1991; Kleehammer et al., 1990; Kushnir, 1986; Pagana, 1992; Quint, 1965; Timmins \& Kaliszer, 2002; Williams, 1993). These studies focused on the characteristics of faculty teachers and clinical staff nurses that students viewed as most important. All within-case and across-case themes in the present study addressed Subquestion $A$.

Subquestion B

What support systems sustain the student during the clinical laboratory experience?

Outside of the clinical. All three students in the study identilied sources of support outside the clinical. Ann received moral support from her husband, mother, and friends when faced with the demands of the clinical experience. Ann's husband helped oy listening to her concerns and allowed her to ventilate her feclings. Ann is mother, as well 
as her friends outside the nursing program, supported her by listening to her concerns as by offering encouragement.

Kathy received her main support outside of clinical from her husband, who listened to her concerns about the clinical and offered encouragement. Susan's brother provided her the most support outside of the clinical. He listened to her concerns and helped her to see positive aspects of clinical days that were the most stressful for her

Inside of the clinical. The faculty teacher, the clinical staff nurses, and peers provided support to Ann, Kathy, and Susan during the clinical. Additionally, Ann and Kathy noted explicitly that patients were also instrumental in giving encouragement and helping them gain confidence in their new skills. While Ann and Kathy interact with a small group of carefully selected peers, Susan freely interacts with all of her peers. The three students in this study ask for and receive assistance and answers to questions as well as receive support and encouragement from their peers. With these friends, the three students confided problems and shared successes.

Each student freely turned to the faculty teacher when they required assistance in the clinical. For example, the faculty teacher supported $\Lambda$ nn by praising her for her accomplishments. After the incident when Ann felt she had been abandoned on the unit, the faculty teacher took her aside and comforted her and showed concern for her wellbeing. Ann felt supported by the clinical staff nurses and stated that without exception, all of these nurses made themselves available to her and showed an interest in her clinical learning experience.

The current faculty teacher provided the most support for Kathy during the clinical. Kathy felt comfortable approaching her and sensed that this teacher wanted to help her learn. Kathy interacted more closely with certain clinical staff nurses who 
seemed to want to help her. She identified one nurse in particular with whom she especially enjoyed working. This nurse took an interest in Kathy's clinical learning experience and allowed Kathy to perform additional tasks under her supervision. As a result, Kathy developed a trusting relationship with her and felt strongly supported by this nurse during clinical experiences as evidenced in the theme, Issues of trust. Kathy expressed that although she had difficulty trusting people, she had developed a trusting relationship with the faculty teacher and selected clinical stafl nurses she encountered during the study.

Susan felt supported by the faculty teacher and all clinical staff nurses and eage:ly turned to these professionals for advice and guidance. Without reservation, she turned to the faculty teacher and any of the clinical staff nurses for assistance or for answers to her questions. She viewed the social setting of the clinical as an opportunity to learn and assumed that everyone wanted to help her.

The literature does not explore the concept of peer support systems. Previous literature supported the findings in regard to faculty teacher support (Cooper, 1982; Lee et al., 2002; Mogan \& Knox, 1987; Nehring, 1990; O’Shea \& Parsons. 1979; Streubert. 1989) and clinical staff nurses support (Atack et al., 2000; Dunn \& Hansford, 1997; Glover, 2000). However, findings from some studies disagreed with findings from the present study and cited problems in interactions with clinical staff nurses (Campbell et al., 1994; Jackson \& Mannix, 2001; Jackson \& Neighbors, 1988; Streubert; Turkoski, 1987) and faculty teachers (Admi, 1997; Kim, 1997; Kleehammer et al., 1990; Kushnir, 1986; Pagana, 1992; Wong, 1978) as sources of stress and anxiety in the clinical experience rather than sources of support. Additionally, the patient as a source of support and confirmation has not been previously explored in the literature. 
Within-case themes corresponding to this subquestion are Someone to lean on. Professionals as shepherds in a structured context, and Collaborative learning. The across-case theme, Support facilitators likewise addressed Subquestion B. All of these are consistent with the Hinshaw Model of Socialization (1976, 1986).

Subquestion $C$

How do the faculty teacher and the clinical staff nurse influence student learnin: in the clinical setting and interaction in the clinical setting?

The faculty teacher and clinical staff nurses clearly structure learning in the clinical setting. First, both serve as role models and demonstrate how a professional nurse acts and what they do. The faculty teacher, as the nursing program and student advocate, functions as a facilitator who structures the clinical experience according to the ideals of the profession as taught in the classroom. The clinical staff nurses also functions as an advocate for the patient, for professionals in the field of nursing, and for practitioncrs on duty during the cllinical.

The faculıy teacher faces the sometimes difficult task of guiding the students and reconciling the image of the nurse as a paragon of perfection with the reality of the clinical learning environment. The faculty teacher demonstrates flexibility and adaptability in working in the real world of the hospital clinical without compromising the guiding principles of nursing. For example, the faculty teacher explained that there were acceptable deviations in the performance of certain skills when the critical elements of that skill were not compromised. However, she pointed out to students when she was not in agreement with a clinical staff nurse and would not allow the students to perform the skill according to the instructions of that nurse. She tactfully explained that although she could not interfere with the manner in which the nurse performed the skill, students 
were not allowed to deviate from a learned procedure. Other research lindings support these findings in regard to the role of faculty teachers in structuring clinical experience (Bergman \& Gaitskill, 1990; Brown, 1981; Cooper, 1982; Kiker, 1972; Knox \& Mogan, 1985; Lee et al., 2002; Mogan \& Knox, 1987: Nehring. 1990; 0’ Shea \& Parsons. $1979 ;$ Pugh, 1988). Previous literature also cited the importance of the role of the clinical staff nurse in structuring clinical experience ( $\Lambda$ tack et al., 2000; Campbell et al., 1994; Dunn \& Hansford, 1997; Glover, 2000; Grindel ct al., 2001; Jackson \& Mannix, 2001; Jackson \& Neighbors, 1988; Streubcrt, 1989; Thompson, 1998; Turkoski, 1987).

The faculty teacher also uses the post-conference time to debrief students and allow discussion of the events of the clinical day. She plans learning activities such as taking students to observe diagnostic tests, discusses contradictions in the clinical setting, and invites former students to speak to offer encouragement. These activities promote socialization and help the students to grow as nurses. The clinical post-conference was not explored in previous literature.

The facully teacher also structures the elinical learning experience when she assigns selected patients to the students. In making these assignments, the faculty teacher considers the clinical staff nurse with whom the assigned student will work. Therefore, the faculty teacher pairs students with clinical staff nurses whose personality and willingness to mentor students match the needs of the student. In addition, the faculty teacher selects specilic students in the clinical to assist other students. She assigns a student who has a particular strength or expertise in performing a skill to review the skill with a less experienced student. The ability to organize work in the clinical experience was cited by Williams (1993) as important to students. Kiker (1973) found that students ranked the ability to organize clinical experience in a manner meaningful to students as 
the most essential characteristic of faculty teachers. The clinical staff nurse, as another role model, provided one-on-one help and guidanee with new skill performance. The clinical staff nurse serves as a source of detailed patient information beyond what the faculty teacher and the chart provide. The clinical staff nurse also represents the reality of nursing practice.

The within-case themes that address Subquestion C are Someone to lean on, Professionals as shepherds in a structured context, and Collaborative learning. The across-case themes relating to Subquestion C are Transition into nursing role, Support facilitators, and Idealism versus reality.

\section{Recommendations}

This study provides a rich description of the clinical learning experience of three nursing students. The findings are significant to nursing students, faculty teachers, clinical staff nurses, and nursing program administrators. The following section includes recommendations for policy/application to the lield of nursing and future research.

\section{Policy Considerations}

The expressive, rich descriptions in the case narratives should be available to students entering nursing programs as well as prospective students. $\Lambda$ s students read the words of other students, they can estimate what clinical experience will be like and have a better understanding of expectations and demands placed upon them. While this multicase study report informs people from all walks of life, especially for those who may have only observed what nurses do in a hospital, these detailed descriptions provide guidance for students in preparation for clinical experience. In addition, the accounts of the faculty teacher and clinical staff nurses provide valuable information to students regarding clinical experience. 
Findings should also be shared with faculty teachers. Faculty teachers can benelit from this study through understanding students' perceptions of clinical experience. The laculty teacher may respond to students needs of which they were previously unaware Faculty teachers may also benefit from the viewpoint of clinical staff nurses, because the staff nurse remains in the clinical learning facility and has a unique perspective.

Clinical staff nurses should also be informed of the study findings. The everyday language used in the case narrative report allows the story to be told more easily (Merriam, 1998). From reading the students' descriptions of the hospital, clinical staff nurses may see for the lirst time the importance of their role in clinical education. These nurses would benelit from the study through understanding the restraints placed on students and faculty teachers and recognizing ways in which students can be supported.

Nursing program administrators should have the information from this study, which may facilitate students passing the clinical component and completing their program of study. This study may remind administrators of the importance of the socialization relationship that forms between the faculty teacher and student. This tie supports role development, passing grades, and eventually, program completion. If the administrator can maintain a low student-to-teacher ratio, this important association can develop more easily. 'This study uncovers information about nursing students in the clinical environment that can be applied to clinical nursing education to support the best possible programs (Merriam, 1998). This information, in turn, may contribute to increasing the retention and graduation numbers of nursing students.

\section{Future Research}

Additional studies of nursing students in the clinical setting are recommended. While the present study examined the clinical experience of associate degree nursing 
students, baccalaureate nursing students and diploma program students should also be included in further studies of clinical experience. Future research is recommended to explore whether the different levels of nursing preparation contribute to the problems encountered by students with respect to their feeling overwhelmed. Information about whether participants are first generation college students should be included in future studies to investigate the impact of this variable on the clinical experience of nursing students. For example, the students seemed stressed and surprised about the extent of outside clinical preparation that was required. Would children of professionals, who have watched their parents bring work home, have a different reaction to this compared to children of factory workers who leave the job at the end of the day?

This case study included three nursing students in the third semester of a foursemester program. Studies including additional cases at different levels in nursing preparation programs might provide additional information about the sludent experience in the clinical. The literature explores the impact of some significant others during clinical, but does not completely describe specific people and relationships. Further studies that include additional participants, or other role group perspectives, such as patients, physicians, and friends and families of nursing students might provide more information. Additional research on the role of the clinical staff nurse in the clinical is also needed. Research exploring the contribution of the clinical postconference and student characteristics of determination, confidence, initiative, trust, positive outlook, belief in a higher power, and perseverance would also be helpfull. Related to this is the issue of empowerment and self-determination. Are these perspectives primarily developed in the fields of disabilities studies, relevant to the fragile egos of beginning student nurses in the clinical setting? Similarly, investigations across professions may be 
fruitful. How do the clinical experiences of nursing students compare to doctors, dentists, teachers, etc.?

This qualitative, multiple-case study highlights a problem in the literature that has not been explicitly addressed: What is the nominal validity of the constructs that are examined in this and other studies of nursing education, particularly with respect to the clinical setting? Many of the concepts identified in this study, and in the extant research as well, seem to have considerable overlap in meaning and content yet masclucrade under different names. An exhaustive review of this work with the purpose of sorting out these redundancies would be of considerable benefit to the field.

This research also raises the issue of critical thinking in clinical nursing education. One of the students, Susan, was determined to experience as many different procedures as possible in order to increase her repertoire of skills. Yet no one student cin ever observe/participate in every possible procedure or eventuality. The only way to be sure that all students are adequately prepared as professionals is to enhance their ability to think critically, to extrapolate from similar experiences, to have the ability to continue learning on their own, to know how to learn. Further rescarch explicitly focused on how students learn this capacity and how to enhance it are sorely needed.

Future research should examine the findings in the mentoring literature and in the nursing education literature to search for common findings. Additionally, future research with students who drop out is recommended to explore the reasons that students do not complete nursing preparation programs. The experiences of those who exit a nursing program may be qualitatively different from those who finish.

\section{Conclusions}

This qualitative, multiple-case study of three associate degree nursing students 
provided a story of learning in the hospital clinical setting. From the in-depth descriptions in the narratives and from information from others who informed the case--the faculty teacher and clinical staff nurses--a complex portrait of the clinical education experience emerged. The three students overcame obstacles and made personal sacrifices to enter and remain in the nursing program. They echoed determination to succeed and reach the goal of becoming a nurse throughout the narrative accounts. 'The students lived the process of undergoing a transition from student to nurse. These students voiced awareness of this metamorphosis, and celebrated each small victory that marked their progress. The clinical was very much a shared experience by these three students who depended on each other and the prolessionals for encouragement and support.

The Hinshaw Model of Socialization $(1976,1986)$ provided the lens through which the data were analyzed to address the research question and subquestions. The students demonstrated the socialization behaviors identified by Hinshaw. In the first phase, Transition of Anticipated Role Expectations to the Role Expectations of Societal Group, all three students entered the new professional role voluntarily, with no previous experience in the field, but with preconceived ideas of what the profession was like. The students" previous roles, which they brought with them into the new profession, gave them a perspective for evaluation of the new role. In the second phase, Attac/lment to Significant Others/Label Incongruencies, the students formed strong attachment to signilicant professionals, the laculty teacher and the elinical staff nurses. The students recognized situations in the clinical that were incongruent with what they learned in the school practice lab and the classroom. When faced with these discrepancies, the students expressed strong emotional reactions. In the third phase, Internalization of Role Values/Behaviors, the students incorporated the levels of Compliance when they 
carefully performed correct procedures while under the supervision of the faculty teacher and the clinical staff nurses. The Identification phase was demonstrated when the students mimicked the behaviors of the faculty teacher and the clinical staff nurses. However, the students did not demonstrate the third level, Internalization, because they had not yet internalized all standards of their new nursing role because their educational preparation was not complete.

In the across-case analysis, data were conceptualized from all the cases and revealed similarities and differences among the three students. Background was similar because the students all came into the nursing profession as novices. Their preconceived ideas of what nurses did were based on observations of nurses who cared for family members. Transition into nursing role was evident from the narratives as the students reported their progress in becoming nurses. They viewed each success in the clinical as one step closer to their goal. All three students possessed Determination and no matter the barriers they faced, they continued and would not give up. Each student had Support facilitators, family, peers, the faculty teacher, and clinical staff nurses, who helped the students in the complex clinical environment. The students faced Idealism versus reality, and had to reconcile differences in the principles they were taught with the realities they were confronted with in the clinical. Changes in social interactions were experienced by all three students. Because of the time demands placed on each student, they had less time for family and friends and no time for leisure activities. Each student represented Individual Perspectives. Ann experienced anxiety about the performing skills and possibly harming a patient. Kathy had issues of trust and carefully evaluated each person in the clinical before establishing any relationship. Susan viewed the clinical as a social context for learning and freely interacted with everyone. She exhibited a positive energy 
and zest for learning in the clinical setting.

This study adds to the knowledge base in nursing clinical experience and shows how students become socialized into the nursing profession. Yes, the students in this study are becoming nurses. They describe their growth by the progress they make and because they feel more confident in the nursing role than they did when they began the nursing preparation program. The faculty teacher and the clinical staff nurses comment that they see the students" growth and development by their ability to perform psychomotor and critical thinking skills more confidently in the clinical. The students make the transition toward the nursing role under the watch ful eyc of the faculty teacher and clinical staff nurses who serve as shepherds. The faculty teacher, the clinical stalf nurses, peers, and patients influence the socialization of nursing students. The professionals serve as role models and demonstrate the reality of nursing. The peers provide encouragement, support, and partnerships in learning. Praise from the patient verifies to the students that they are transitioning into the professional nurse.

Beyond the value of this research of rich cases that can increase understanding of the complexities, stressors, and rewards of the clinical setting, primarily from the perspective of student nurses, this study also explores several issues that have not been previously reported in the literature. Thus this study functions on two levels: (a) case stories that provide a visceral introduction to the lived experience of clinical nurse students and (b) extension of the extant knowledge base to a number of concepts that can possibly be investigated in future research. Both of these are important. There is currently a serious nursing shortage and far too many students drop out, never completing their professional training. Inderstanding why, and being able to apply that knowledge, is vital in a society in which the demands for qualified health care givers are increasing. 


\section{REFERENCES}

Admi, H. (1997). Nursing students' stress during the initial clinical experience. Journai of Nursing Education, 36, 323-327.

American Association of Colleges of Nursing. (January, 2001). Strategies to reduce the nursing shortage. Retrieved September 9, 2005 from

http://www aacn.nche.edu/Publications/positions/tricshortage

American Association of Colleges of Nursing. (2002). Hallmarks of the professional nursing practice environment. Journal of Professional Nursing, 18, 295-304.

American Association of Colleges of Nursing. (2005). Enrollment and graduation in baccalaureate and graduate programs in mursing (Publication No. 04-05-1). Washingtor, DC: Author.

American College of Nurse Practitioners. (n.d.). Retrieved November 12, 2007, from hin//www anporg/dauliasp

American Hospital Association. (2005). Resource center: Statistics and studies.

Retrieved January 2, 2006, from

http://www.hospitalconnect.com/aha/resource_center/statistics/statistics.html

Ashworth, P., \& Morrison, P. (1989). Some ambiguities of the student's role in undergraduate nurse training. Journal of Advanced Nursing, 14, 1009-1015.

Atack, L., Comacu, M., Kenny, R., LaBelle, N., \& Miller, D. (2000). Student and staff relationships in a clinical practice model: Impact on learning. Journal of Nursing Education, 39, 387-392. 
Bachman, M. L. (1999). Anxiety, critical thinking, and age as performance predictors of community college nursing students (Doctoral Dissertation, Colorado State University, 1999). Dissertation Abstracts International, 60, 1026.

Barham, V. Z. (1965). Identifying effective behaviors of the nursing instructor through critical incidents. Nursing Research, 14, 65-68.

Beck, C. T. (1993). Nursing students' initial clinical experience: A phenomenological study. International Journal of Nursing Students, 30, 489-497.

Beck, C. T. (1995). Burnout in undergraduate nursing students. Nurse Educator, 20(4), 19-23.

Beck, D. L., \& Srivastava, R. (1991). Perceived level and sources of stress in baccalaureate nursing students. Journal of Nursing Education, 30, 127-133.

Bell, M. L. (1991). Learning a complex nursing skill: Student anxiety and the eflect of preclinical skill evaluation. Journal of Nursing Education, 30, 222-226.

Benner, P. (1984). From novice to expert: Excellence and power in clinical nursing practice. Upper Saddle River, NJ: Prentice Hall.

Berger, K. J., \& Williams, M. B. (1999). Fundamentals of nursing: Collaborating for optimal health (2nd ed., Vol. 1). Stamford, CT: Appleton \& Lange.

Bergman, K., \& Gaitskill, T. (1990). Faculty and student perceptions of effective elinical tcachers. Journal of Professional Nursing, 6, 33-44.

Biggers, T., Zimmerman, R., \& Alpert, G. (1988). Nursing, nursing education, and anxicty. Journal of Nursing Education, 27, 411-417.

Billings, D., \& Halstead, J. (1998). Teaching in nursing: A guide for faculty. St. Louis: Elsevier Science.

Billings, D., \& Halstead, J. (2005). Teaching in nursing: A guide for faculty (2nd ed.). St. 
Louis: Elscvier: Science.

Blainey, C. (1980). Anxiety in the undergraduate medical-surgical nursing student. Journal of Nursing Education, I9(8), 33-36.

Blais, K., Hayes, J., Kozier, B., \& Erb, G. (2002). Professional nursing practice (4th ed.) Upper Saddle River, NJ: Prentice Hall.

Boyle, D., Popkess-Vawter, S., \& Taunton, R. (1996). Socialization of new graduate nurses in critical care. Heart and Lung, 25, 141-154.

Brown, S. 'T. (1981). Faculty and student perceptions of effective clinical teachers. Journal of Nursing Education, 20(9), 4-16.

Burns, N., \& Grove, S. K. (1999). Understanding nursing research (2nd ed.). Philadelphia: W. B. Saunders Company.

Campbell, C. (1985). Stress survey: Disturbing findings...nurses are under stress. Nursing Mirror, $160(26), 16-19$.

Campbell, I. E., Larrivee, L., Field, P. A., Day, R. D., \& Reutter, L. (1994). I earning to nurse in the clinical setting. Journal of Advanced Nursing, 20,1125-1131.

Carpenito, L., \& Duespohl, T. (1985). A guide for effective clinical instruction (2nd ed.). Aspen, $\mathrm{CO}$ : Rockville.

Carter, E. W. (1982). Stress in nursing students: Dispelling some of the myths. Nursing Outlook, 20, 248-252.

Chapman, R., \& Orb, A. (2000). The nursing students" lived experience of clinical practice. The Australian Electronic Journal of Nursing Education, 5(2), 2-16.

Chapman, R., \& Orb, A. (2001). Coping strategies in clinical practice: The nursing students' lived experience. Contemporary Nurse, $I /(1), 95-102$.

Chun-Heung, L. \& French, P. (1997). Education in the practicum: A study of the ward 
learning climate in IIong Kong. Journal of Advanced Nursing, 26, 455-462.

Clark, C. (2004). The professional socialization of graduating students in generic and two-plus-two baccalaureate completion programs. Journal of Nursing Education. $43,346-351$.

Clouder, L. (2003). Becoming professional: Exploring the complexities of professional socialization in health and social care. Learning in Health and Social Care, 2, $213-222$

Cohen H. (1981). The nurses's quest for professional identity. Menlo Park, CA: AddisonWesley Publishing Company.

College Entrance Examination Board. (2008). The College Handbook, 45(210), 460.

Cooper, G. (1982). Characteristics students view as important in nurse faculty role models. Unpublished master's thesis, University of Mississippi at the Medical Center, Jackson.

Creswell, J. W. (1997). Qualitative inquiry and research design: Choosing among five traditions. Thousand Oaks, CA: Sage.

Dalme, F. C. (1983). Nursing students and the development of personal identity. In N. L. Chaska (Ed.), The nursing profession: A time to speak (pp. 134-145). New York: McGraw Hill.

Davis, F. (1966, September). Professional socialization as subjective experiences: The process of doctrinal conversion among student nurses. Paper presented at the Sixtin World Congress of Sociology, Evian, France.

Deary, I., Watson, R., \& Hogston, R. (2003). A longitudinal study of burnout and attrition in nursing students. Journal of Advanced Nursing, 43, 71-81.

Digiacomo, I. II. (1993). The clinical experience in nursing education: $\Lambda$ case study 
(Doctoral dissertation, Columbia University Teachers College, 1993).

Dissertation Abstracts International, 54, 1330.

Dixon, J., \& Koerner, B. (1976). Faculty and student pereeptions of elfective classroom teaching. Nursing Research, 25, 300-305.

Dunn, S., \& Burnett, P. (1995). The development of a clinical learning environment scale. Journal of Advanced Nursing, 22, 1166-1173.

Dunn, S. V., \& Ilansford, B. (1997). Undergraduate nursing students" pereeptions of their clinical environment. Journal of Advanced Nursing, 25, 1299-1306.

Elkan, R., \& Robinson, T. (1993). Project 2000): The gap between theory and practice. Nurse Education Today, 13, 285-298.

Elliot, M. (2002). The clinical environment: A source of stress for undergraduate nurses. Australian Journal of Advanced Nursing, 20(1), 34-38.

Elliot, P. (1993). Locality based teaching. Senior Nurse, 13, 35-39.

Ellis, J. R., \& Hartley, C. L. (1988). Nursing in today's world: ('hallenges, issues, and trends (3rd ed.). Philadelphia: J. B. Lippincott Company.

Fox, D., Diamond, L., Walsh, R., Knopf, L., \& Hogden, J. (1963). Correlates of satisfaction and stress with nursing school experience. Nursing Research, 12(2), $83-88$

Gans, H. (1982). The participant observer as a human being: Observations on the personal aspects of fieldwork. In R.G. Burgess (Ed.), Field research: A sourcebook and ficld manual (pp. 53-61). I.ondon: Allen \& Unwin.

Geertz, C. (1973). The interpretation of cultures. New York: Basic Books.

Glaser, B., \& Strauss, A. (1967). The discovery of grounded theory: Strategies for qualitative research. Chicago: Aldine. 
Glossop, C. (2002). Student nurse attrition: Use of an exit-interview procedure to determine students’ leaving reasons. Nurse Education Today, 22, 375-386.

Glover, P. (2000). Feedback: I listened, reflected and utilized. International Journal of Nursing Practice, 6, 247-252.

Grealish, L., \& Carroll, G. (1998). Beyond preceptorship and supervision: A third clinical teaching model cmerges for Australian nursing education. Australian Journal of Advanced Nursing, I5(2), 3-11.

Grindel, C. G, Bateman, A. L., Patsdaughter, C. A., Babington, L. M., \& Medici, G. (2001). Student contributions to clinical agencies: A comparison of adult health and psychiatric staff nurses perceptions. Nursing and Health Care Perspectiver, $22,197-202$

Gunter, L. M. (1969). The developing nursing student. Nursing Research, 18, 237 243.

Hamill, C. (1995). The phenomenon of stress as perceived by Project 2000 student nurses: A case study. Journal of Advanced Nursing, 21, 528-536.

Harris, M. (1979): Cultural materialism: The struggle for a science of culture. New York: Random House.

Hinshaw, $\Lambda .(1977)$. Socialization and resocialization of nurses for professional mursing practice (National I eague for Nursing Pub. No. 15-1659). New York: National L.eague for Nursing.

Ilinshaw, A. (1986). Socialization and resocialization of nurses for professional nursing practice. In E. C. I Iein \& M. Nicholson (Eds.), Contemporary leadership behavior: Selected readings (2nd ed., pp. 25-40). Boston: I ittle Brown.

Infante, M. (1975). The clinical laboratory in nursing education. New York: John Wiley 
and Sons.

In fante, M. (1985). The clinical laboratory in nursing education (2nd ed.). New York: John Wiley and Sons.

Infante, M., Forbes, E., Houldin, A, \& Naylor, M. (1989). $\Lambda$ clinical teaching project: Examination of a clinical teaching model. Journal of Professional Nursing, 5, 132139.

Jackson, D., \& Mannix, J. (2001). Clinical nurses as teachers: Insights from students of nursing in their first semester of study. Journal of Clinical Nursing, 10, 270-277.

Jackson, J.. \& Neighbors, M. (1988). ^ study of nurses" attitudes towards associate degree nursing students. Journal of Advanced Nursing, 13, 405-409.

Jacobson, M. (1966). Effective and ineffective behavior of teachers of nursing as determined by their students. Nursing Research, 15, 218-222.

Jeffreys, M. (2004). Nursing student retention: Understanding the process and making a difference. New York: Springer Publishing Company.

Jones, M. C., \& Johnston, D. W. (1997). Distress, stress and coping in lirst-ycar studen1. nurses. Journat of Advanced Nursing, 26, 475-482.

Kalisch, P. A., \& Kalisch, B. J. (1986). The advance of American nursing ( 2 nd ed.). Boston: Little Brown.

Kalisch, P. A., \& Kalisch, B. J. (2004). American nursing: A history' (4th ed.). Philadelphia: Lippincott Williams \& Wilkins.

Kane, L. J. (1998). Perceived sources and level of stress experienced by student nurses in associate and baccalaureate degree programs (Master's thesis, Grand Valley State University-Allendale, Michigan, 1997). Masters Abstracts International. 36, 782.

Kelman, H. (1961). Process of opinion changes. Public Opinion Quarterly, 25, 57. 
Kentucky Board of Nursing. (2005, May 31). Licensure statistic reports. Retrieved June 3, 2005, available from htp:/www./rostate ky.us/kar $201020 / 310 . \mathrm{mm}$

Kiker, M. (1973). Characteristics of the effective teacher. Nursing Outlook, 21, 721-723.

Kim, K. H. (1997). Perceived levels and sources of anxiety of senior nursing students in the clinical setting (Doctoral dissertation, University of Wisconsin-Milwaukee, 1997). Dissertation Abstracts International, 58, 1801.

Klechammer, K., Hart, A. L., \& Keck, J. F. (1990). Nursing students`perceptions of anxiety-producing situations in the clinical setting. Journal of Nursing Education. 29, 183-187.

Knowlton, K. (1985). Professional socialization of graduate students in clinical psychology at the University of Nebraska Lincoln (Doctoral dissertation, University of Nebraska, Lincoln, 1985). Dissertation Abstracts International, 46. 2813.

Knox, J., \& Mogan, J. (1985). Important clinical teacher behaviors as perceived by university nursing faculty, students and graduates. Journal of Advanced Nursing, $10,25-30$.

Kozier, B., Erb, G., Berman, A., \& Snyder, S. (2004). Fundamentals of nursing concepts, process, and practice (7th ed.). Upper Saddle River, NJ: Pearson Prentice Hall.

Kramer, M. (1974). Reality shock: Why nurses leave nursing. St. Louis: Mosby.

Kushnir, T. (1986). Stress and social facilitation: The effects of the presence of an instructor on student nurses' behavior. Journal of Advanced Nursing, 11, 13-19.

Langan, J. C. (2003). Faculty practice and roles of staff nurses and clinical faculty in nursing student learning. Journal of Professional Nursing, 19, 76-84.

I.eCompte, M., \& Preissle, J. (1993). Ethnography and qualitative design in educational research (2nd ed.). Orlando, FL: Academic Press. 
Lee, W., Cholowski. K..\& Williams, A. (2002). Nursing students' and clinical educators" perceptions of characteristics of effective clinical educators in an Australian university school of nursing. Journal of Advanced Nursing, 39, 412-420.

Leininger, M (1995). Teaching transcultural nursing in undergraduate and graduate programs. journal of Transcultural Nursing, 6, 10-26.

Lincoln, Y. \& Guba, E. (1985). Naturalistic inquiry. Beverly IIIls, CA: Sage.

Lindop, E. (1989). Individual stress and its relationship to termination of nurse training Nurse Education Today, 9, 172-179.

Lowery. B., Keane, A.. \& Ilyman. I. (1971). Nursing students and faculty opinion on student evaluation. Nursing Research, 20, 436-439.

MacMaster, E. (1979). Sources of stress in university nursing students. Nursing Papers: Perspectives in Nursing, 114, 87-96.

Maslach, C. (1982). Burnout-the cost of caring. Englewood Cliffs, NJ: Prentice Hall.

Massarweh, I. (1999). Promoting a positive clinical experience. Nurse Educutor, 24(3), 44-47.

Mehabrian, A. (1980). Basic dimensions for a general psychological theory. Cambridge, MA: Oelgeschlager, Gum and Wain Publishers.

Meier, P., \& Pugh, E. (1986). The case study: A viable approach to clinical research. Research in Nursing and Health, 9, 195-202.

Melia, (1987). Learning and working: The occupational socialization of murses. London: Tavistock.

Merriam, S. B. (1998). Qualitative research and case study applications in education. San Francisco: Jossey-Bass Publishers.

Mogan, J., \& Knox, J. (1987). Characteristics of 'best' and 'worst' clinical teachers as 
perceived by university faculty and students. Journal of Advanced Nursing, 12, 331-337.

Moore, W. (1970). The professions: Roles and rules. New York: Russell Sage Foundation.

National League for Nursing. (2004). Nursing data review academic year 2003, Vol. I: Contemporary RN nursing education. New York: Author.

Nehring, V. (1990). Nursing clinical effectiveness inventory: A replication sludy of the characteristics of 'best' and 'worst' clinical teachers as perceived by nursing faculty and students. Journal of Advanced Nursing, 15, 934-940.

Nikou, V. R. (1999). The relationship among hardiness, stress, and health-promoting behaviors in undergraduate nursing students (Doctoral dissertation, New York University, 1999). Dissertation Abstracts International, 59, 4730.

Norman, L., Buerhaus, P., Donclan, K., \& McCloskey, B. (2005). Nursing students assess nursing education. Journal of Professional Nursing, 21, 150-158.

Office of Technology $\Lambda$ ssessment. (n.d.). The OT $\Lambda$ Legacy. Retrieved May 3, 2005 , from http://www.princeton.edu/ ota/

O'Shea, H.. \& Parsons, M. (1979). Clinical instruction: Effective and ineffective teacher behaviors. Nursing Outlook, 27, 411-415.

Pagana, K. D. (1988). Stresses and threats reported by baccalaureate students in relation to an initial clinical experience. Journal of Nursing Education, 27, 418-424.

Pagana, K. D. (1992). Psychometric evaluation of the clinical stress questionnaire. Journal of Nursing Education, 28, 169-174.

Parkes, K. (1985). Stressful episodes reported by first year student nurses: $\Lambda$ descriptive account. Journal of Social Science and Medicine, 20, 945-953. 
Patton, M. (1990). Qualitative evaluation methods (2nd ed.). Thousand Oaks, CA: Sage.

Perkins Grant Data Report--Student Demographics. 2006. Associate degree nursing programs [Data file].

Phillips, A. P. (1988). Reducing nursing students" anxiety level and increasing retention of materials. Journal of Nursing Education, 27, 35-41.

Polanyi, M. (1967). The tacit dimension. New York: Doubleday Anchor Books.

Polit, D., Beck, C., \& Hungler, B. (2006). Essentials of nursing research: Methods, appraisal and atilization (5th ed.). Philadelphia: Lippincott.

Polit, D., \& Ilungler, B. (1989). Essentials of nursing research: Methods, appraisal and utilization (2nd ed.). Philadelphia: I ippincott.

Polit, D., \& Hungler, B. (1999). Nursing research: Principles and methods (6th ed.). Philadelphia: Lippincott.

Pringle, D., \& Green, L. (2004). Examining the cause of attrition from schools of nursing in Canada. The pulse of renewal: A focus on nursing human resources. Canadian Journal of Nursing Leadership, 18(4), 1-60.

Pugh, E. J. (1986). Research on clinical teaching. In W. L. Holzemer (Ed.), Review of nursing research in nursing education (pp. 73-92). New York: National I eague for Nursing.

Pugh, E. J. (1988). Soliciting student input to improve clinical teaching. Nurse Eductutor, $13(5), 28-33$

Quint, J. (1965). The hidden hazards in patient assignments. Nursing Outlook, 13(11), 5054.

Reilly, D., \& Oermann, M. (1990). Clinical teaching in nursing education (2nd ed.). Ncw York: National Ieague for Nursing. 
Robinson, V. (1946). The story of nursing. Philadelphia: L ippincott.

Russo, J. (1984). Multimodal approaches to student test anxiety. The Clearing House, $58,162-166$

Safrict, B. (1992). Health care dollars and regulatory cents: The role of advanced practice nurses. Yale Joumal of Regulation 9, 417-487.

Sands, D. J., \& Wehmeyer, M. L. (Eds.). (1996). Self-determination across the lifespan: Independence and choice with people with disabilities. Baltimore: Paul II. Brooks Publishing.

Schlechty, P. C., \& Noblit, G. W. (1982). Some uses of sociological theory in educational evaluation. In $\Lambda$. C. Kerchoff (Series ed.) \& R. G. Corwin (Vol. ed.), Research in sociology of ediucation and socialization (Vol. 3, pp. 283-306). (ireenwich, ("T: JAI Press.

Sellek, T. (1982). Satisfying and anxiety-creating incidents for nursing students. Nursing Times, 78, 137-140.

Shipton, S. P. (2002). The process of secking stress-care: Coping as experienced by senior baccalaureate nursing students in response to appraised clinical stress. Journal of Nursing Education, 41, 243-256.

Simpson, I. (1967). Patterns of socialization into professions: The case of student nurses. Sociological Inquiry, 37, 47-54.

Simpson, I. (1970). Socialization and resocialization of nurses for professional nursing practice. New York: National League for Nursing.

Speck, B. J. (1990). The effect of guided imagery upon first semester nursing students performing their lirst injections. Journal of Nursing Education, 29, 346-350.

Spradley, J. (1979). The ethnographic interview. Austin, TX: Holt, Rinchart \& Winston. 
Stein, J. (1997). Empowerment in women's health. Atlantic Highlands, NJ: Zed Books Ltd.

Steubbe, B. (1980). Student and faculty perspectives on the role of the nursing instructor. Journal of Nursing Education, 19, 4-5.

Streubert, H. J. (1989). A description of clinical experience by clinical nurse educators and students (Doctoral dissertation, Indiana University School of Medicine, 1989). Dissertation Abstracts International, 50, 906.

Swafford, C. (1992). The presence of anxiety in first year associate degree nursing students and the effectiveness of a stress management program (Doctoral dissertation, University of Tennessee at Knoxville, 1992). Dissertation Abstracts International, 53, 3404.

Thompson, J. M. (1998). The lived experience of the staff nurse relating to the student nurse during the elinical learning experience (Doctoral dissertation, $\Lambda$ delphi University, 1998). Dissertation Ahstracts International, 58, 6493.

Thorell-Ekstrand, I.. \& Bjorvell. C. (1995). Nursing students' experience of care planning activities in clinical education. Nursing Education Today, 15, 196-203.

Timmins, F., \& Kaliszer, M. (2002). Aspects of nurse education programmes that frequently cause stress to nursing students: Fact-finding sample survey. Nurse Education Today, 22, 203-211.

Turkoski, B. (1987). Reducing stress in nursing students" clinical learning experience. Journal of Nursing Education, 26, 335-337.

United States Bureau of Labor Statistics. (2005). Registered nurses. Retrieved December 12, 2005 from http:/www.bls.gov/

United States Census Bureau. (2000). United States census 2000). Retrieved January 31, 
2006, from http://www.census.gov/geo/www/index.html

United States Department of I Iealth and I fuman Services. (2004). 2004 Preliminary

findings: National sample survey of registered nurses. Retrieved October 26, 2006, from

http://bhpr.hrsa.gov/healthworkforce/reports/rnpopulation/preliminaryfindings.htm United States Department of Health and I luman Services. (2005). Projected supply,

demand, and shortages of registered murses: 200()-2020. Retrieved September 9, 2005 Irom http:/www.bhpr.hrsa.gov/healthworkforce/reports/rnproject/report.htm

Viahealth. (2004). The Rochester city hospital raining school for nurses. Retrieved May 10, 2004, from http:/www.viahealth.org/archives/nursing.html

Vollman, $\Lambda .(1989)$. The clinical instructor of nursing and the learning environment: $\Lambda$ qualitative study (Doctoral Dissertation, University of Ottawa, Canada, 1990). Dissertation Abstracts International, 52, 5763.

Waugaman, W. (1981). From nurse to nurse anesthetist: Effects of proficssional socialization on career commitment (Doctoral dissertation, University of Pittsburgh, 1981). Dissertation Abstracts International, 43, 2906.

Wentworth, W. (1980). Context and understanding: An inquiry into socialization theory: New York: Elsevier.

White, R., \& Ewan, C. (1991). Clinical teaching in nursing. London: Chapman and Hall. Wiens, A. G. (2002). Can we reverse the nursing shortage trend? Retrieved August 31 2005 from the Eastern Mennonite University Web site: hit: ww emuncusondex php 1345

Williams, R. P. (1993). The concerns of beginning nursing students. Jeurnal of Nursing, and Health Care, 14,81-86. 
Wilson, M. (1994). Nursing student perspective of learning in a clinical setting. Journal of Nursing Education, 33, 81-86.

Windsor, A. (1987). Nursing students` perceptions of clinical experience. Journal of Nursing Education, 26, 150-154.

Wine, J. (1980). Cognitive attentional theory of test anxiety. In I. G. Sarason (Ed.), Tes: anxiety (pp. 349-385). Hillsdale, NJ: Erlbaum.

Wong, J. (1979). The inability to transfer classroom learning to clinical nursing practice. Journal of Advanced Nursing, 4, 161-168.

Wong, S. (1978). Nurse-teacher behaviors in the clinical field: Apparent effect on nursing students' learning. Journal of Advanced Nursing, 3, 369-372.

Younger, J. (1985). Practical approaches to clinical research. Pediatric Nursing. 7, 137

Zerwekh, J., \& Claborn, J. (2000). Today's nursing (3rd ed.). Philadelphia: W. B. Saunders.

Zimmerman, A., \& Waltman, N. (1986). Effective clinical behaviors of faculty: A review of the literature. Nurse Educator, 11(1), 31-34.

Zimmerman, M. A., \& Warschausky, S. (1998). Empowerment theory for rehabilitation research: Conceptual and methodological issues. Psychology 43, 3-16. 
APPENDIX A

STUDENT SCREENING QUESTIONNAIRE 


\section{Student Screening Questionnaire}

1. Name (for identification only; will not be used

in any analysis or reports)

2. Age (please LIST)

3. Gender (please (HECK one) Male__ Female

4. Racial/Lthnic Identification (please (HFCK one) White Asian Hispanic African American Native American

Other (list)

5. Current Marital Status (please CIILCK onc)

Married__ Single__ Divorced ___

6. Number of children___ (please LIST)

7. Do you already hold academic degrees? If so, what? Date carned?

8. Where are you from?

9. Did you come into the nursing program immediately after completing the prerequisites? If no1, how long after?

10. Have you been enrolled in a nursing program prior to this one? If so, what type? When?

11. Do you currently or have you in the past worked/voluntecred in the health care field? If yes, when and in what position?

12. Would you be willing to discuss your nursing clinical experiences in this program as long as the information was kept anonymous and confidential?

13. Please list the grades you received in each of your previous nursing courses with a clinical component outside of the school lab. 
APPENDIX B

STUDENT INTERVIEW SCHEDULES 


\section{Student Interview Questions}

\section{Interview one:}

1. Describe what led up to your decision to go into nursing.

2. Think back to the time when you applied to the nursing program. Take me through that experience.

3. Think about your life before you entered the nursing program. Iow is your present life different than belore you started the nursing program?

(Use as prompts if student does not include)

What about .....?

a. home lile

b. leisure

c. relationships

d. intellectual

e. financial

1. general quality

g. use of time.

4. Tell me how you feel now about your decision to enter nursing as compared to how you lelt when you first started.

5. What do you know now that you did not know before which would inlluence your decision to enter nursing?

6. Think about a typical clinical day and describe it for me. Walk me through your last clinical experience from the time you got there, until you left. Anything else? 
7. While I observed you at the hospital, I noticed (event). Could you explain for me what was happening then?

8. Think of (skill observed during observation) that you have performed in clinical.

Tell me, step by step, what thoughts were going through your mind while you were the performing that specific skill.

9. The first time you performed (this skill), what did you know about it before as compared to actually doing it?

What additional things did you learn from doing it?

10. Describe for me what practicing the skill in the school lab was like as compared to performing it in clinical.

11. How does the school lab prepare you for your clinical time?

12. If I were a student in your clinical lab, what kinds of things would I hear students talk about?

13. What are some phrases or sayings that students use when talking about clinical?

What is usually going on when those phrases or sayings are used? Give me an example.

14. Tell me about the skills that you have practiced in clinical today. (Probe for the following if students do not provide information.) What kind of skills?

a. psychomotor?

b. problem-solving (critical thinking)? 
c. social (socialization)?

15. We've talked about what you do in clinical. What do you like the most about clinical? Can you give me an example? (ask, if necessary)

16. What do you like least about clinical? Can you give me an example? (ask, if necessary)

17. What seems most challenging for you in the clinical lab?

(If necessary, .. . Tell me more.)

When you feel this challenge, what do you do?

Describe a recent time when you felt this challenge and tell me what you did.

18. You have told me about a typical clinical day. Now think of a day that was not at all typical and tell me about that.

Describe how you responded to this atypical day.

19. What concerns you most while you are in clinical?

(If student does not mention, ask what concerns most about these particular types of skills.)

What concerns you most about solving problems ....?

a. skills you perform (psychomotor)?

b. problem-solving (critical thinking)?

c. social interactions (socialization)?

d. anything else?

20. When you are away from the clinical lab. . at home or some other place. . what kinds of things concern you most about your clinical?

21. When you have concerns about elinical, no matter where you are, while you are 
here or when you are at home, what do you do?

22. Compare your learning experiences in the clinical lab to your other classes.

(Probe for this information if not included in the answer.)

How are they different?

Give me examples of how these are different. 


\section{Student Interview Questions}

\section{Interview two:}

1. Describe a clinical experience that was very positive for you.

2. What do you do when you have had a particularly positive elinical experience?

Give me an example of a positive situation and what you did.

3. Describe for me how you feel about your clinical performance now as compared to when you first started last year.

4. Describe to me the grading or evaluation process in clinicals. Tell me how you feel about it.

5. What kinds of things help you more than anything else when you are trying to do well in your clinical?

Could you give an example?

6. What kinds of things keep you from doing well during clinical? Could you give me an example?

7. Walk me through the process of how you prepare for clinical?

8. What do you think is the most important part of the preparation for clinical?

9. What is the most frustrating about preparation?

10. What do you see as your major strengths?

11. What do you recognize as areas you would like to improve?

12. You have no doubt, developed relationships with people in different roles during clinical. Tell me your the most valuable relationship in clinical? 
Why is this person or relationship the most important to you?

Describe this person and what it's like working with this person?

13. What do you think is the role of your faculty teacher during clinical?

14. When do you interact with her?

15. What are some reasons that you would interact with her?

16. Describe a recent interaction with her.

17. How would you describe the role of the clinical staff nurses during your clinical experience?

18. When do you interact with her/him?

19. What are some reasons that you would interact with her/him?

20. Describe an interaction you have had with her/him.

21. There are other students in the clinical lab at the same as you. Describe your relationship with the other nursing students.

22. When do you interact with them?

23. What are some reasons that you would interact with a classmate.

24. When you need help or support in clinical, to whom do you turn?

25. Tell me about specific situations and what happened.

26. Who is the person you talk to for emotional support about a particularly challenging clinical day?

Why this person?

27. How would this person typically respond to you?

28. What relationship in clinical makes you feel the most at case?

29. Tell me about it. 
30. What relationship in clinical makes you feel the least comfortable?

31. Tell me about it.

32. Tell me about the friends you have made in the nursing program.

(Use as probes if the student does not include.)

33. Tell me about the friends closest to you in nursing school. Who do you hang out with?

a. How has your circle of friends changed since beginning nursing school?

b. How has your circle of friends changed since clinicals began?

c. Describe how your leisure activities have changed since starting nursing school.

34. Describe how your leisure activities have changed since starting clinicals.

35. Describe your relationships with friends outside your clinical lab.

36. How have these relationships changed because of clinical?

37. Think back over recent clinical days. Can you describe a time when you began to feel like a "real nurse"?

What caused you to feel this way? 
APPENDIX C

FACULTY TEACHER INTERVIEW SCHLDUILS 


\section{Faculty Teacher Interview Questions}

1. What is your educational preparation?

2. Describe any additional preparation that you have.

3. How did you decide to enter nursing?

4. How long have you been an RN?

5. What brought you into teaching nursing?

6. How long have you taught nursing?

7. What do you know now that you did not know before that would affect your decision to teach in nursing?

8. Tell me how your education prepared you for teaching clinicals.

9. What do you think is the overall purpose of the clinical experience?

10. How would you articulate your role in accomplishing this purpose?

11. What do you enjoy most about what you do?

Why?

12. What do you enjoy least?

13. What challenges do you face in teaching clinicals?

14. Walk me through the last clinical experience that you taught from the time you began the day until you left.

Do you have anything else to add?

15. What strategies do you use to manage 10 students across a six-hour day?

16. If you were asked to describe the overall clinical experience, what adjectives would you use?

17. Take me through your view of what a typical clinical day is like for a 
student?

18. What adjectives have you heard students use to describe the overall

clinical experience?

19. If I were a student in your clinical lab, what would I hear students talking about?

When do you observe and hear this?

20. What kinds of things do you think students worry most about during clinicals?

21. During an observation, I noticed (event with student). Could you explain what was happening then?

22. What kinds of things occur during clinicals that you feel help students learn the most?

Give me an example.

23. What kinds of problems occur during clinicals that you think are barriers to student learning?

24. What do you think is most difficult about clinical evaluation? Why?

25. Describe your interaction with students.
a. when do you interact with them?
b. what are the reasons that you would interact with them?
c. describe an interaction you have had with them.

26. Describe clinical experiences that you feel are most positive for students.

27. How do you see students react when they have had a particularly positive 
day? Give me an example.

28. How does a student react during a particularly challenging and upsecting day?

29. What strategies do you use to encourage students to maximize preparation time?

30. What are the consequences for a student who arrives to clinicals unprepared?

31. Describe your interaction with the unprepared student.

32. Describe clinical experiences that you feel are very challenging for students.

33. Tell me about your expectations of students in clinical at this point in the semester.

(II the faulty teacher does not include in the answer, use these probes.) What do you expect at this time for....?
a. curriculum goals?
b. problem-solving?
c. critical thinking?
d. psychomotor skills?

What do you expect at the end of the semester?

34. Describe for me how you look for evidence of a student's critical thinking?

35. Describe your clinical experience at the time you were a student? How do you draw from that experience today in your clinical work with 
students?

36. Can you give me an example of when a student identified a situation beyond their knowledge and experience and sought your assistance?

37. Describe the student who secks assistance?

38. For the third semester associate nursing student, what clinical strengths do you typically observe?

39. What kinds of clinical practices need more assistance than others?

40. How do you move a student from focusing only on regimented, methodic, routine patient care to analyzing, recognizing, and responding to unexpected patient needs?

41. When you supervise a student during the performance ol a first-time skill, what strategies do you use to support the student during this time?

42. What is your perception of the role of clinical staff nurses?

43. Describe how students interact with each other?

44. Describe your interaction with clinical staff nurses.

44. What are your ideas on how clinical staff nurses contribute to student learning?

45. Describe for me how the student coordinates care with the clinical staff nurse.

Give me examples.

46. Describe how student interact with clinical staff nurses.

47. What strategies do you use when you discover a conflict between the student and the staff nurse? 
48. What do you do when you have a different opinion than the staff nurse?

49. Describe possible results of a tense faculty-staff nurse relationship during clinical?

50. What are some clues that a student may be unsuccessful in clinical?

51. When you feel that a student needs additional help, what do you do?

52. What are clues that a student will excel in clinical?

53. What do you do differently for this type of student?

54. Describe how students interact with clinical staff nurses?

55. What is your perception of the importance of clinical student peer groups?

56. What are signals that a student is becoming a "real nurse"?

What do you notice? 
APPENDIX D

CIINICAL STAFF NURSE INTERVIEW SCIIEDUIIES 


\section{Clinical Staff Nurse Questions}

1. How long have you been a nurse? RN or LPN?

2. What is your educational preparation?

Additional preparation?

3. How did you decide to enter nursing?

4. Describe your career from that decision to the present.

5. What do you enjoy most about what you do?

Least?

6. What do you know now that you did not know before that would affect your decision to enter nursing?

7. What challenges do you face in working with students during clinicals?

8. What do you see as the purpose of clinicals for students?

9. What would you articulate as your role in accomplishing this purpose?

10. Think about a typical clinical day with students and describe it lor me.

11. What kinds of things do you think most concern students during clinicals? Why?

12. During an observation, I noticed (event with student and staff nurse). Could you explain what was happening?

13. Describe a time when you assist a student with a skill.

14. What kinds of things do you hear students talking about? Give me an example.

15. What kinds of things occur in clinical that you feel help students learn the most? 
Why?

Give an example.

16. What kinds of problems during clinical do you feel are barriers to student learning?

17. What kinds of situations are most difficult for students in clinical?

Why?

18. Describe a clinical experience that you feel was very positive for students.

19. How do you see students react when they have had a particularly positive day?

Give an example.

20. Tell me about your expectations of students during clinical?

(Use as probes if not mentioned.)

What do you expect. . ?

a. problem solving?

b. critical thinking?

c. psychomotor skills?

21. Describe how the presence of students affects the unit?

Explain how you manage your normal work when the students are present.

22. Explain how nursing students on the unit adds to your work in addition to your normal responsibilities.

23. Describe a clinical experience that you feel was very challenging for students.

24. How do you see students react when they have had a particularly 
challenging day?

Give an example.

If you observe this student having a hard time or upset, what do you do? What type of student do you think requires the most personal support? Why?

25. When you were a student, how did you leel about clinicals?

26. Does this experience affect your role as a clinical staff nurse in dealing witlı students?

27. When you have a group of nursing students on the unit just beginning in clinical, what expectations do you have in regard to their developmental level?

Towards the end of the semester?

28. When you observe a student only working on the routine methodic level, what do you do to help that student begin to analyze emergent patient needs?

29. What are your ideas on how clinical staff nurses contribute to student learning in clinicals?

30. How do you handle problems that occur with students in clinical?

31. What type of support do you typically give to students in clinical?

32. What are some clues that a student may be unsuccessful in clinical?

33. When you feel that a student needs additional help, what do you do?

34. What are some clues that a student will excel in clinical?

35. What do you do differently for this type of student? 
36. What do you see as the role of the faculty teacher?

37. Describe your relationship with faculty teachers.

38. Describe times that you directly interact with faculty teachers

39. Therapeutic communication with individuals, families, and other health care providers is a very important aspect of clinical experience for students. Can you describe how you see students communicate with these groups?

40. What is your perception of how students interact with the faculty teacher?

41. What is your perception of how students relate to other students?

42. Describe your interaction with students.

43. What are the reasons that you typically interact with them?

44. Give me an example of a time during a recent clinical that you worked directly with a student

45. What does the student do that signals you that he/she is becoming a "real nurse"? 
APPENDIX E

OBSERVATION SCHEDULES 
Sample Form for Data Collection

Observation

Student:

Time:

Date:

Field Notes and Observation
Observation Focus

1. Skills (Psychomotor)

2. Problem-solving (Critical thinking)

3. Work with others (Socialization)

Field Researcher's Memos 
APPENDIX I

\section{DOCUMENI IORM}


Sample liorm for Data Collection

Document

Document:

Date

Notes

Content Focus:

1. Skills

2. Work with others or

Collaborative evidence

Field Researcher"s Comments 
APPENDIX G

SAMPLE CARD 
$10 / 19 / 06$

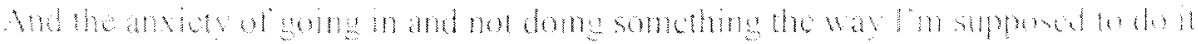




\section{CURRICULUM VITAE}

NAME: $\quad$ Rhonda Stuart Helm

ADDRESS: 427 Sumpter Ave.

Bowling Green, KY 42101

DOB: $\quad$ Bowling Green, KY - May 7, 1951

EDUC $\triangle$ TION

\& TRAINING: A.D., Nursing

Western KY University

1970-72

B.S., Nursing

Western KY University

1987-89

M.S., Nursing

Murray State University

1991-1994

Masters Thesis: Characteristics of 'Best' and 'W'orst' Clinical Teachers as Perceived by University Faculty and Students: A Replication Study

PROFESSIONAL SOCIETIES:

Sigma Theta Tau International Honor Society of Nursing

American Nurses Association

KY Nurses Association

Research Council, The Medical Center at Bowling Green

PUBLICATIONS:

Helm, R. S. (2005, Oct., Nov., Dec.). Implementing the Practicum Requirement, Kentucky Nurse 53(4), 6. 